UNITED STATES DEPARTMENT OF THE INTERIOR

J. A. Krug, Secretary

GEOLOGICAL SURVEY

W. E. Wrather, Director

\title{
Bulletin 957-D
}

\section{GEOPHYSICAL ABSTRACTS 131}

\section{OCTOBER-DECEMBER 1947}

BY

\section{L. SKITSKY}

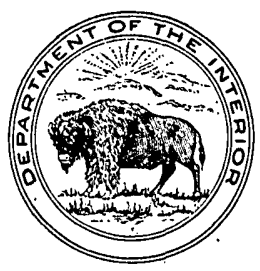

' UNITED STATES

GOVERNMENT PRINTING OFFICE

WASHINGTON : 1948 


\section{CONTENTS}

- Page

Foreword

1. Gravitational methods _._. 180

2. Magnetic methods _

3. Seismic methods

4. Electrical methods _._. 203

5. Radioactive methods _.

6. Geothermal methods _...

7. Geochemical methods_._.

8. Unclassified geophysical subjects__._.

9. Related nongeophysical subjects

10. Patents

Index to Geophysical Abstracts 131, October-December 1947 _.

Index to Geophysical Abstracts 128-131, January-December 1947_._._. 241

\section{NO'TICE OF PUBLICATION}

Publication of this quarterly serial by the United States Department of the Interior, Geological Survey is resumed after a 4-year interval, during which it was issued by the Bureau of Mines.

Copies may be purchased singly or by annual subscription from the Superintendent of Documents, Government Printing Office, Washington 25, D. C. For subscription, the Superintendent of Documents will accept a deposit of $\$ 5$ in payment for subsequent issues. When this fund is near depletion, the subscriber will be notified. The deposit may also be used to cover purchase of any other publication from the Superintendent of Documents. 


\title{
GEOPHYSICAL - ABSTRACTS 131, OCTOBER-DECEMBER 1947
}

\author{
By V. L. SkitsKY
}

\section{FOREWORD}

Geophysical Abstracts are issued by the Section of Geophysics of the Geological Survey, United States Department of the Interior, as an aid to those engaged in geophysical research and exploration. The publication covers world literature on geophysics contained in periodicals, books, and patents. It deals with exploration by gravitational, magnetic, seismic, electrical, radioactive, geothermal, and geochemical methods and with underlying geophysical theory, research, and related subjects.

Inasmuch as geophysicists in the field may have little opportunity to consult libraries, the policy is to provide abstracts sufficiently informative in themselves to keep readers abreast of developments in the United States and abroad.

Distribution.-Geophysical Abstracts 1-86 were issued as Information Circulars by the U. S. Bureau of Mines; 87-111 were issued as Bulletins of the Geological Survey; and 112-127 were issued as Information Circulars by the Bureau of Mines. Beginning with 128, Geophysical Abstracts will again be published as Bulletins of the Geological Survey.

Within limits of availability, Geophysical Abstracts issued as Information Circulars may be obtained free of charge from Publications Distribution Section, Bureau of Mines. Geophysical Abstracts issued as Bulletins of the Geological Survey may be purchased as single copies or by subscription from the Superintendent of Documents, Government Printing Office, Washington 25, D. C.

Author's reprints.-The Geological Sưrvey will appreciate receiving reprints of publications and patent specifications from authors and inventors. These will be filed for reference after being abstracted. Foreign publications and patents with little circulation in the United States are especially desired. In reproducing authors' abstracts the 
Geological Survey reserves the right to make minor changes in accordance with its editorial policy.

All reprints and correspondence other than orders for copies of Geophysical Abstracts should be addressed to the Director, Geological - Survey, United States Department of the Interior, Washington 2.5, D. C.

\section{GRAVITATIONAL METHODS}

9519. Andersen, Einar. Gravity measurements in Sjaelland, Møen, Falster, and Lolland by means of the Askania gravimeter' Geod. Inst. Skrifter, ser. 3, vol. 10, 68 pp., Copenhagen, 1947.

Test measurements were made with the Askania gravimeter in Denmark as a part of research by the Royal Geodetic Institute into the advantages of different instruments and methods for gravity determination. The measuring techniques, field procedures, calculations, and results are described. A net of triangles was established by measurements of first order, wherein gravity differences between stations were determined at least twice. Later, measurements of second order formed series of minor groups of nets in which the gravity differences were determined once. Further detailed measurements were arranged in groups of seven stations, with readings at a base station made immediately before and after each group. The mean error for a detail station with only one measurement was \pm 0.25 milligal and for a detail station with two measurements \pm 0.18 milligal. $-V$. $S$.

9520. Clark, G. L. Note on the velocity ${ }_{5}^{\top}$ of propagation of gravitation: Cambridge Philos. Soc. Proc.,.,vol. 43, no. 2, pp. 178-182, Cambridge, England, 1947.

The.approximate value of the world invariant. $\mathrm{B}_{\mu \nu \sigma} \mathrm{B}_{\mathrm{e}}^{\mu \nu \sigma}$ at a point in a plane containing a rotating cohesive system, such as a rod, is calculated for a point at great distances from the system. It is found that the invariant has a stationary value when the rod is seen to be pointing toward the point in question. It is concluded that the speed of propagation of gravitation is the same as that of light.-Author's abstract.

Frey, Eugene. Hartville iron district, Platte County, Wyoming: U. S. Bur. Mines, Rept. Inv. 4086, 3 pp., Washington, D. C., June 1947. See Geophys. abstract 9546.

9521. Goguel, Jean, L'equilibre des pressions dans la compensation isostatique locale des masses [The equilibrium of pressures in local isostatic compensation of masses] : Acad. Sci. Comptes Rendus, vol. 224, no. 22, pp. 1543-1546, Paris, 1947.

In its original form isostatic compensation was conceived in terms of an equilibrium of pressures on the surface of compensation, but present research deals with a compensation of masses. The author inquires into what, in the latter case, becomes of the pressures on the surface or compensation. The method consists in postulating a differentiation of the earth's crust into solid compartments floating in equilibrium in a liquid filling the fissures between them. The variation of gravity with the height of the different compartments is ignored. As regards local compensation of masses, the conclusion is reached that an equality of 
masses in compartments of equal surface results in an equality of pressures on the surface of compensation.

In accompanying remarks, $P$. Lejay observes that such a conclusion inheres in Pratt's isostatic hypothesis but cannot be based on a postulation of solid blocks floating in a liquid because such an assumption completely changes the distribution of forces on the surfaces between the blocks. - $V$. S.

9522. Hammer, Sigmund. A new calculation technique for quantitative interpretations in gravity prospecting [abstract] : Oil and Gas Jour., vol 45, no. 47, p. 126, Tulsa, Okla., 1947.

In this technique, the densities of the various strata in an assumed geologic structure are considered as unknown and are determined by least squares to give the best possible fit between the computed and observed gravity effects of the assumed structure. If the computed result does not fit the observed data, it is immediately evident that the assumed structure is incorrect because no trial-and-error manipulation of the density values can improve the fit. If the computed result does fit the observed data, the reasonableness of the computed densities is the principal criterion for judging the geologic reasonableness of the interpreted structure.

The technique has been tested in practice and has been found very useful. It is especially convenient for utilizing gravity data to choose between different structures postulated by equally competent geologists. Examples are given.

9523. Holopainen, P. E. On the gravity field and the isostatic structure of the earth's crust in the east Alps: Isostat. Inst. Internat. Assoc. Geod., Pub., no. 16, 94 pp., Helsinki, 1947.

The author has reduced the gravity data from the east Alps according to different isostatic assumptions and has studied the conditions of isostatic equilibrium of this region. He finds that isostatic compensation over the whole area is almost complete. As regards the thickness of the earth's crust, the value $T=20$ kilometers seems the most probable, especially for the central part of the east Alps. Local compensation of that part is obvious, but a slight regionality may exist in the northern and the southern areas.

The clear mass deficit of the central part can be explained by the buckling hypothesis of Vening Meinesz, whereas the positive character of the Dinarides and of the Landeck-Hochkönig line may be attributed to a rising of these areas with the central part. The reducing calculations are described, and the results are tabulated and discussed.-V. $S$.

9524. Hubbert, M. K. Gravitational terrain effects of two-dimensional topographic features [abstract]: Oil and Gas. Jour., vol. 45, no. 47, p. 123, Tulsa, Okla., 1947.

If terrain corrections are not systematically made when conducting gravity surveys, it is a matter of some importance to locate stations away from points for which this effect is a maximum. While this fact is fully appreciated, our literature is deficient in information that a field man could use in determining how great would be the effect of a given topographic feature or how far away the station should be placed to keep the error within prescribed limits. 
To meet this need, continuous profiles of terrain effects across 47 different forms of two-dimensional topography have been computed and are presented. These are expressed dimensionally so that each figure represents an infinite class of features having the same shape. In addition, the profile for each plotted ridge is also valid for valleys of the same form, but inverted. The data thus are applicable to a double infinity of cases.

These profiles are also useful to the interpretative staff for determining quickly whether certain small anomalies are significant or whether they

$\dot{*}$ are more probably the result of local uncorrected terrain.

9525. Huelin, G. S. El gravimetro Boliden [The Boliden gravimeter]: Rev. Geofis., vol. 2, pp. 417-421, Madrid, Oct.-Dec. 1943.

A detailed description is given of a nonastatic gravimeter which has springs supporting a mobile mass so mounted that small displacements produce very slight variations of electrical capacity measurable by means of an oscillating circuit.-Cent. Nat. Rech. Sci., Bull. Anal., vol. 8, no. 5, pt. 1, p. 931, Paris, 1947, translated by V. S.

9526. Khramoi, A. I. On gravimetric surveying in conditions of complex topography [in Russian] : Prikladnaia Geofizika, no. 3, pp. 139-148, Moscow, 1947.

In 1941-43 a gravimeter survey was made in an area of the Bashkir pre-Urals, U. S. S. R., previously surveyed with variometers. The combined results were plotted on a map as isodifferences between gravimeter and variometer data and were compared with a corrected map of Bouguer gravimeter values. A study of this material by the author revealed a correspondence between the pattern of isodifferences and topographic relief-and an underestimation of the effects of relief in the data.

To trace the causes of underestimation and to evaluate the resulting. errors, the calculations of reduction are analyzed for possible inaccuracies, and the effects of topography on variometer observations are examined. It is found that relief can be underestimated both in gravimeter and variometer data. In the Bashkir surveys such errors have produced a discrepancy between the gravimeter and variometer values equal to 2.2 milligals for évery 100 meters of elevation. The causes generally may be an incorrect evaluation of density in the Bouguer reduction, an insufficient vertical gradient, a change of gradient with elevation, and underestimation of the effects of the boundary between the unconsolidated upper layer and the denser underlying rocks.- $V$. S.

9527. Lejay, Pierre. Mesures de pesanteur exécutées dans le sud-est de la France en 1941 [Measurements of gravity in the southeast of France in 1941], 102 pp., Comité National Français de Geodesie et Geophysique, Paris, 1942.

The gravity survey conclucted in southern France in 1940 was extended to the Lyon-Valence-Grenoble-Geneva region in 1941. Measurements were made at 1.54 stations with the previously used Holweck-Lejay gravimeters corrected for base and temperature. A comparison of the obtained values with those determined independently with a Thyssen gravimeter indicated a general precision of 1.0 milligal. 
The results are tabulated, and the Bougner anomalies are mapped. They show that the isostatic compensation of the Alps is centered at a relatively shallow depth under the crystalline rocks. The pre-Alpian Vercors and Chambarand Mountains register negative anomalies, whereas the hilly area near Lyon and the region to the west of the lower Saône show a notable increase of gravity. In the plain to the east of Lyon and in the Rhone bend no important gravity variation is indicated.-V. S. (For the survey in southern France see Geophys. Abstracts 130, no. 9338.)

9528. Lejay, Pierre. Mesures de pesanteur exécutées dans le Massif Central, Septembre 1941 [Measurements of gravity in the Massif Central, September 1941], 23 pp., Comité National Français de Géodesie et G'éophysique, Paris, 1942.

A gravity survey begun in the northern part of the French Alps was continued in the mountains of the Massif Central, France, in September 1941. The data for the 30 stations occupied are tabulated. Though considered insufficient for a final gravity map of the region, they give a general outline of the anomalies between the cities of Lyon and Limoges. $-V$. $\mathbf{S}$.

9529. Magnée, I. de; and Evrard, P. Le gravimètre Nørgaard [The N $\not r g a a r d$ gravimeter] : Soc. Géol. Belgique Annales, vol. 70, Bull. 1, pp. 35B-48B, Liége, 1946.

The Norgaard gravimeter is described with regard to its principles, construction, sensitivity, temperature correction, general precision, and advantages. It is found that the instrument is easily handled because of its small size, light weight, improved thermal control, and regular drift. A measurement requires not more than an hour, including calculations, and a number of stations can be occupied without regulation of the instrument, even at different altitudes. A precision of 0.1 milligal is attainable in field work, and a thrice-repeated measurement has been reported to have a probably error of \pm 0.07 milligal. The Faye-Bouguer corrections are discussed.-V. S. (See also Geophys. Abstracts 126, no. 8650.)

9530. Morelli, Carlo. Compensazione della rete internazionale delle stazioni di riferimento per le misure di gravita relativa [Compensation of the international net of reference stations for the measurement of relative gravity ]: Istit. Geofis. Trieste Pub., no. 211, 111 pp. Trieste, 1946.

The adjustment of the international net of gravity reference stations is discussed with regard to general questions of method, such as the selection of stations and connections, precision and errors, mathematical equations, and calculation by the methods of Gauss and of indeterminate coefficients. A tabulation is given of the values of compensation computed by the author according to the Gauss method for the stations tied into the net after 1909. These stations are shown on a map, and further desirable extensions of the international net in Europe, Africa, Asia, America, and Australia are indicated.- $-\nabla$. S. 
9531. Robertson, E. I. Gravitational methods of prospecting for oil : Petroleum, vol. 10, no. 7, pp. 155-158, London, 1947.

A brief account is given of the principles, instruments, and geologic fundamentals of the gravitational method of petroleum exploration. Significantly, the magnitude of gravity at any observation point depends upon the latitude, altitude, topography, and geology. Therefore, gravity measurements can be interpreted in terms of geology alone only after the other variables in the data have been reduced to common values. When thus corrected, the measurements show density differences between the types of rocks constituting the local geologic formations.

The pendulum and the gravimeter measure the difference in gravity between two stations, whereas the torsion balance measures the rate of change with horizontal distance. The construction of these instruments is outlined. Measurements made with them are not a means of detecting oil pools directly, but they do reveal subsurface density contrasts indicative of geologic features commonly associated with oil, such as anticlines, buried hills, salt domes, and faults. The relation of these geologic forms to oil pools is discussed.-V. S.

9532. Rozanov, L. N. On the relationship between rock density and tectonics in the Buguruslan region [in Russian]: Prikladnaia Geofizika, no. 3, pp. 173-180, Moscow, 1947.

To facilitate the interpretation of gravitational data in the Buguruslan region, U. S. S. R., a study was made of changes in the density of sedimentary rocks within a single geologic structure. A total of 724 cores from 10 boreholes, sampled at intervals of 1 meter, were analyzed. The results showed that within the same stratigraphic horizon the values of average density increase from the axis toward the limbs of the structure. Isolines of density generally coincide with the contour lines of a structural map.

The findings, tabulated and illustrated by maps, suggest the hypothesis that each epoch of sedimentation has its own phases of tectonic compaction and consolidation followed by phases of erosion and new sedimentation. In this cyclic process the older sediments go through a greater number of consolidations and become denser.- $-\mathbf{S}$.

9533. Sagui, C. L. Les tremblements de terre et la gravitation [Earthquakes and gravitation 1: Inst. de Fisiograf. y Geol. Pub., vol. 6, no. 28, 25 pp., Rosario, Argentina, 1946.

The electromagnetic theory of gravitation is used to explain the causes of earthquakes. It is assumed, in analogy with the formation of sunspots, that a difference of electromagnetic level forms between the interior and the exterior of the earth owing to irradiation from the surface, which carries away with it some part of the electromagnetic mass of the gravitational atmosphere. The electromagnetic excess thus accumulating in the internal terrestrial gravitational field erupts at cerain moments toward the surface and modifies the existing gravitational potential at these places.' If at this time the layers of the shell are subjected to strong orogenic compression, they will oscillate from such shock in a manner similar to the vibration of a tightly drawn cord that is plucked. 
Earthquakes are thus explained on the one hand by orogenic compression and on the other hand by disturbed gravitational equilibrium readjusted in a limited area. Examples of earthquakes on dry land and under water are given to illustrate the hypothesis. $-V . S$.

9534. Thyer, R. F. Gravity survey to determine extent of coal measures: Chem. Eng. Min. Rev., vol. 39, no. 2, pp. 57-62, Melbourne, Australia, 1946.

In 1946 a gravity survey was made at the Leigh Creek coal field north of Adelaide, Australia, to determine the outer edges of two coal seams around the periphery of the coal basin. The gravity gradiometer of Shaw and Lancaster-Jones and the Humble-Truman gravimeter, used for the work, indicated a variation of 0.3 to 0.6 milligal, caused by difference in density between the comparatively light coal and the enclosing rocks. The gravity-gradient vectors were resolved into the part due to basement, effect and the part due to the coal seams. The results relating to the northern limits of the seams closely agreed with the limits previously fixed by geologic interpretation of existing drill logs. In the southern portion, the results suggested that the lower seam is more extensive than hitherto believed, and this was confirmed by a drill hole.- $V$. $S$.

9535. 'Wegener, Kurt. L'Andamento della gravita sui mari [The change of gravity values over the sea] : Geotis. Pura e Appl., vol. 5, nos. 3-4, pp. 107110, Milan, 1943.

The gravity measurements made by Vening Meinesz at sea and the reductions of Heiskanen are utilized to examine the distribution of gravity along certain major east-west traverses across the Atlantic, Pacific, and Indian Oceans. The findings serve for plotting profiles of gravity and of ocean topography with reference to sea level and to a horizon 5,000 feet deep, respectively. The results for the Atlantic and the Pacific profiles confirm some previously established data and suggest new conclusions. In the localities investigated, values of gravity at sea level are usually found to be normal in places where the depth exceeds 5 kilometers. $-V$. $\boldsymbol{S}$.

9536. Woollard, G. P. Regional gravity survey of northeastern United States and eastern Canada [abstract] : Geol. Soc. America Bull., vol. 57, no. 12, pt. 2, pp. 1245-1246, Baltimore, Md., 1946.

During the period $1942-46$, over 2,000 gravity observations along profiles at approximately 10-mile intervals have been made in the area noith of Washington, D. C., south of the St. Lawrence River, and from the Atlantic coast westward to the Allegheny Mountains.

Bouguer anomalies, based on a density of 2.67 , indicate marked variation in the thickness of the earth's crust and considerable lack of isostatic equilibrium.

\section{MAGNETIC METHODS}

9537. Ambolt, Nils. The magnetic homogeneity of testing grounds for investigation and compensation of airplane compasses: Kungl. Sjökarteverket, Jordmagn. Pub. 14, 9 pp., Stockholm, 1946.

Practice in testing magnetic compasses has shown the need of ascertaining the magnetic homogeneity of the testing grounds. The author 
conducted such investigations at all important Swedish airports and describes his work. The instrument used for determining the magnetic azimuth was a Wild double-image prism compass mounted on a tripod. In the survey of an ordinary testing-ground 20 meters square, the observation points usually formed a network of squares 2 meters on a side, with the compass mounted half that distance above the ground. The results showed that the ground can be considered magnetically homogeneous when the difference in compass variation between two points within the testing area is less than $0.7^{\circ}$. The 40 investigations of the author revealed 8 testing grounds where the variations were too large. Tables of results are given. $-V . S$.

9538. Bartels, J. Daily international magnetic character-figures, $C$, for the year's 1884 to 1889 : Terres Magn. and Atmos. Electr., vol. 52, no. 1, pp. 38-38, Baltimore, Md., 1947.

The international magnetic character-figures, $C$, have been determined beginning with the year 1884, but the data for the years 1884-89 have not been published heretofore. Tabulations of the values for this period are presented. $-\nabla . S$.

9539. Čechura, F. Magnetická deklinace na Řipu a v okoli [Magnetic declination on the Řip Mountain and its surroundings]: Věstnik Královské České 'Společnosti Nauk, no. 19, 20 pp., Prague, Czechoslovakia, 1939.

The magnetic disturbance in the region of the řip basalt peak, Czechoslovakia, was investigated by measurements of magnetic declination. It was found that anomalous values are distributed within an irregularly bounded area of about 2.8 by 3.5 kilometers and that they decrease with elevation. The basalt mass of the peak affects the magnetic needle in the manner of a magnetic rod oriented with its southern pole upward, suggesting that the peak's magnetization was induced by the geomagnetic field. Strong anomolous readings along two almost mutually perpendicular lines indicate the existence of two subterranean fissures through the intersection of which the basalt lava rose to form the peak. $-\nabla$ : $s$.

9540. Cork, J. M., Shreffler, R. G., and Shull, F: B. Magnetic field measurement in beta-spectroscopy : Rev. Sci. Instruments, vol. 18, no. 5, pp. 315-316, Lancaster, Pa., 1947.

A device to measure precisely the instantaneous value of a maynetic field is described. It consists of a drum armature wound on a lucite form and rotated by a synchronous motor. The direct voltage output is taken off by commutator and brushes, both of silver, to a potentiometer. Changes of 0.01 gauss can be observed. A simple self-legulating circuit is described.-Author's abstract.

9541. Diukov, A. I. An experiment in the magnetic orientation of borehole cores from the eastern Donbas [in Russian] : Razvedka Nedr, vol. 12, no. 4, pp. 33-36, Moscow, 1946.

Azimuthal determination of the extent and strike of geologic formations can be aided by the study of oriented borehole cores. For a magnetic orientation, Morozov, and Strotskii have offered a "polar" method which consists of cutting a thin disk from a core perpendicular to the borehole axis, marking thereon the apparent direction of strike 
in the core, suspending the disk from the center, allowing it to assume polar orientation, and reading the azimuth of the strike. For a check, the disk is subjected to the effect of a magnetic force opposite in direction to polar attraction and should turn $180^{\circ}$.

This method was tested by the author in 1941 in application to Eastern Donbas cores of Carboniferous age. The results showed the suitability of polar orientation for cores of Donbas sandstones and argillaceous schists. Recommendations are given on the optimal use of the method. $-V . S$.

9542. Dreyer; R. M. Magnetic survey of the Bala intrusive, Riley County, Kansas : Kansas Geol. Survey Bull. 70, pt. 2, pp. 21-28, Lawrence, Kansas, 1947.

In 1946 a magnetic survey was made of the Bala intrusive, one of the few igneous bodies exposed in Kansas. Inasmuch as it contains magnetite, chromite, and ferromagnesian silicates, the intrusive was expected to register a marked anomaly relative to the surrounding shale and limestone. The work was done with a Schmidt-type vertical magnetometer to supplement drill-hole data and determine how near the rock came to the surface.

The results, represented by an isogam map, show a complex anomaly reaching a magnitude of 3,500 gammas. Its illiptical annular high follows the border's of the topographic and structural summit, trends eastward in the direction of the plunge, and completely surrounds an elliptical low, similar to the anomaly found by V. J. Blum over igneous pipes near Canon City, Colorado. These findings agree with the drill data and are interpreted to indicate that relatively large amounts of the intrusive occur near the surface. $-\dot{V}$. $S$.

9543. Fanselau, G. Ergebnisse der erdmagnetischen Beobachtungen Prof. Filchners auf seiner zweiten Tibetreise 1935-37, I Teil ['The results of Frofessor Filchner's geomagnetic observations during his second expedition to Tibet in 1935-37, part 1] : Geophys. Inst. Potsdam Abh., no. 7, 35 pp., Berlin, 1943.

Preliminary data are presented on geomagnetic declination, horizontal intensity, and inclination in Tibet, central Asia, measured during Filchner's second expedition in 1935-37. All three elements were determined at 209 stations, with observations repeated several times at a number of stations. The results for $\mathrm{D}, \mathrm{H}$, and $\mathrm{I}$ are tabulated, and the instrumental constants, corrections, and details of measurements are discussed. Additional data, calculations, final maps, and geophysical conclusions will be given in later papers. $-V . S$.

9544. Ferraro, V. C. A. The radial stability of the geomagnetic ring current: Terres. Magn. and Atmos. Electr., vol. 51, no. 4, pp. 547-555, Baltimole, 、 Md., 1946.

An exact solution is given of an idealized problem, approximately treated by $\mathrm{S}$. Chapman and the writer in an earlier: paper dealing with the radial stability of a geomagnetic ring, in which the ring is replaced by an electrically neutral uniform cylindrical current-sheet whose axis is parallel to the magnetic axis of the earth. The conclusions of that paper are substantiated, and though it is shown that the sheet is in 
reality unstable, the rate at which instability sets in is so slow that the sheet may well be considered to be stable. This rate is, moreover, comparable with the rate of decrease of intense and moderate magnetic storms.-Author's abstract. (For earlier paper see Geophys. Abstracts 105, no. 6012.)

9545. Fleming, J. A., and others. Magnetic results from the Watheroo Observatory, 1919-35, and 1936-44: Carnegie Inst. Washington, Dept. Terres. Magn., Research Pub. 175, vol. 7A, 1122 pp., vol. 7B, 520 pp.; Washington, D. C., 1947.

Data obtained at the Watheroo Magnetic Observatory, Western Australia, during the years 1919-35 and 1936-44 are presented in two volumes. The observations are entered in hourly values on monthly tabulations. Separate tables are given for horizontal intensity, vertical intensity, and declination. From the basic data, tabulations are derived for noncyclic change and diurnal variation of the various elements. Magnetograms typical of the storm conditions encountered from time to time are given in the first volume.- $\boldsymbol{V}$. S.

9546. Frey, Eugene. Hartville iron district, Platte County, Wyo.: U. S. Bur: Mines, Rept. Inv. 4086, 3 pp., Washington, D. C., June 1947.

The magnetometer surveys made by the Bureau of Mines Geophysical Section included the Good Fortune mine and six grid areas in the Hartville district. The sections surveyed were found to be magnetically low. A study of the maps does not redeal any marked correlation between magnetic anomalies and structure or mineralization.

The magnetometer survey was followed by a gravity-meter survey. Eight grid areas and 87.25 miles of traverse were laid out, 4,068 geophysical stations with elevations were set, and 3,354 stations were observed during the survey. These grid areas and traverses were laid out in accordance with the general requirements of the geological problems. Only grids 1, 2, 4, and 9 were completed.-Report, $p .3$.

9547. Frowe, Eugene. A total-field magnetometer for mobile operation [abstract] : Oil and Gas Jour., vol. 45, no. 47, p. 120, Tulsa, Okla., 1947.

A magnetometer which measures the earth's total magnetic field is described. The detector or measuring element of the magnetometer contains three mutually perpendicular elements, two of which are utilized to orient the third, which in turn operates a recording apparatus to record the total magnetic field. The detector elements are of the inductive type and do not require ferromagnetic material to give them the high sensitivity required in geophysical work.

The presence of a magnetic field in the region of the detector causes alternating currents to be generated in the detector elements. These currents are amplified to actuate thyratron tubes, which control the orienting and neutralizing functions of the magnetometer. A tape recorder gives continuous field readings. The accuracy of the mágnetic data obtained is better than 10 gammas.

9548. Groves, A. W. Results of magnetometric survey at Benallt manganese mine, Rhiw, Caernarvonshire: Inst. Min. Metallurgy Bull. 484, pp. 1-24, London, 1947.

In 1944 a magnetic survey was made at the Benallt manganese mine, Caernarvonshire, to locate additional ore bodies. Though Benallt is 
regarded as one of the most complicated metalliferous mines in the British Isles, the ore being a complex mixture of manganese silicates with subsidiary manganese and iron oxides, preliminary tests indicated that a compass needle responded to high grades of ore but not to commercially unprofitable grades.

In the course of trial measurements the Thalen-Tiberg magnetometer proved insufficiently sensitive, and a Watts vertical variometer requiring no correction for temperature was used for the survey. Several areas were investigated, with the station intervals reduced from the customary span to as little as $\mathbf{5}$ to 20 feet in some sections. The results revealed seven anomalies, three of which were considered to indicate workable ore bodies. Boreholes' confirmed the findings, and about 10,000 tons of ore have been extracted. Further drilling is recommended.$V$ : S. (A discussion appeared in Inst. Min. Metallurgy Bull. 486, pp. 37-47, London, 1947.)

9549. Jensen, Homer. Recent techniques and projects for the airborne magnetometer [abstract] : Oil and Gas Jour., vol. 45, no. 47 , p. 125, Tulsa, Okla., 1947.

During 1946 intensive preparations were made to develop new airborne magnetometer instruments and to use them in commercial surveys. Gulf Research and Development Corp. conducted successful flights, and in January 1947, Aero Service Corp., using the Gulf magnetometer, started the first contract survey with this new device. Advantage has been taken of the intensive engineering and the great backlog of practical experience associated with the governmental surveys. The detector remains at the end of a cable outside of the aircraft to minimize the effects of stray fields, and the correlation techniques through continuous strip photographs and Shoran guides continue along lines developed in the earlier surveys. In general, records are made continuously where possible; with intermittent fiducial marks established for correlation of the various continuous records of ground track, altitude, and magnetic intensity.

An extensive survey of the whole Bahamas area will be started early in 1947. Shoran will be used not only to guide the aircraft but to provide an intensive net of low-order triangulation over the entire area to tie in positions of the Shoran stations. Segments of the survey patterns will be similar, permitting the use of standard printed forms for presentation of the data currently with the progress of the survey.-Condensed by V.S.

9550. Jones, W. M. Some theoretical considerations of anomalies of magnetic declination in New Zealand: New Zealand Jour. Sci. Technology, vol. 28, no. 5, pp. 296-303, Wellington, New Zealand, 1947.

Using an average value for magnetic inclination for New Zealand, the declination anomalies from a sphere under induction in the earth's field are shown for twelve different levels, ranging from.1.0 to $3 \cdot 2$ times the radius of the sphere above its centre. The possibility is discussed of approximating the field of an actual rock body by a combination of spheres. An example is given of the effects of measurement on a sloping surface.-Author's abstract.

9551. Kalinin, Iu. D. Prediction of the extent of secular variations in the vertical component of the geomagnetic field for the territory of the U.S.S.R. 
[in Russian, with English summary] : Acad. Sci. U.R.S.S. Bull. (Izvestiia), Sér. Géog. et Géophys., vol. 10, no. 3, pp. 233-246, Moscow, 1946.

For the preparation of geomagnetic maps of future epochs it is necessary to predict the secular variations of the vertical component $Z$ of the geomagnetic field. The author offers a mathematical method for such prediction and illustrates it by the example of secular variations in the vertical geomagnetic eomponent over the territory of the U.S.S.R. The variations are expressed in terms of spherical harmonic series for successive periods of decreasing length from 1825 to 1945 , and the value of $Z$ is deduced therefrom for $1945-50$. In the calculations, the general scheme of J. Bartels' harmonic analysis of secular variations employing Legendre's. spherical harmonics is applied to the magnetic data of V. P. Orlov and M. M. Ivanov, and the dependence of the coefficients of harmonics upon time is expressed by a series of sinusoidal curves. Mathematical derivation is presented.- $V$. $S$.

9552. Klaasse, J. M., Rumbaugh, L. H., and Jensen, H. Applications of Shoran and photographic techniques to aerial magnetic surveys [abstract]: Oil and Gas Jour., vol. 45, no. 47, p. 123., Tulsa, Okla., 1947.

Airborne magnetic surveying poses three problems: (1) Obtaining and recording accurate magnetic data, (2) correlating these data with the position of the surveying airplane, and (3) eliminating or compensating for the effects of magnetometer drift and time variations in the earth's magnetic field.

First, a grid or network of systematic flight lines is laid out to cover the area to be surveyed. A continuous record of the total magnetic field is obtained along each flight line by means of the AN/ASQ-3A magnetometer modified for geophysical work. Position over variable terrain is determined by direct visual contact, using accurate maps if available, or trimetrogon photographs if the area is poorly charted or uncharted. In either case, position is recorded and correlated with magnetic data through the use of a modified Sonne strip camera and a system of coordinated relay-operated number counters.

Position over featureless terrain or extensive water bodies is determined with Shoran (AN/APN-3). Aircraft Shoran position is obtained and correlated with magnetic data by number counters and a recorder operated semiautomatically from the Shoran set. Effects of magnetometer drift and time variations in the earth's magnetic field are minimized by the choice and arrangement of flight lines. Time variations in the earth's field are recorded by a ground station.-Condensed by V. S.

9553. McGarva-Bruckshaw, J. The magnetic method of geophysical prospecting: Petroleum, vol. 10, no. 6, pp. 122-125, London, 1947.

Magnetic prospecting is discussed with reference to the nature of the geomagnetic field, magnetic properties of rocks, effects of permanent magnetism, magnetic anomalies, search for oil, surveying instruments, and aerial exploration, As a guide for finding oil, magnetic anomalies are considered to have a limited value by themselves, the main function of magnetic surveys being the detection of areas suitable for detailed exploration by other methods. The advantages of aerial magnetic leconnaissance are indicated. - T. S. 
9554. Morelli, Carlo. Anomalie magnetiche e declinazione in quota in Italia con speciale riguardo per la navigazione aerea strumentale [Italy's magnetic anomalies and declinations at high altitude, with special reference to aerial navigation by instrument] : Geofis. Pura e Appl., vol. 7, nos. 1-4, pp. 1-15, Milan, 1945.

The disturbing effects of certain magnetically anomalous regions in Italy on compass-guided aerial navigation are calculated by the method of Malkin verified by Ramsayer's experiments. With a view to correcting for these effects, special maps of declination are proposed for strongly magnetic localities, with isogons drawn for the principal altitudes of flying, as illustrated by a map for the island of Stromboli. The parts of Italy requiring such safeguards are delineated. For navigation in the rest of Italy the use of the method devised by the author for referring isogons to the normal magnetic field is recommended. $-V$. $S$.

9555. Niggli, Einst. Magnetische Messungen an der Mangan-Eisenerzlagerstätte Fianell, Val Ferrera [Magnetic measurements at the manganese-iron ore deposit of Fianell, Val Ferrera ] : Schweizer. Min. Pet. Mitt., vol. 26, no. 2, pp. 92-115, 1 map, Frauenfeld, Switzerland, 1946.

The small Alpine deposit of manganese and iron ore at Fianell, Switzerland, 7,560 feet above sea level, shows remarkable peculiarities in the magnetic properties of its ores. The iron ores, mostly hematite, are very weakly magnetic, whereas the greater part of the manganese ores, occurring as small lenses, have a volume susceptibility of 0.002 to 0.091 and show typical ferro-magnetic properties. The very strong magnetism of the latter ores is caused by jacobsite, $(\mathrm{Mn}, \mathrm{Fe})_{3} \mathrm{O}_{4}$, which together with braunite constitutes the manganese ores.

The magnetic survey of the deposit showed a fairly normal magnetic field over iron ore but very strong positive anomalies over outcropping manganese ores, with the maximum anomaly of vertical intensity reaching $+1,113$ gammas. Accoldingly, it was possible to trace the manganese ore lenses within the ore body. The survey is one of the very rare examples of direct location of manganese ore by magnetic methods.Author's abstract, condensed by V. S.

9556. Owen, David. The lines of force through neutral points in a magnetic field: Phys. Soc. London Proc., vol. 59, pt. 1, no. 331, pp. 14-18, London, 1947.

It is shown that, having precisely located a neutral point in a magnetic field as the point of intersection of two directional loci, it is practicable to draw the lines of force passing through the point. The theory of the field near a neutral point is treated from a geometrical point of view. • Examples are shown of fields plotted when a bar magnet is set parallel or at an angle to the earth's horizontal field.-Author's abstract.

9557. Savornin, André. Prospection magnétique a l'Ambohidranomoro, ouest de Madagascar [Magnetic prospecting at Ambohidranomoro, in western Madagascar] : Serv. des Mines Annales Géol., no. 10, pp. 53-58, Tananarive, Madagascar, 1939.

The Ambohidranomoro structure in the western part of Madagascar, repeatedly mapped geologically, was surveyed in 1937 with the vertical magnetic balance of Schmidt to delineate local intrusions and test the 
usefulness of magnetic measurements for oil search. In all, 138 measurements were made at 104 stations along 7 traverses shown on a map. The method of calibration, the field technique, and the calculation of corrected values are described.

The results, represented by an isoanomaly map, show several scattered negative anomalies ranging from -44 to -237 gammas. They point to the existence of a batholith at depth branching into two large dikes and thin subvertical veins but fail to show favorable structures because of an insufficient density of observation stations. It is concluded that local oil search by the magnetic method requires the use of a network with an average interval of 40 to 60 meters.-V.S.

9558. Terada, K. Electric current as a probable cause of daily magnetic variation : Terres. Magn. and Atmos. Electr., vol. 52, no. 2, pp. 189-200, Baltimore, Md., 1947.

Simple formulas have been deduced which may be used to calculate the electric currents of external and internal origin causing the daily magnetic variation. These current systems are found to agree with those obtained purely mathematically by J. Bartels. The method offered is shown to involve no serious errors.

The calculations (to the first approximation) of the vertical component of the daily magnetic variation, as compared with observed values, indicate the location of the external current, with some ambiguities depending upon the characteristics of the electric currents in the interior of the earth's crust. The results appear to be the first to show the location of the electric current of external origin of the daily magnetic variation from study of observed geomagnetic data.

The plausible conclusion is that the electric current probably responsible for the daily magnetic variation flows in the $E$ layer of its neighbor.-Author's summary, condensed by $\nabla$. S.

9559. U. S. Coast and Geodetic Survey. Isogonic chart for 1945, United States: Chart 3077, 31 by 47 inches, Washington, D. C., July 1946.

The new edition of the isogonic chart of the United States shows the distribution of magnetic declination for 1945. It marks a departure from the previous edition for 1940 in that it is prepared on a more detailed base map drawn on a scale of 1:5,000,000 and extends farther to the east. The lines of equal declination and of equal annual change are completely redrawn and cover the entire territory within the borders of the chart. Moreover, the isogonic lines have been derived by a new method that gives more consistent recognition to local irregularities than did the former methods. $-V$. $s$.

9560. Werner, Sture. Determinations of the magnetic susceptibility of ores and rocks from Swedish iron ore deposits : Sveriges Geod. Undersokning, vol. 39, no. 5, 79 pp., Stockholm, 1945.

To improve the interpretation of magnetic maps of Swedish ore deposits, determinations were made of the susceptibility of their rocks and ores in a magnetized field of the strength of the geomagnetic field. In the method of $\mathrm{E}$. Thellier employed for this purpose, a dirill-core sample is inserted in a solenoid and magnetized in its longitudinal direction. The resulting magnetic field of the sample acts on a magnet outside the solenoid and causes it to turn through an angle depending on 
the magnetization. A comparison between this angle and the angle produced by an evaluation coil substituted for the sample makes possible the calculation of the susceptibility of the sample.

The results obtained on 525 drill cores from 27 Swedish mines are tabulated and discussed with regard to demagnetization, remanent magnetism, dependence of susceptibility on magnetite content, susceptibility of magnetite, and other factors. $-\nabla$. $S$.

\section{SEISMIC METHODS}

9561. Bugailo, V. A. Determination of average velocity by the methods of summation, difference, and constant difference [in Russian] : Prikladnaia Geofizika, no. 3, pp. 131-138, Moscow, 1947.

The average velocity of reflected seismic waves propagated from the shot point to the reflecting horizon is usually calculated by the method of quadratic coordinates or of theoretical hodographs when the more precise data of seismic logging are lacking. However, in the first of these methods, inaccurate determination of the minimum of the hyperbola leads to considerable errors, and in the second method the plotting of the average curve may be a source of error.

To overcome these defects the author offers the new methods of summation, difterence, and constant difference, which employ quadratic coordinates and hodographs but obviate the use of hyperbolic minima and curvilinear plotting. The underlying equations involving the angular coefficient and other values are deduced. Of the three proposals, the method of constant difference, comparable in precision with the conventional method of theoretical hodographs, is considered superior to others, and a chart of squared times plotted against distances is given to simplify the calculations. $-V . S$.

9562. Congdon, R. I. The design and testing of a versatile dynamic seismometer [abstract] : Geophysics, vol. 11, no. 3, p. 422, Tulsa, Okla., 1946.

Previous theoretical results are used to produce a dynamic seismometer capable of being changed-easily to tarious conditions of response. The frequency of maximum response and sharpness of response of the seismometer are independently variable, the instrument's electrical impedance remaining fixed. Methods used in testing this seismometer from initial magnetic measurements to final testing are discussed.

9563. Critikos, N. A. Relazioni fra i fenomeni sismici e le manifestazioni vulcaniche nel Mar Egeo e nella Grecia Orientale [Relationships between seismic phenomena and volcanic manifestations in the Aegean Sea and eastern Greece] : Geofis. Pura e Appl., vol. 8, nos. 5-6, pp. 145-159, Milan, 1946.

The author reviews briefly the new volcanoes of Greece and the manifestations of volcanic activity in the Aegean Sea and eastern Greece. From the microseismic and macroseismic data of some of the earthquakes that occurred during 1928-45, he concludes that they belong in the category of magmatic earthquakes. His study of the conditions and location of the epicenters shows the existence of a relationship between seismic and volcanic activities and proves that magmatic action continues in the subsurface of the region considered.-Author's abstract.

$775754-48-3$ 
9564. Ewing, Maurice. Geophysical investigations of continental borders [abstract] : Tulsa Geol. Soc. Digest, vol. 15, p. 77, Tulsa, Okla., 1947.

Seismic refraction measurements were made over several traverses extending from the Atlantic coast line to the edge of the Continental Shelf in Maine, New Jersey, and Massachusetts. An unconsolidated layer with a velocity of $5,800 \mathrm{ft} . / \mathrm{sec}$., a semiconsolidated layer with a velocity of $11,500 \mathrm{ft} . / \mathrm{sec}$, and the basement with a velocity of 18,000 ft./sec. were traced across each traverse. Reversed profiles were used to determine slopes and true velocities. It was found that depth to the basement increases abruptly near the beach at Cape May, and about 40 miles offshore at New York. Other results are reported. The findings agree with previous data where such were available.-Condensed by V.S.

9565. Gamburtsev, G. A. Correlation systems of observations in prospecting by methods of seismic reflection and refraction [in Russian]: Acad. Sci. U.R.S.S. Bull. (Izvestiia), Sér. Gẹ́og. et Géophys., vol. 10, no. 1, pp. 19-29, Moscow, 1946.

A study is made of the use of correlation systems of seismic observations-arrangements of records establishing continuity of traces of seismic waves and wave phases-in exploration by methods of reflection and refraction. The organization of these systems in a plane generally is inceterminate, allowing several solutions.' The author shows that indeterminateness can be eliminated by reducing the problem to several separate two-dimensional cases in which observations are correlated in a generalized plane. Such reductions are investigated by an analysis of the simplified systems, with plotting of corresponding correlation sequences wherein the author's method of representation of 'seismic fields proves to be of assistance (see Geophys. Abstracts 129, no. 9193). The inquiry is illustrated by examples and suggestions on procedure. Certain new correlation systems suitable for use in prospecting are considered.- $\boldsymbol{V}$. S.

9566. Grenet, Gaston, and Bayard-Duclaux, F. Le séismograph vertical universel faux Wenner C. G. 1. [The Modified-Wenner C. G. 1. universal vertical seismograph] : Ann. Géophys., vol. 2, no. 2, pp. 104-114, Paris, 1946.

In contrast to the original Wenner seismograph consisting of a pendulum damped at the critical point and a galvanometer damped much beyond this point, the modified Wenner seismograph has a critically damped galvanometer and a strongly damped pendulum. The construction of the apparatus and the general equations of its movement, amplification, and responses are presented (see also Geophys. 'Abstracts 100, no. 5340). It is shown mathematically that the properties of such a seismograph resemble those of one with a mechanical amplification and a galvanometer. Variations in the period of pendulum oscillations are considered to have no effect on the seismograph's response to ground movements and on the amplification of sinusoidal movement. An example of a 20 -percent variation of the oscillation period is calculated, and samples of seismograms are shown.-V. S. 
9567. Gubanov, A. Rayleigh waves at the boundary between a solid body and a liquid [in Russian] : Zhur. Eksperim. i Teoret. Fiz., vol. 15, no. 9, pp. 497-502, Moscow, 1945.

Mathematical formulas are deduced to express the propagation of surface waves of the Rayleigh type in the case of a solid body entirely covered with a liquid. This question is of interest in the investigation of seismic waves propagated on the ocean floor. The effect of the viscosity of the liquid on the damping of Rayleigh waves is expressed by equations of hydrodynamics. It is found that the water mass diminishes the velocity of propagation and that viscosity produces dispersion and eventual extinction at smaller velocities. $-V$. S.

9568. Gutenberg, B., and Richter, C. F. Earthquake study in southern California, 1946: Am. Geophys. Union Trans., vol. 28, no. 4, pp. 633-634, Washington, D. C., 1947.

Progress in earthquake studies in southern California is reported for the year 1946. The results of the New Mexico atomic bomb test of 1945 and of the Bikini atomic bomb test of 1946 have yielded travel times of $P$ within about 2 seconds of those calculated from standard travel times of earthquake waves corrected for a surface focus. The research on microseisms conducted by the United States Navy has indicated that a large fraction of the energy in the microseisms associated with hurricanes is transmitted from the surface to the bottom of the ocean by elastic waves. The study of the earthquake of January 26,1947, in Central America has led to a tentative identification of the theoretically expected phase $P K K K P$ on the seismograms. Other investigations are listed.- $V$. S.

9569. Haggerty, P.: E., and Olson, R. W. Preliminary results of a study of seismograph sensitivity requirements [abstract]: Oil and Gas. Jour., vol. 45, no. 47, p. 120 . Tulsa, Okla., 1947.

The sensitivity of a seismograph system need be no greater than that necessary to raise the lowest expected ground-disturbance level to a reasonable fraction of full-scale deflection. This paper draws preliminary conclusions from data on ground-disturbance level as related to wind, temperature, and other factors in an effort to determine the minimum ground-disturbance level which may be expected for any appreciable period of time.

9570. Hansen, R. F. Un nuevo sistema de perfiles de reflexion [A new system of seismic reflection profiles] : Bol. Inform. Petrol., vol. 24, no. 272, pp. 237247, Buenos Aires, 1947.

The principles of seismic exploration of the subsoil are outlined briefly, and particular attention is given to reflection profiling used in preference to other techniques in Argentina. Three basic varieties of such profiling are distinguished, their underlying principles are examined mathematically, and their shortcomings are noted. To correct the shortcomings, a new system of reflection profiles is offered, its purposes and advantages are discussed, and the related equations are presented.- - V. S. 
9571. Harris, Sidon. Modern seismic techniques applied to geophysical exploration in west Texas: Oil and Gas Jour., vol. 46, no. 11, pp. 60-63, Tulsa, Okla., 1947.

In western Texas exploration for oil is conducted both by seismic reflection and refraction methods. Reflection practices are similar to those in other oil provinces, and the costs range between $\$ 15,000$ and $\$ 17,000$ a month. Refraction work is used because of the presence of hard deposits close to the surface, such as the Edwards lime and patches of caliche. It has the advantage of eliminating interference from such deposits by the placing of seismographs at a considerable distance from the shot point, but it costs as much as $\$ 35,000$ a month, with permit fees. The procedures employed include spot refraction shooting, broadside continuous-line shooting, and certain forms of arc and fan spot shooting.

The type of seismic method best suited for an area varies with local geology. To aid in its proper choice, the oil region of western Texas and eastern New Mexico is divided into 15 provinces, which are shown on a map and are discussed with regard to advisable seismic techniques and their cost. $-V$. S.

9572. Hughes, D. S. Response characteristics of seismograph at the University of Texas: Am. Geophys. Union Trans., vol. 28, no. 5, pp. 691-695, Washington, D. C., 1947.

The horizontal pendulums of the seismograph at the University of Texas have been equipped with McComb-Romberg "pick-ups.". Instead of recording directly, the light from the pick-up mirror falls on a split photo cell; the current from this photo cell is amplified and sent through the recording galvanometer. The output of the amplifier is also fed to an auxiliary circuit which controls the intensity of the recording light so that its brilliance is approximately proportional to the speed with which the galvanometer spot is moving.

The McComb-Romberg pick-up involves viscous coupling between the seismograph beam and the remainder of the system. A method of measuring the magnification at all relevant frequencies is described.-Author's abstract.

9573. Jersey, N. J. de. Seismological evidence bearing on crustal thickness in the southwest Pacific: Univ. Queensland Papers, Dept. Geology, vol. 3, no. 2, 18 pp., Brisbane, 1946.

A' study has been made of evidence bearing on crustal thickness in Australia and the adjacent southwest Pacific, the materials used being mainly seismograms recorded at Brisbane. For the Australian Continent, the evidence from surface waves indicates a crustal thickness or the order of $\mathbf{4 0}$ kilometers down to the Mohorovicic discontinuity. For the adjacent suboceanic area to the east, a continuous structure is indicated by observations of an amplitude ratio $P P / P$, and this is supported by data on surface waves which, in addition, indicate a total crustal thickness of the order of 25 kilometers, comparable with that of the crustal layers under the Atlantic and Indian Oceans.-Excerpt from Conclusions, p. 17. 
9574. Landsberg, $H$. and Neuberger, $H$. On difference of $P$-wave velocities: Bur. Centr. Séismol. Internat. Pub., Sér. A, Trav. Sci., no. 16, pp. 35-42, Strasbourg, 1946.

The authors' hypothesis of regional differences in wave velocities, derived from previous studies of systematic deviations of travel-time residuals for the $P$ wave, was subjected to verification by a statistical analysis of extensive and homogeneous material. For this purpose, the mean absolute residuals of $\boldsymbol{P}$ travel times were computed from the records of a number of selected stations for a total of 162 strong earthquakes between 1918 and 1932, and all values were corrected for ellipticity according to Bullen's tables. The results bore out the previous conclusion that the western European and Russian residuals have values considerably below those found for the Pacific and American stations.

An analysis was also made of relative residuals with signs preserved, computed from records of all available stations for earthquakes in restricted epicentral territories only, and additional data on regional differences were obtained. $-V$. $S$.

9575. Leet, D. L. Microseisms in New England-Case history of a storm: Geophysics, vol. 12, no. 4, pp. 639-650, Tulsa, Okla, 1947.

A microseismic storm recorded at the Harvard Seismograph Station November 14-16, 1945, is analyzed. Associated meteorological conditions are described. Rayleigh waves and $Q$ waves are identified. Rayleigh waves are used to determine the direction of approach of the microseisms. It is found that the microseisms did not radiate from the center of the barometric low and that at the height of the storm they approached the station from several directions. The position of the cold front associated with the storm correlated better than that of the barometric low with the directions from which microseisms were observed.-Author's abstract.

9576. Magnani, Mario. Tettonica e sismicità nella regione Albanese [Tectonics and seismicity of the Albanian region]: Geofis. Pura e Appl., vol. 8, nos. 1-2, pp. 1-42, Milan, 1946.

The frequency of earthquakes in Albania is a sign of the general instability of this region. When the results of the tectonic synthesis, made possible by the present progress of geologic knowledge on Albania, are compared with seismic records, it is seen that the seismicity of the region depends essentially on its tectonics. The earthquakes in southern Albania appear to be caused by special tectonic adjustments; the earthquakes in the north, by tangential movements; and the earthquakes on the coastal plain, probably, by continuous movements of emergence. The discussion is accompanied by an appendix giving a list of earthquakes, a description of the geology underlying the towns and the large villages affected, and an account of damage to buildings.-Author's: abstract, revised by $V$. S.

9577. Mansfield, R. H. Universal slide rule for linear velocity vs. depth calculations: Geophysics, vol. 12, no. 4, pp. 557-575, Tulsa, Okla., 1947.

Described in detail in the main body of the paper is a circular slide rule designed to be used for many calculations where the seismic veloc- 
ity varies linearly with the distance from a datum plane usually horizontal); that is, where $V=V_{0}+a z$. Here $V_{0}$ is the velocity at datum, and $a$ is the rate of change of velocity with respect to depth $z$. Table 1 lists, in the first column, data that must be given and, in the second column, what may be found from it by using the present slide rule. Except for that of line 10, all calculations are limited only by the accuracy of reading the scales, which is sufficient for most practical purposes. The calculation of line 10 is approximate only, but needs to be corrected over only about 5 percent of its usually used range; this correction is very simply made.-Author's abstract.

9578. Nishkian, L. H. Vertical vibration recorders for the Golden Gate Bridge: Seismol. Soc. America Bull., vol. 37, no. 2, pp. 81-88, Berkeley, Calif., 1947.

To study the types of motion occurring in suspension bridges under. the action of wind, the author experimented with P. Byerly's vibration recorder placed on the Golden Gate Bridge in California. The test gave satisfactory results, and several recorders were built according to a special design of Byerly for extensive investigation. This model consists of a weight of about 25 pounds suspended from a coil spring 4 feet long in extended condition. Vertical motions are changed to horizontal ones by a system of a horizontal arm and a vertical rod. A pen fastened to the vertical rod records the motion on a rotating drum. Details of construction are indicated and tracings of records are shown.V. S.

9579. O'Connell, D. J. K. Deep focus earthquakes, 1909-12: Roy. Soc. New South Wales Jour. and Proc., vol. 80, pt. 1, pp. 14-19, Sydney, Australia, 1946.

With the aim of extending the material available for the study of deep-focus earthquakes the author reexamined the early records of the Riverview seismographs. All the shocks that could be identified as being of deep focus were analysed. With the aid of all available reports from other stations, epicenters, depths, and origin times were obtained for 39 shocks from March 1909 to the end of 1912. Magnitudes were determined by Gutenberg's method.

The catalogue should be fairly complete for the southwest Pacific zone, at any rate for the deeper shocks of at least moderate intensity.Author's abstract.

9580. Omer, G. C., Jr. Differential-motion seismographs: Seismol. Soc. America Bull., vol. 37, no. 3, pp. 197-215, Berkeley, Calif., 1947.

A group of nonpendular seismographs actuated by the phase differences at two points in the earth's crust are analyzed for their transient and their steady-state behavior. The seismographs considered are the Benioff Linear Strain seismograph, the tranșversely driven rod seismograph suggested by Benioff, terminated rod seismographs of a new type, and a seismograph utilizing optical interference.-Author's abstract.

0581. Oulianoff. N. Le tremblement de terre du 25 janvier 1046 et la structure profonde des Alpes [The earthquake of January 25, 1946, and the deep structure of the Alns]: Soc. Vaudoise Sci. Natur. Bull., vol. 63, no. 268, pp. 367-391, Lausanne, 1947.

The author discusses the local seismic records of the earthquake of January 25, 1946, in Switzerland, the first strong shock in this country 
since 1855, with a view to verifying his hypotheses on the deep geology of the Alps. He gives consideration to the location of the epicenter, the damping of seismic waves, focal depth, velocities of propagation, and the direction of the horizontal component of the seismic ray. The evidence regarding the velocity of $P_{2}$ waves tends to indicate the presence of a granitic layer under the thin sediments in the direction of Neuchatel, a continuity between the granitic masses known to exist at the Aar River and at the Black Forest near Bâle, and a greater extension of thèse masses in the direction of Chur than in the direction of Zurich. Other 'deductions are made. On the basis of the findings, a map is drawn showing distribution of granitic masses in the region. $-V$. S.

9582. Pekeris, C. L. New methods for interpretation of seismic records from underwater explosions [abstract] : Oil and Gas Jour., vol. 45, no. 47, p. 126, Tulsa, Okla., 1947.

A study of the wave theory of propagation of sound produced by explosion in shallow water revealed that, in addition to the arrival times of the various refracted waves used in the seismic exploration of the ocean bottoms by the standard refraction method, the pressure wave received at large ranges from the source should exhibit certain features, which are also characteristic of the depth of water and the structure of the bottom.

All of the theoretically predicted new features have been discovered and measured in a study of more than 120 records obtained by $M$. Ewing and $\mathrm{L}$. Worzel at five stations on the eastern continental margin. The deductions about the structure of the bottom made from the various features, including the standard refraction data, are consistent.-Condensed by $V$. S.

9583. Pluvinage, Philippe. Application du calcul symbolique à certains problèmes de réglage des séismographes eléctromagnétiques [Application of symbolic calculus to certain problems of regulation of electromagnetic seismographs] : Ann. Géophys., vol. 2, no. 2, pp. 179-184, Paris, 1946.

Modifications in the response of an electromagnetic seismograph to brisk ground movement, occasioned by a change in its characteristics subsequent to the last calibration, are calculated in the general theoretical case and in two particular cases. The angular displacement of the galvanometer corresponding to the ground displacement is expressed by a linear differential equation of the 4 th order with constant coefficients, and the different responses of the apparatus are further determined by symbolic calculus, which furnishes equations of displacement, velocity, and constant acceleration. The calculations are presented.-V:S. (See also Geophys. 'Abstracts 129, no. 9196.)

9584. Poisson, Charles. La séismicité de Madagascar [The seismicity of Madagascar ] : Acad. Sci. Comptes Rendus, vol. 224, no. 10, pp. 699-700, Paris, 1947.

The seismicity of the island of Madagascar is discussed on the basis of records of the Tananarive Observatory for 1927-46. During that period 267 shocks occurred over the total area of 592,000 square kilometers, or an average of 2.2 shocks per year per 100,000 square kilometers. An area of 310 square kilometers comprising the capital registered 62 percent of the shocks. None of the shocks attained fntensity 
values in class VIII of the International Scale. It is concluded that the seismicity of Madagascar is somewhat less intense than that of France.V.S.

9585. Renner, D. S. Seismometer engineering [abstract]: Geophysics, vol. 11, no. 3, p. 416, Tulsa, Okla., 1946.

Theory of design, as illustrated by the dynamic and reluctance types, is introduced by differential equations. Equivalent circuits are then discussed. Next response parameters $Q$ and $W$ are used, and optimum designs are considered with these parameters given. Optimum relations involving actual design parameters are finally evolved.

9586. Riznichenko, Iu. V. Master chart of theoretical hodographs of reflected waves [in Russian, with English summary] : Acad. Sci. U.R.S.S. Bull. (Izvestiia), Sér. Géogr. et Géophys., vol. 10, no. 5, pp. 435-448, Moscow, 1946.

An improved master chart is offered for the determination of seismic velocities on the basis of theoretical time curves (hodographs) of reflected waves. Its construction presupposes a plane-surface boundary and a constant velocity, rendering it suitable for two-dimensional interpretation. Within these limitations, the chart is applicable to any travel time or wave velocity and to the reflecting boundary's depth and inclination angle and can serve for interpreting single hodographs, converging hodographs, and series of hodographs. The operations of best fit involved in such uses are described, the principles and equations underlying the chart are explained, and other methods of velocity determination are appraised critically. $-V . S$.

9587. Rothé, E. Les tremblements de terre et la radioactivité [Earthquakes and radioactivity] : Bur. Centr. Séismol. Internat. Pub., Sér. A, Trav. Sci., no. 16, pp. 87-94, Strasbourg, 1946.

Among the causes of earthquakes the author is inclined to include the heat continuously generated by radioactive substances. These substances, located particularly in the upper strata of the earth's crust having a low density, produce marked thermal differences at various points in the magna. Thus, 1 gram of uranium gives off $9.5 \times 10^{-5}$ calories per hour, and 1 grain of thorium, $2.2 \times 10^{-5}$ calories per hour. As a result, a mechanism of tectonic disturbance is set in operation, mainly by such properties of materials as the increase of volume by fusion and the raising of the fusion point by pressure. Eventually fissures are opened and masses of molten basalt rise through them to intrude into the bases of continents, causing progressive deterioration of their margins. According to the author these changes must affect isostatic equilibrium and contribute to the generation of seismic disturbances. $-V$. S.

9588. Sadovskii, M. A. The seismic effect of explosions in the case of weak ground and monolithic structure [in Russian]: Trudy Seismol. Inst., No. 117, pp. 56-64, Moscow, 1945.

This paper-describes an investigation of the seismic effect of an explosion upon a monolithic structure standing on weak ground. The results of the observations show that such a structure introduces strong distortions in the movement of the ground, practically eliminating the 
horizontal component of motion. As a result, the vibrations of the structure are reduced to vertical displacements and to a rocking about a horizontal axis passing through the foundation. A comparison between the observed inclination angles of the structure and of the ground surface indicates that the movement of the structure very closely resembles a rocking motion on the seismic wave.-Author's abstract, translated by $V$. S.

Sagui, C. L. Les tremblements de terre et la gravitation [Earthquakes and gravitation]. See Geophys. abstract 9533.

9589. Treskov, A. A. Concerning reflected seismic waves [in Russian] : Trudy Seismol. Inst., no. 117, pp. 1-8, Moscow, 1945.

A study is made of exchange points on the branches of reflection hodographs. The application of certain experimentally ascertained properties of wave paths and of the principle of Fermat leads to a determination of the velocities compatible with the formation of exchange waves. This analysis shows that only in certain definite cases do epicentral distances of points where a PSS hodograph trace branches from an $S S$ hodograph trace and where a $P S$ trace branches from an $S$ trace agree with actual observations, such as the instance of Gutenberg's hodographs. The condition to be satisfied is that the velocity of longitudinal waves reflected from the horizon should remain within limits of 7.5 to $8.5 \mathrm{~km}$./sec. Thus, a formation of reflection exchange waves is possible only at the lower boundary of a basalt layer which is characterized by a velocity of $8 \mathrm{~km}$./sec. $-\nabla$. $S$.

9590. Ulrich, F. P., and.Hollis, E. P. Progress report of seismological work by the United States Coast and Geodetic Survey in the western United States during 1945: Seismol. Soc. America Bull., vol. 37, no. 2, pp. 89-100, Berkeley, Calif., 1947.

The seismological work of the United States Coast and Geodetic Survey in the western United States during 1945 has consisted primarily of the collection of earthquake information, the operation of strongmotion stations, and extensive field work on two large blasts. The Chief of the Seismological Field Survey, was assigned to special duty in the South and Central American republics for several months on a seismological program sponsored jointly by the State Department and the Coast and Geodetic Survey. Each of these topics, as well as certain incidental matters, are discussed briefly.-Authors' preface.

9591. Valle, P. E. Sull' energia associata alle onde sismiche SKS ed $S K K S$ [Concerning the energy associated with seismic waves SKS and $S K K S$ ] : Ric. Sci. Progr. Tecn., vol. 14, pp. 8-14, Rome, 1943.

The energy of the seismic waves $S K S$ and $S K K S$ is calculated as a function of the distance to the epicenter. It is found that energy sufficient to prevent the overshadowing of these waves by other waves in seismograms exists only at a focal distance of $76^{\circ}$ to $104^{\circ}$. Consideration also is given to the literature on $S$ waves in their relation to the terrestrial core and the physical constants in the interior of the earth.V. S. (An abstract appeared in Zentralb. Geophys., Meteorol. u. Geod., vol. 11, no. 4, p. 194, Berlin, 1943.) 
9592. Van Beveren, O. F. Seismic exploration in Sumatra [abstract] : Petroleum Worḷd, vol. 44, no. 3, p. 39, Los Angeles, Calif., 1947.

A large area of jungle and swamp in central Sumatra was mapped with the reflection seismograph between 1937 and 1941. The field con: ditions are described, and the methods used in achieving a high rate of production in spite of difficult terrain are indicated.

9593. Vecchia, O. Alcuni casi di strutture geologiche con strati a bassa velocita nella sismica di rifrazione [Certain cases of geologic structure with layers characterized by a low seismic refraction velocity]: Riv. Geominer., 1945/1946, pp. 9-18, Milan, 1947 (?).

The study of layers characterized by a low seismic refraction velocity has been largely neglected as not admitting of mathematical analysis. It is usually considered possible to calculate from travel-time curves only the maximum and the minimum velocity values and the thickness of the low-velocity layers. The author shows that, theoretically, even this calculation is partly erroneous because the method employed cannot serve to determine the minimum velocity.

In practice, the difficulties are still greater inasmuch as only a few points on the travel-time curves are known, so that the presence of low-velocity layers has to be ignored in interpretation unless additional data are available. The magnitude of the errors thus involved is illustrated by a series of schematic geologic cases, for which the errors are deduced mathematically and computed in numerical examples. $-V$. S.

9594. Wood, H. O. Earthquakes in southern California with geologic relations, parts 1-2: Seismol. Soc. America Bull., vol. 37, no. 2, pp. 107-157, no. 3, pp. 217-256, Berkeley, Calif., 1947.

A brief historical outline concerning the investigation is followed by description of the geologic faulting in the region. Data on the instrumentally recorded earthquakes of recent years, giving shock magnitudes and the location of epicenters, are tabulated, with notes, comments, and discussion of the quality of the location of the shocks and the incompleteness of the information. Summaries of the tabulation are made in different ways. Maps show the geographic interrelationships of the shocks tabulated and the faults. These relationships are also discussed in the text.

Earthquake magnitude is discussed with relation to the method used in mapping the epicenters, and its energy equivalence is considered. A table shows the geographic distribution of the seismic energy and the corresponding variation in the "density" of activity as well as the corresponding number of shocks. The correlation of the earthquake origins with the faulting is discussed. The prevailing depth of the origins is considered and, based upon the findings, a hypothesis is ad. vanced to account for the random, or scatter, distribution of many small shocks away from the mapped faults-that is, repeated, migrating slips of small area on nearly horizontal planes at or near the depth of origin, with resultant growth of regional strain. As yet this is only a hypothesis, but the importance of continuing consideration of it is emphasized. The possibility of such action elsewhere, with the production of great earthquakes having large areas of high intensity, is suggested. No basis for earthquake prediction has resulted from the investigation. Future needs are discussed briefly.-Author's abstract. 
9595. Zetler, B. D. Travel times of seismic sea waves to Honolulu: Pacific Science, vol. 1, no. 3, pp. 185-188, Honolulu, 1947.

To provide a basis for predicting the time at which a seismic sea wave will reach the Hawaiian Islands, a chart has been prepared of the Pacific Ocean showing the travel times from the plotted positions of known earthquake epicenters to Honolulu. If the place and time of a disturbance are known, the arrival time of the wave at Honolulu can be determined. The chart is presented, and the methods of its preparation and use are described. A table lists the data used for mapping the geographic positions of epicenters, the Greenwich time of seismic disturbances, the locations of the gauges which recorded receipt of the seismic sea wave in the Hawaiian Islands, the observed travel times, and the differences between computed and observed travel times. $\boldsymbol{V}$. $\mathbf{S}$.

9596. Zvolinskii, N. V. Rayleigh waves in a heterogeneous elastic hemisphere of a particular type [in Russian] : Acad. Sci. U.R.S.S. Bull. (Izvestiia), Sér. Géog. et Géophys., vol. 9, no. 3, pp. 261-278, Moscow, 1945.

A study is made of the free oscillation of a heterogeneous elastic hemisphere in which the density and the coefficients of Lamé are identical exponential functions of depth. It is assumed that no stress exists on the boundaries, all displacements and stresses disappear at infinite depth, and seismic velocities are constant. In the analysis attention is given to a mathematical derivation of the relationship between the length of a wave and the frequency of oscillation, and to the spectrum of the possible values of phase velocity. An investigation is also made of a medium having a zero coefficient of Poisson, and of the asymptotic oscillations of short waves in the case of arbitrary values of the elasticity constant. The results of the inquiry show that the hemisphere considered has a normal wave dispersion and that there are no Love waves in it. $-V . S$.

\section{ELECTRICAL METHODS}

9597. Al'pin, L. M. Sources of the electrical field in the theory of electrical prospecting [in Russian]: Prikladnaia Geofizika, no. 3, pp. 56-100, Moscow, 1947.

The electrical fields used in electrical prospecting and logging are analyzed mathematically on the assumption that anomalies are caused by a distribution of charges induced at the places of discontinuity in homogeneous media. Attention is given to the particular cases of electrical fields from point sources created in conditions of plane and curvilinear boundaries, to the distribution of induced charges in vertical electrical sounding, and to the density of charges which exist at the surface and determine the shape of the curve of sounding.-Author's abstract, translated by $V$. S.

9598. Blackburn, M. S. Radiographic method of geophysical exploration: World Oil, vol. 126, no. 11, pp. 43-46, Houston, Tex., 1947.

Radiographic prospecting is done by electromagnetic measurements of radio field intensities. In the original investigations the intensities of standard broadcast stations were measured over known faults, anticlines, synclines, and salt domes. The tests indicated that anomalous readings correlate with geologic structure and with oil and gas produc- 
tion. Records showed both gradual and sudden changes that were substantially duplicated in repeated runs.

For prospecting, a continuous automatic recording is made with equipment transported on an automobile at speeds up to 50 miles per hour. From the data it is possible to draw contour maps of structure and de: lineate faults. Commercial application has been made since 1936 on the Gulf coast and in Canada.-V. S.

9599. Corsaro, G. Review of the corrosion process: Nat. Eng., vol. 50, pp. 537539, Chicago, Ill., July 1946.

A discussion is given of the electrochemical principles involved in corrosion; how-laws of electricity apply in corrosive action; anodic and cathodic areas; parts played by hydrogen and oxygen in the corrosion process; oxide films; factors which influence corrosive action on ferrous metals in contact with aqueous solutions; and protective measures which may be taken to retard or eliminate corrosion.-Corrosion, vol. 3, no. 7, Abstracts, $p$. 29, Pittsburgh, Pa., 1946.

9600. Dinger, J. E., and Gunn, Ross. Electrical effects associated with a change of state of water: Terres. Magn. and Atmos. Electr., vol. 51, no. 4, pp. 477-494, Baltimore, Md., 1946.

A method for measuring the change in contact potential of a waterair interface as the water freezes or melts is described. These measurements indicate that a change of the order of 10 volts rapidly occurs at the time of freezing of the surface of the water. After freezing this contact potential diminishes, the rate depending upon the temperature of the ice, until the potential is approximately that which existed before freezing. The melting of the ice produces no appreciable change in the contact potential. The presence of dissolved gases is essential for the observed charging effect to occur. This fact indicates that the charging effect is related to earlier experiments on the cataphoresis of gas bubbles as described in the literature. No important charge production accompanies the freezing of even pure water in the absence of dissolved gases.-Authors' abstract, condensed by V.S.

9601. Eisler, J. D., and Silverman, D. Multichannel pen recorder for electrical logging operations: Geophysics, vol. 12, no. 3, pp. 414-423, Tulsa, Okla., 1947.

Principle of operation, constructional details, and performance of a servo-mechanism type pen recorder are described. The recorder comprises two independent channels of servo-amplifier and motor, each capable of moving an inking pen in a rectilinear fashion across a chart moving proportionally to the borehole depth traversed by an electrode array. The speed and resolution of the recorder is more than adequate for electrical logging requirements. The recorder is capable of recording both d.-c. and a.-c. signals.-Authors' a.bstract.

9602. Kulichenk0, N. I. The electrical probe [in Russian]: Razvedka Nedr, vol. 12, no. 4, pp. 39-41, Moscow, 1946.

In 1941 the author constructed an improved model of his electrical probe designed for sounding boreholes. The instrument consists of graduated wooden rods screwed together and equipped with an electric cable throughout their length, a head device at the lower end, an electric 
bulb at the upper end, and a battery supplying current. The head device carries two projecting, springing laminae in caliperlike fashion, which have on their sides protruding copper knobs connected with the cable. These knobs slide along the formations composing the walls when the probe is lowered into a borehole and close the cricuit upon meeting a conducting zone, so that the bulb at the surface lights up. The probe is used for reconnaissance testing of shallow boreholes in exploration for sulfide veins. $-V$. $S$.

9603. Lee, B. D. Potentiometric model studies [abstract] : Oil and Gas Jour., vol. 45 , no. 46, p. 145, Tulsa, Okla., 1947.

A simplification of the method of Hurst and McCarty for conducting potentiometric model studies is presented along with experimentally determined invasion patterns for certain idealized flow problems. The analytical solution for one class of these problems is indicated. Finally, a general description is given of a newly developed instrument which permits a direct mapping of flow lines and determination of transit times in potentiometric model studies.

9604. Leontovich, M., and Fock, V. Solution of the problem of propagation of electromagnetic waves along the earth's surface by the parabolic equation method: Jour. Physics, vol. 10, no. 1, pp. 13-24, Moscow, 1946.

The problem of the propagation of electromagnetic waves along the surface of the earth is solved by the parabolic equation method proposed by Leontovich. In the first part of the analysis the surface of the earth is considered as plane, and the well-known formula of Weyl and van der Pol is deduced. This formula turns out to be the exact solution of the parabolic equation for corresponding boundary conditions. In the second part the surface is considered as spherical, and the resulting formula coincides with that which Fock obtained by the method of summation of infinite series furnishing the rigorous solution of the problem.Authors' abstract.

9605. Lewis, W. B. Practical consideration for electrical prospecting [abstract] : Oil and Gas Jour., vol. 45, no. 47, p. 120, Tulsa, Okla., 1947.

The possibility of detecting oil directly through its electrical resistivity presents an incentive for investigating electrical methods that show evidence of sufficient working depths. By the use of low-frequency commutated currents, effects are obtained from several thousand feet below. the surface. Experimental evidence of working depths is presented.

9606. Sheinman, S. M. On transient electromagnetic fields in the earth [in Russian ] : Prikladnaia Geofizika, no. 3, pp. 3-55, Moscow, 1947.

The fundamentals of the mathematical theory of transient electromagnetic fields in the ground are presented. It is shown that in the conditions of the northern Caucasus the field of a symmetrical electrode arrangement of the type $\mathrm{AMNB}$, with $\mathrm{AB} \leq 20$ kilometers, can require as much as 40 to 50 seconds to become established, and that such a duration can introduce considerable errors in the measurements. A comparative analysis is made of the effects of transient fields in the case of various electrode arrangements, and the advantages of schemes with MN perpendicular to $\mathbf{A B}$ over customary schemes are demonstrated.-Author's: abstract, translated by $V$. S. 
9607. Simpson, W. H. An experience with the "megger": Oil and Gas Jour., vol. 46, no: 20, pp. 192, 292-293, Tulsa, Okla., 1947.

To detect a leak in an oil-pipe line issuing from San Joaquin Valley, California, an electrical resistivity survey was made with a megger manufactured in Philadelphia. This instrument is a double-commutator generator operated by a handle and connected with 4 iron pegs driven into the ground at equal intervals along a straight line. The megger's output is 90 volts, and its ohmmeter registers 0.1 to $3,000 \mathrm{ohms}$.

In that area sandy and heavy clay soil alternates abruptly with a reddish-brown sand and conglomerate considerably higher in electrical resistivity. At the spots of lowest resistivity revealed by the megger survey the condition of the pipe was checked by test holes. A leak was discovered at a place where the pipe passed from a clay soil to a sandy soil. Apparently corrosion was caused by galvanic action generated by the difference of the soils. $-V$. $S$.

9608. Siñeriz, J. G. Investigacion hidrologica en Castellón de la Plana por medio del metodo electrico de corriente continua [Hydrological investigation in Castellon de la Plana by the direct current electrical method] : Rev. Geofis., vol. 5, pp. 153-171, Madrid, Apr.-June 1946.

An electrical survey was made to determine by a study of geologic faults and fissures the course of subsurface waters through the impermeable massif separating the Borriol River from the Mediterranean Sea. The work was carried out in connection with a project to establish reservoirs to collect water for irrigation and electrical power on the plain of Castellon, Spain.-Cent. Nat. Rech. Sci., Bull. Anal., vol. 8, no. 5, pt. 1, p. 994, Paris, 1947, translated by $\nabla$. S.

9609. Tarkhov. A. G. A means of increasing the sensitivity of the method of electrical induction [in Russian] : Razvedka Nedr, vol. 12, no. 4, pp. 37-38, Moscow, 1946.

When the method of electrical induction is used for the exploration of small ore deposits registering anomalies weak in themselves and distorted by influences from adjacent conductors, it is essential to increase the sensitivity of the measuring technique. For this purpose, the author suggests reducing the ratio between the primary field $H_{1}$ of the generator and the induced field $H_{2}$ of the earth currents by adjusting the angle of the axis of the generator's receiving coil. A discussion of the effects produced shows that a proper choice of this angle can. decrease the value of $H_{1}$, and so increase the relative efficacy of $H_{2}$. Curves are given of measurements made with the coil set at different angles. In practical application, the receiving coil is turned about its vertical axis to a position assuring sufficient sensitivity. The method is recommended for detailed prospecting. $\rightarrow$. $s$.

\section{RADIOACTIVE METHODS}

9610. Bulashevich, Iu. P. Diffusion of emanation in the ground, with a correction for convection [in Russian]: Acad. Sci. U. R. S. S. Bull. (Izvestiia), Sér. Géog. et Géophys., vol. 11, no. 1, pp. 93-96, Moscow, 1947.

The mathematical equation of diffusion is solved in application to radioactive emanations by a method which takes into account their dissolution in a homogeneous ground and convective transfer to the 
surface by the upward movement of the ground air. The treatment makes use of MacDonald's functions for the cases of a point source and a linear source.

The analysis shows that convective transfer produces an increase of concentration of emanation in a certain zone located over the source and a decrease of concentration in another zone just below' the first zone, as compared with a distribution without convective transfer. The surface separating the two zones has a concentration equal to that existing without transfer. The theoretical results are discussed in relation to the experimental studies of the distribution of emanations surrounding a source, conducted by the Central Institute of Geological Exploration (TsNIGRI).-V. S.

9611. California Oil World. Checking cement behind pipe with radioactivity $\log$ : Vol. 40, no. 13, pp. 9-11, 31, Los Angeles, Calif., 1947.

In the work of cementing the casing or liner after a pipe is run into a well, the actual location of the cement can be checked by radioactive logging if carnotite is used in the cement, particularly in the case of squeeze cementing. After the carnotitic cement is in place, its distribution behind the pipe is indicated by anomalies on the log.

A gamma ray instrument is used for the logging, and a comparison is made between logs run before and after cementing. The post-cementing gamma-ray log may aIso be compared with a precementing electric log, though less satisfactorily. The operating procedure is described, and a practical example is given. $-\nabla$. $S$.

9612. De Ment, Jack. Uranium and thorium prospecting with the Geiger counter: Min. Cong. Jour., vol. 33, no. 8, pp. 30-32, 37-38, Washington, D. C., 1947.

- Many prospectors have assumed that exploration for radioactive substances requires bulky and complicated equipment coupled with an extensive knowledge of physics and electronics. This is far from the case. The technique of radioactive prospecting is by no means difficult, and light portable equipment, no larger than a medium-sized camera, is available for the purpose. The importance of uranium and thorium in the era of atomic power requires little comment. Of additional interest to the prospector is the fact that the presence of radioactivity is often a guide to other important minerals, including ores of vanadium, columbium, and tantalum.-Author's abstract.

9613. Discovery. The Geiger-Mïller counter: Vol. 8, no. 5, pp. 130-131, London, 1947.

The passage of radioactive radiations through gases causes the latter temporarily to conduct electricity. This property is used in measuring radiations by means of ionization chambers, alpha counters, proportional counters, and Geiger-Müller counters. Most commonly used is the Geiger-Müller counter, sensitive both to beta rays and gamma rays. It is a small gas-tight tube usually made of copper or aluminum, which contains a mixture of argon and alcohol vapor and houses an insulated tungsten wire stretched along its axis.

Radiations enter the counter through a thinned-out section in the negatively charged walls, and their ionizing action splits the argon atom 
into an ion pair. The negative component of this pair moves toward the positively charged central wire and produces a pulse of electricity transmitted by the wire to a counting device. Ionization is soon stopped by the alcohol vapor, and the counter is sensitized for other radiations.V.S.

9614. Larsen, E. S., and Keevil, N. B. Radioactivity of the rocks of the batholith of southern California; Geol. Soc. America Bull., vol. 58, no. 6, pp. 483494, Baltimore, Md., 1947.

Determination of radioactivity has been made on 43 rocks, carefully selected from the different mapped units of the complex. Cretaceous batholith of southern California; they range from gabbro to granite. The activity of the gabbro averages about 0.3 alphas $/ \mathrm{mg}$. $/ \mathrm{hr}$.; the tonalites, 0.8 ; the granodiorite, 1.3 ; and the granites, more than 2.0 . The activity of the average rock of the batholith is about 0.9 alphas/mg./hr.

Most of the rocks have been analyzed, and modal compositions are given. The radioactivity and the percentages of $\mathrm{K}_{2} \mathrm{O}, \mathrm{SiO}_{2}$, and $\mathrm{PbO}$ are plotted on a variation diagram. The variation curve for activity nearly parallels that for $\mathrm{K}_{2} \mathrm{O}$, and the ratio of activity to $\mathrm{K}_{2} \mathrm{O}$ is about 0.5 . The radioactivities of some rocks fall far from the variation curve, and the degree of radioactivity correlates with $\mathrm{K}_{2} \mathrm{O}$ content. A less-marked correlation between activity $\mathrm{SiO}_{2}$ and $\mathrm{PbO}$ was also noted. Other results are given.-Authors' abstract, condensed by $\mathrm{V}$. S.

9615. Marble, J. P., and others. Report of the Committee on the Measurement of Geologic Time, 1943-46, 75 pp., Washington, D. C., National Research Council, August 1947.

The progress of investigations falling within the province of the Committee on the Measurement of Geologic Time is reviewed. The subjects covered by the committee include analysis of radioactive minerals, isotopic composition of various elements, measurement of radioactive constituents, connection between geologic and astronomic time, geologic implications of radioactive investigations, and other subjects. Advances are noted in the measurement of age by the ratio $\mathrm{Rb} / \mathrm{Sr}$., in the application of the helium method to igneous and sedimentary rocks, in the radioactive analysis of the titano-columbate series, in the chronology for portions of Pleistocene and post-Pleistocene time, and in some other problems.

The report has five supplements containing a paper by $\mathbf{R}$. F. Beers on the measurement of age ratios of sediments, a paper by J. M. Lopez de Azcona on lead of radioactive origin in tourmaline, notes by A. C. Lane, preliminary reports of the committee, and an annotated bibliography. by J. P. Marble.-V. S.

9616. Shchepot'eva, E. S. The methods of radioactivity measurements-A vacuim method for measuring the Rn content of waters and gases: Acad. Sci. U. R. S. S. Comptes Rendus (Doklady), vol. 41, no. 4, pp. 169-171, Moscow, 1943.

An apparatus is described, which appears to be simple in operation and to enable all $\mathrm{Rn}$ in sample to be measured. Consult original for sketches and operating details.-J. P. Marble, Rept. Comm. Measurement Geot. Time, 1943-46, p. 51, Washington, D. C., 194\%. 
9617. Spence, H. S. Uranium and thorium minerals-information for the use of prospectors: Canadian Min. Jour., vol. 68, no. 9, Gardenvale, Quebec, 1947 ; also Northern Miner, vol. 33, no. 21, pp. 18-19, 22, Toronto, Ontario, 1947.

To aid prospectors of rare metals the Canadian Bureau of Mines has issued an information circular on uranium and thorium minerals. The circular is reproduced. It deals with the character, occurrence, and identification of the minerals and outlines briefly the methods of exploration using photography, spinthariscope, goldleaf electroscope, ultraviolet light, and-Geiger counters. Application to the radioactive minerals found in Canada is discussed. It is pointed out that field methods can serve only to detect the presence of uranium and thorium in a deposit and that a-laboratory analysis is necessary for determining its commercial value. $-V$. $\$$.

Tripp, R. M. Geophysical principles for determining subsurface conditions. See Geophys. abstract.9626.

9618. Tripp, R. M., and O'Boyle, C. C. Beta activity of some carbonaceous materials [abstract] : Geophysics, vol. 11, no. 3, p. 423, Tulsa, Okla., 1946.

The interest in radioactivity logging of boreholes in sedimentary formations and the implications of research on the relation between radioactivity, organic content of sediments, and the origin of petroleum have stimulated quantitative determination by a rapid routine method of the activity of several samples of pollen, oil shales, carbonaceous shales, and bituminous material. Explanations are proposed to account for the wide variations and the significance as regards the origin of petroeum.

9619. Zhirov, K. K. Some questions of radioactivity in geology [in Russian] : Uchenye Zapiski, Ser. Geol.-Pochv. Nauk, no. 9, pp. 100-109, Leningrad, 1940.

This paper gives a brief account of various applications of the data on radioactive disintegration to the calculation of geologic time. The prin-' ciples of the lead method and the helium method are outlined, the estimates of the earth's age are listed, and the contributions of scientists in various countries are indicated, with particular attention to the work of Vernadskii, Khlopin, and Lind. Consideration also is given to the geochemical aspects of radioactive elements. $-V . S$.

\section{GEOTHERMAL METHODS}

9620. Birch, Francis. Crustal structure and surface heat flow near the Colorado Front Range: Am. Geophys. Union Trans., vol. 28, no. 5, pp. 792-797, Washington, D. C., 1947.

Two important assumptions regarding the earth's crust are widely accepted: (1) That in the process of mountain formation the crustal layers are thickened, with the development of "roots" sufficiently great to compensate approximately the visible inequalities of elevation, and (2) that most, if not all, of the radioactive production of heat takes place in the upper layers by virtue of average concentrations of radioactive elements comparable with those found in laboratory samples. If these two assumptions are correct, we may expect to find an increased surface heat flow in and near mountainous or plateau regions. 
The magnitude of the effect to be expected is computed for various sizes of root, distributions of heat production, and intervals since thickening. The analytical results are compared with certain preliminary studies of heat flow along the Colorado Front Range. It is concluded, tentatively, that the more extreme forms of upward concentration of heat production are improbable, but the present data are inadequate for a completely satisfying answer. The bearing of other possible measurements on this problem is briefly discussed.-Author's abstract.

9621. Eyres; N. R., Hartree, D. R., and others. The calculation of variable heat flow in solids: Royal Soc. London Philos: Trans., ser. A, vol. 240, no. 813, pp. 1-57, London, 1946.

A practical method has been developed for evaluating theoretical and numerical solutions of the equations of heat conduction in solids under nonsteady conditions. The presentation of the underlying theory and calculations covers the basic approximation by which the partial differential equation is reduced to a set of ordinary differential equations, and the results of application to bodies of different shapes and degrees of symmetry; some results of calculations of variable heat flow in materials for which the thermal properties are independent of temperature; the general case of heat conduction in a material whose thermal properties vary with temperature; and the concrete instance of an ingot. cooling in a mold. Principal attention is devoted to the problem of variable heat flow free from the restriction of constant diffusivity.- $V$. S.

9622. Kraskovsky, S. A. On the variation of temperatures at great depth over long periods of time [in Russian]: Priroda, no. 6, pp. 54-56, Moscow, 1946.

The earth's crust below a depth of 30 meter's generally is considered to have a steady temperature which increases downward, but few precise data are available. It is conceivable that the climatic conditions

$\because \quad \because$ of past ages have left traces on temperatures at great depths, as supposed by I. Prestwich, A. Voeikov, A. Jentsch, A. Lane, V. Vernadsky, ........ and others; their work is summarized briefly.

Particularly favorable conditions for the investigation of this problem exist in the permafrost zone, and measurements recently were made in wells as deep as 28 meters at the Skovorodino geothermal station in the Amur region, Siberia. M. I. Sumgin found in these data indications of a decline of temperature with depth below the belt of the minimum annual amplitude of thermal variation; he concluded that existing climatic conditions can modify the distribution of temperature in depth. However, A. N. Tikhonov has pointed out weaknesses in the technique used at the Skovorodino station. The various investigations are reviewed, and further studies in the permafrost zone are considered promising $-V$. $s$.

\section{GEOCHEMICAL METHODS}

9623. Deegan, C. J. The mass spectrometer and what it does: Oil and Gas Jour., vol. 46, no. 18, pp. 64-65, 91, Tulsa, Okla., 1947.

Gas analysis by means of the mass spectrometer is explained for the layman and is illustrated by diagrams. The apparatus breaks up hydrocarbon gas molecules by smashing them with electron bullets, 
collects the fragments, sorts them by weight, and counts the number of fragments of each weight. The resulting distribution curves make identification of gases possible because the molecules of each gas always break up into the same number of fragments of the same weight, and because the pattern of distribution of these numbers and weights is unique and distinctive for each gas. The individual patterns obtained by analysis may be used in identifying gases separately or in mixtures.V. S.

9624. Hills, E. S. The metalliferous geochemical zones of Austrialia: Econ. Geology, vol. 42, no. 5, pp. 478-491, Lancaster, Pa., 1947.

Spot maps showing recorded occurrences of minerals containing certain elements as essential or important constituents have been prepared in an attempt to discover and delimit the main metallogenetic provinces of Australia. Correlation with geological events is evident in a broad way, and it is shown that in Paleozoic and later times there has been a progressive shift in the location of successively developed ore zones from west to èast in eastern Australia.-Author's abstract.

9625. Ransone, W. R. Geochemical history of the Hardy oil field, Jones County, Texas: Geophysics, vol. 12, no. 3, pp. 384-392, Tulsa, Okla., 1947.

The exploration history of the Hardy oil field is unusual in that its discovery followed from drilling on a geochemical anomaly. In the immediate vicinity of the anomaly there was no evidence of closed structure either from a reflection seismograph survey which preceded or from a core drill investigation which followed the geochemical survey.

The geochemical survey, which covered a portion of Jones County, Texas, was initiated in August 1942. The discovery well in the Hardy field was completed in November 1943 and opened a new Canyon sand pay zone. Development of the field has shown that the sand pinches out across a nose, forming a typical stratigraphic reservoir. Thus, as a result of that discovery and subsequent development, the predictions from all three exploration methods-geochemical, reflection seismograph, and core drill-have been confirmed.-Author's abstract.

9626. Tripp, R. M. Geophysical principles for determining subsurface conditions: Oil Weekly, vol. 126, no. 2, pp. 34-36, Houston, Tex., 1947.

To explain certain geochemical anomalies in the Rocky Mountain region, the upward migration of methane from subsurface reservoirs is expressed thermodynamically, and a calculation is made of the values of pressure, volume, temperature, water-vapor content, and enthalpy. It is found that a large amount of water vapor is lost in the upper strata during the migration, with consequent cooling. The effect of this local phenomenon can be the precipitation of ions having a very small solubility product, or the flocculation of hydrophyllic colloids having a small zeta potential.

These processes are discussed with regard to their diagnostic value, and a possible prospecting technique is indicated consisting of determining the concentration of radioactive minerals in the zone of maximum colloidicity and simultaneously ascertaining the mineral wax content. Experiments have shown that concurrent anomalies in both these properties are related to the presence of petroleum at depth. $-\nabla$. S. 
9627. Warren, H. V., and Howatson, C. H. 'Biogeochemical prospecting for copper and zinc: Geol. Soc. America Bull., vol. 58, no. 9, pp. 803-820, Baltimore, Md., 1947.

Agriculturists have long been interested in the minor-element content of trees and lesser plants and of the soils in which they grow. The authors have been interested in the relation of plants to ore deposits and have carried on in British Columbia a series of investigations which indicate that the zinc and copper content of some trees and lesser plants may reflect, to a striking extent, the presence of zinc and copper concentrations in the underlying soils or rock formations.-Authors' abstract.

9628. ZoBell, C. E. Bacterial release of oil from oil-bearing materials: World Oil, vol. 126 , no. 13 , pp. $36-47$, vol. 127 , no. 1, pp. 35-41, Houston, Tex., 1947.

The ability of certain bacteria to liberate oil from oil-bearing sands under certain conditions may point the way to a wider understanding of the phenomena underlying the accumulation or formation of hydrocarbons in reservoirs. Study of such bacterial action may lead to the ultimate recovery of a large portion of oil now left in place. The author describes the experiments carried out to define basic principles of bacterial action under conditions simulating those of the oil reservoir. The findings given offer a basis for continuing research and clarify existing limitations.-Author's abstract.

\section{UNCLASSIFIED GEOPHYSICAL SUBJECTS}

9629. Andreev, B. A. The calculation of the spatial distribution of potential fields and its utilization in exploration geophysics [in Russian]: Acad. Sci. U. R. S. S. Bull (Izvestiia), Stér. Géog. et Géophys., vol. 11, no. 1, pp. 79-92, Moscow, 1947.

The author discusses methods of calculating the spatial distribution of potential fields in relation to different problems of exploration geophysics. He recommends for calculations a formula which furnishes the solution of Dirichlet's problem for an infinite plane. Theoretical considerations and practical examples are presented to demonstrate that the application of this formula is relatively simple and yields accurate results. It is shown that the method can be used for the analysis of the results of aeromagnetic surveys and for the reduction of geophysical observations to one plane.-Author's abstract.

9630. Boss, R. L., and Hilseweck, W. J. Developments in west Texas and southeastern New Mexico in 1946: Am. Assoc. Petroleum Geologists Bull., vol. 31, no. 6, pp. 1018-1038, Tulsa, Okla., 1947.

In 1946, 335 exploratory holes were drilled in western Texas in quest of oil, with 123 holes successful, and 65 exploratory holes were drilled in southeastern New Mexico, with 15 holes successful. Growth in geophysical activity in western Texas was shown by an increase from 30 parties in January to 50 parties in December and in southeastern New Mexico from 22 parties in January to 25 parties in December. The marked progress of geophysical work in western Texas resulted mainly from an increase in the number of seismic parties from 26 to 41 ; gravity and magnetic work also increased. The discovery of Ellenburger oil 
on the Eastern platform in southwestern Kent County, Texas, was due to seismic work.- $\nabla$. S.

9631. Bradley, W. S [H]. Program of the United States Geological Survey: Mines Mag., vol. 37, no. 7, pp. 17-19, 33, 36, 40, Denver, Colo., 1947.

- The postwar program of the U. S. Geological Survey with respect to its traditional activities of regional geologic mapping, long range research, and evaluation of national mineral resources is outlined. Exploration for metallic ores by private enterprise will be aided by a mapping of the regional setting of known deposits, eventually to be extended to the large intervening areas. Research will also be undertaken to investigate, develop, and test geophysical methods and adapt them to the search for ores and to other geologic work. Studies will be made of the application of geochemical methods to exploration for ores.

To aid petroleum exploration, systematic surface and subsurface surveying of the stratigraphy of promising regions is proposed for determining the changes in facies and the distribution and thickness of oilproducing formations. Long-range research will deal with the geochemistry of hot springs, the regimen of hydrothermal alteration, existing geologic processes, and related noneconomic problems. Other phases of the program are outlined.- - . S.

9632. Bull, A. J. Terrestrial heat and earth movements : Geologists' Assoc. Proc., vol. 58, no. 2, pp. 115-124, London, 1947.

This paper is a contribution to the idea that the mountain-building force is merely gravity, and that the disturbance calling it into play is the unequal heating of subcrustal material by radioactive elements. It would appear that the idea is in accord with some known facts of tectonics. Joly's opinion was that "the broad physiographic features of the globe are involved in the events arising out of isostasy and the radioactivity of the rocks."-Author's summary, condensed by $\nabla$. S.

9633. Bureau O. F. M. N., A. N., S. S. S. R. The scientific activity of the Division of Physico-Mathematical Scierices of the Academy of Sciences of the U. S. S. R. and its affiliated institutions in the year 1945 [in Russian] : Acad. Sci. U. R. S. S. Bull. (Izvestiia), Sér. Physique, vol. 10, no. 3, pp. 319-329, Moscow, 1946.

A brief account is given of the scientific work conducted by the Physico-Mathematical Division of the Academy of Sciences of the U. S. S. R. (O. F. M. N., A. N., S. S. S. R.) in 1945. Its affiliates include the Lebeder Institute of Physics, the Institute of Physical Problems, the PhysicalTechnical Institute, the Institute of Theoretical Geophysics, the Seismological Institute, the Steklov Mathematical Institute, and other bodies.

Among the investigations of the Institute of Theoretical Geophysics are listed the seismic studies of G. A. Gamburtsev, I. S. Berson, Iu. V. Riznichenko, N. V. Zvolinskii, and others; the electrical studies of A. N. Tikhonov, G. V. Chistiakov, and A. G. Ivanov; the magnetic studies of A. G. Kalashnikov and V. V. Koliubakin; and the geothermal studies of S: S. Kovner and O. B. Murav'ev. The Seismological Institute is reported to have conducted research on deep-focus earthquakes, epicentral and hypocentral distribution in the Crimea, earthquakes in central Asia, rotation of the earth, and other subjects. $-\nabla$. S. 
9634. California Oil World. Trends and techniques in petroleum exploration: Vol. 40, no. 15, pp. 3-13, Los Angeles, Calif., 1947.

The general trend in petroleum exploration toward the use of geology, geophysics, geochemistry, and microbiology is noted, and the nature of the various new techniques is indicated briefly. Particular attention is given to the development of aerial photography and to the exploratory applications of aerogeology and aeromagnetic surveying.- $V$. S.

9635. Conselho Nacional do Petróleo, Brazil. Relatório de 1945 [Brazilian National Council of Petroleum. Report for 1945], 218 pp., Rio de Janeiro, 1947.

This report includes an account of geophysical exploration for oil made in Brazil by magnetic and seismic methods during 1945 and proposed for 1946. The surveys were conducted by the United Geophysical Co., S. A., according to plans laid out by E. De Golyer in the generab region of Baía de Todos os Santos, State of Bahia. Seven magnetic profiles were traced, and several areas were explored by seismic reflection. The work is described and illustrated by maps. $-V$. S.

9636. Cullen, R. J. Developments in Oklahoma in 1946; Am. Assoc. Petroleum Geologists Bull., vol. 31, no. 6, pp. 1006-1014, Tulsa, Okla., 1947.

During 1946 petroleum development and exploratory drilling in Oklahoma exceeded the levels of 1945 . Of the 3,000 wells drilled, $58 \mathrm{~s}$ were exploratory and led to the discovery of 71 oil pools, 22 gas pools, and some minor pays. Geophysical work, on the contrary, declined considerably from its high record in 1945. A total of 113 holes was drilled on the basis of geophysical exploration in 1946 as compared with 270 holes in 1945. The number of seismograph crew months was 436 in 1946 compared with 622.5 in 1945 ; of gravimeter crew months, 96 in 1946 compared with 106.5 in 1945 ; and of magnetometer crew months, 3 in 1946 compared with 23 in 1945.- $-V$. S.

9637. Gassmann, Fritz. Die Entwicklung der Geophysik in Zürich in den letzten 50 Jahren [The development of geophysics in Zurich during, the last 50 years] : Naturf. Gesell. Zürich, Festsch. zur 200-Jahr-Feier, pp. 248-252, Zurich, 1946.

A brief account is given of the development of seismic and geomagnetie investigations in Zurich, Switzerland, during the past half century. The section on earthquake studies outlines the work of the initial Earthquake Commission, which functioned during 1880-1912, and of the subsequent Swiss Earthquake Observatory under A. de Quervain, which began using modern seismographs. The contributions of $A$. Kreis and E. Wanner are indicated, and brief remarks are made on seismological investigations of geologic and engineering problems.

The section on geomagnetic studies lists $w$. Brückmann's survey of 1927-31 and the work of the Regensberg variometer station. The two pronounced mugnctic anomalies in Switzerland-near Lausanne and near Ticino_have been investigated by P. Mercanton, E. Wanner, E. Weber, and $\mathrm{E}$. Niggli, with the assistance of the Geophysical Institute at Ticino. The institute has also conducted magnetic surveys of iron deposits in the Alps. Electrical methods have been used for exploration by W. Fisch, 0 . Münger, and $\mathbf{H}$. Knecht.- $-\mathrm{s}$. 
9638. Jakosky, J. J. Whither exploration: Am. Assoc. Petroleum Geologists Bull., vol. 31, no. 7, pp. 1118-1124, Tulsa; Okla., 1947 ; also Geophysics, vol. 12, no. 3, pp. 361-368, Tulsa, Okla., 1947.

During the past decade oil produced in the United States has exceeded the total amount of new oil discovered. The economic, technologic, and political factors causing this situation are examined. It is found that, in the period considered, lease-operating costs have increased only 17 percent, drilling or development costs have increased 80 percent, and exploration costs have increased more than 400 percent.

The chief reason for the growth of exploration costs is the declining effectiveness of current geological and geophysical methods. Exploration techniques have their cycles, each lasting for a relatively few years. At present the areas most amenable to known techniques have been well covered, and recourse is made to more intensive geologic work supported by two or more geophysical methods. The latter methods are being perfected by improved instrumentation, superior field procedures, and fuller interpretation. These refinements increase the cost of their application without augmenting discoveries proportionally. Other causes of higher exploration costs are considered. $-V . S$.

9639. Krinitzsky, E. L. Geophysics and its applications to speleology: Nat. Speleol. Soc. Bull., no. 9, pp. 19-21, Washington, D. C., Sept. 1947.

A brief outline is given of gravitational, magnetic, seismic, and electrical methods of prospecting in application to the spotting of subterranean caves. Electrical sounding is found to be practically the only geophysical method that can be of any value to speleologists, but it requires competent handling and expensive equipment. Its greatest usefulness is for locating blocked cave entrances situated in or near sink boles. $-V . S$.

9640. Moody, G. B. Developments in California in 1946: Am. Assoc. Petroleum Geologists Bull., vol. 31, no. 6, pp. 931-946, Tulsa, Okla., 1947.

During 1946 petroleum exploration in California diminished from the record level of 1945 but was substantially, above that of 1944 . Subsurface geology was the dominant factor in the location of drill holes. Where it was the sole guide, 20 percent of the exploratory wells were successful and 13 percent of the wildcats. Geophysics was used less but scored 23 percent success for exploratory wells and 16 percent for wildcats in the ventures for which it was solely responsible. The drillhole footage discovered per work unit, however, was less for geophysical methods than for geologic methods. Seismic methods were 23 percent successful in the location of gas wildcats in new fields. At the close of 1946, 12 seismograph parties and 2 gravimeter parties were active.V. S.

9641. National Research Council of Canada, Associate Committee on Geodesy and Geophysics. Canadian Geophysical Bulletin; Ottawa, 1947.

The Canadian Geophysical Bulletin is issued quarterly by the Associate Committee on Geodesy and Geophysics, National Research Council of Canada, to provide information on current work of practical and theoretical interest and to furnish a bibliography of recent Canadian nublica- 
tions. The contents cover meteorology, hydrology, oceanography, seismology, vulcanology, terrestrial electromagnetism, atmospheric ionization, geodesy, tectonics, geothermometry, and radioactivity. $-\boldsymbol{V}$. ' $\mathbf{S}$.

9642. Nature. Canadian research in geodesy and geophysics: Vol. 159, no. 4036, pp. 344-345, London, 1947.

The Associate Committee on Geodesy and Geophysics of the National Research Council of Canada, originally formed in 1945, has been reorganized as a central body for directing and coordinating research in various fields of geophysical investigation, including prospecting, and for disseminating information on such work. The activities to be coordinated will be carried out by government departments, private companies, and universities and will be financed partly by them and partly by the Associate Committee, which has funds for the award of grants to aid specific projects. The investigations so far undertaken are listed, and the possibilities of geophysical study and exploration in Canada are indicated.

The work of the Associated Committee is supplemented by the work of the Geophysical Committee of the Geology Division of the Canadian Institute of Mining and Metallurgy, which deals with problems of assessment, customs, taxes, operational methods, and professional ethics. $-\nabla . S$.

9643. Per'kov, N. A. Methods of oil-well logging in the United States [in Russian] : Razvedka Nedr, vol. 12, no. 2, pp. 59-66, no. 3, pp. 45-50, Moscow, 1946.

In 1944-45 the author traveled in the United States to study the logging of oil wells. In his report he describes various types of electrical logging, radioactive logging, thermal logging, mechanical logging, borehole-fluid analysis, coring, perforation, curvature determination, and other approaches to well surveying. - D. S.

9644. Slichter, L. B. Current status and potentialities of geophysical prospecting for ore: Mining Jour., vol. 229, no. 5840, pp. 460-463, no. 5841, pp. 477479, London, 1947.

Geophysical exploration for ore can be conducted by flux methods and by wave methods. The methods of each group are examined, and their potentialities are appraised: The flux group, comprising the gravitational, magnetic, and electrical methods, has received wide application but has a limited range of penetration because of the complexity of geologic formations. Attention is given to means for overcoming this difficulty. Simple model techniques would assist in the interpretation of magnetic and electrical data. The electrical inductive methods can be considerably improved by advances in instrumentation and in field operation. A more extensive application of electrical methods in conjunction with drilling and underground workings should be useful. The other flux methods can be chiefly improved by better understanding. application, and interpretation.

In the wave group only the seismic method is suitable for exploration, bit it has the greatest range of penetration and the highest accuracy for determining position or outlining structure. Ax phases of the application of seismic methods to mining exploration should be investigated.-D. S. 
9645. Stagg, J. M. Summary report on the extraordinary general assembly of the International Union of Geodesy and Geophysics (IUGG), Cambridge, England, July 29 to August 2, 1946: Terres. Magn. and Atmos. Electr., vol. 51, no. 4, pp. 509-515, Baltimore, Md., 1946.

An extraordinary general assembly of the International Union of Geodesy and Geophysics was held in Cambridge, England, on July 29 to August 2, 1946, with representation from 16 countries. The delegates met in full session and in committee. A summary of the agenda items and resolutions is given. $-V$. S.

9646. Van Weelden, I. A. Modern developments in geophysical prospecting: Inst. Petrol. Jour., vol. 33, no. 282, pp. 344-355, London, 1947.

Recent developments in geophysical prospecting for oil are discussed with respect to improvements, extensions, and innovations made in methods. It is found that gravitational methods have been perfected by advances in the sensitivity of instruments; in the control of temperature, creep, and magnetization; and in the ease of operation. Seismic methods have been improved by the development of the refractioncorrelation technique, which makes use of second arrivals and is suited particularly for shallow investigations and superficial high-speed layers. Seismic amplitude control and the quality of explosives also have advanced.

The new applications of existing methods include gravity and seismic surveying under water and magnetic surveying from the air. Electrical surface methods, soil analysis, and electronic devices are considered to be relatively new approaches still in the developmental stage. $-\boldsymbol{\nabla}$. $\mathbf{S}$.

9647. Vecchia, 0 . L'avvenire della geofisica nelle ricerche di petrolio negli S. U. A. [The future of geophysics in oil exploration in the United States.] : Riv. Geominer., 1945/1946, pp. 23-29, Milan, 1947(?).

The future of applied geophysics in oil search can best be appraised from an examination of its application in the United States, where it appears to have made the greatest progress. A brief review is given of the current uses of different geophysical methods, as revealed by the most recent literature in that country, and their possibilities are examined, especially with regard to geological interpretation. The methods considered include gravimetric, magnetic, seismic, electric, geochemical, and radioactive techniques, and well logging.-Author's abstract, translated by $\boldsymbol{\nabla}$. S.

9648. Weeks, L. G. Highlights on developments in foreign petroleum fields : Am. Assoc. Petroleum Geologists Bull., vol. 31, no. 7, pp. 1135-1193, Tulsa, Okla., 1947.

A brief account is given of recent petroleum exploration and development in nearly 70 countries of the world. The information, predominantly geologic and economic in character, is illustrated by sketch maps showing sedimentary areas and oil flelds. In the case of most countries the data include a few statistics on geophysical prospecting. In addition, the figures of geophysical crew .months reported during 1946 are tabulated at the end. The table credits the United States with 4,210 seismic crew months, 1,656 gravity crew months, and 239 magnetic crew months ; Venezuela with at least 341 seismic crew months, 147.5 gravity 
crew months, and 14 magnetic crew months ; and Colombia with at least 138 seismic crew months, 63 gravity crew months, and 9 magnetic crew months. Other figures are given.- $\boldsymbol{V} . \mathbf{S}$.

9649. Wilson, C. O. Seeking Arctic oil: Oil and Gas Jour., vol. 46, no. 16, pp. 78-81, 125-131, Tulsa, Okla., 1947.

U. S. Naval Petroleum Reserve No. 4 in Alaska, comprising 35,000 square miles, is being explored with the aid of aerial photography, study of surface geology, aeromagnetic surveys, aerial and ground gravitational surveys, seismic surveys, test hole drilling, and laboratory analysis.

The aeromagnetic work was done in $1945-46$ and covered 70,000 square miles from the Canning River to the west coast. On the basis of the information obtained, gravitational exploration is now being made in the north on the ground and with a Cessna-140 airplane, which transports a gravimeter and carries skis and pontoons for landing at selected locations for readings. In the Ikpikpuk area northwest of Umiat, 2 seismic parties work with the aid of RD-8 tractors, weasels, and wanigans on sleds used for the transportation and housing of equipment and men. Progress of the geophysical work is outlined and indicated on a map, and the local geology is described. $-V$. S.

(For climatic conditions see article by the same author, Climate major factor in determining exploration work in northern Alaska: Oil and Gas Jour., vol. 46, no. 15, pp. 62-66, Tulsa,.Okla., 1947.)

9650. Wilson, J. H. Case history of the Fort Collins extension, Larimer County, Colorado: Geophysics, vol. 12, no. 3, pp. 393-401, Tulsa, Okla., 1947.

The results of a gravity meter survey of the Fort Collins field, Larimer County, Colorado, both before and after elimination of regional effects; is presented together with subsequent seismograph and subsurface studies which led to the development of a small northward extension of the Fort Collins oil field. Other geophysical work in the area is reviewed.-Author's abstract.

9651. Young, G. J. Elements of mining, 4th ed., 755 pp., New York, McGraw-Hill Co., 1946.

This textbook on mining, designed for students, instructors, and mining men, includes a chapter on the geological essential and geophysical methods of prospecting. A brief description is given of the principles, instruments, and procedures of the magnetic, gravimetric, seismic, and electrical methods in their application to ore search.- $\boldsymbol{V}$. $\mathbf{S}$. (For 3d edition see Geophys. Abstracts 46, no. 1241.)

\section{RELATED NONGEOPHYSICAL SUBJECTS}

9652. American Society of Civil Engineers. Definitions of surveying terms: Manuals of Engineering Practice, no. 15, 22 pp., New York, 1938.

The committee established by the Surveying and Mapping Division of the American Society of Civil Engineers for dealing with the definition of surveying terms has published a manual on the technical terminology used in surveying. More than 200 terms considered ambiguous, doubtful, or comparatively new are defined as to their best usage and in part are illustrated by examples.-V.S. 
9653. Anderegg, Fred. Aerial negatives and prints, their classification and preservation in the United States: Am. Geophys. Union Trans., vol. 28, no. 4, pp. 523-527, Washington, D. C., 1947.

A study has been made of the methods of classification and preservation of aerial photographic negatives and prints that are used by various governmental agencies. The general plan of filing is described as well as the availability of prints to users. A more efficient use of the accumulated data would be accomplished by placing all of the records under the care of the National Archives.-Author's abstract.

9654. Bichan, W. J. Structural principles controlling the occurrence of ore in the Kolar gold field: Econ. Geology, vol. 42, no. 2, pp. 93-136, Lancaster, Pa., 1947.

The Kolar gold field, Mysore, is regarded as the clearest example of structural control in the formation of gold-bearing ore bodies. The producing Champion lode is in a quartz-filled fracture system in a basin of infolded hornblende schists and allied eruptives, underlain by a complex of granitic rocks. The structural influences have been effected by such processes as drag openings and fissure-forming pressures exerted upon hanging-wall wedge blocks, which combined in producing host chambers for the quartz veins bearing the gold. The paper submits for study a number of geologic patterns considered novel.- $-\mathbf{S}$.

9655. Callaham, Ludmila. Russian-English technical and chemical dictionary, 794 pp., New York, John Wiley \& Sons, 1947.

The book contains scientifically organized references to 80,000 terms likely to appear in technical articles. It provides a complete coverage of terms in organic and inorganic chemistry, chemical technology, and mineralogy ; an extensive coverage of terms in metallurgy, mining, geology, engineering, physics, botany, pharmacy, machinery, and mechanics; and a more limited coverage of terms in agriculture, entomology, medicine, aeronautics, meteorology, and military science. It also includes terms of particular value to industrial technologists.-Mines Mag., vol. 37, no. 4, p. 41, Denver, .Colo., 1947, condensed by V. S.

9656. Chace, F. M. The search for ore deposits-geologic methods and concepts [abstract] : Econ. Geology, vol. 42, no. 4, pp. 414-415, Lancaster, Pa., 1947.

In known districts the search for ore deposits should be based on detailed geological and historical knowledge of the mineralized area, and all possible structural, mineralogical, and theoretical concepts and guides should be developed and used. With these as a background, attention can be given to extensions of known ore bodies, repetitions of known ore bodies, new ore bodies of previously unrecognized structural control, and extensions of known districts:

The search for new districts should be based on a knowledge of regional geology. The two methods of approach now in use are the search for a specific metal or mineral and the investigation of a specific area. In either case different geologic concepts may be useful, such as metallogenetic provinces, distribution of ore deposits with respect to batholiths and stocks, relation of ore deposits to regional structure, physiography as a guide to ore, rock alteration, and physical and chemical properties of rocks.-Condensed by $V$. S. 
9657. Davis, R. E., and Foote, F. S. Surveying-Theory and practice, 3d ed., 1032 pp., New York, McGraw-Hill Co., 1940.

This volume is primarily a textbook for students, engineers, and surveyors. The elementary phases of theory and practice are treated in detail, and the advanced methods suitable for extensive surveys under a variety of conditions are discussed in the light of their relative advantages. Part 1 presents introductory considerations; part 2 describes the fundamental operations common to all branches of surveying; and part 3 deals with entire surveys of different types, including mine surveys and photogrammetric surveys. Tables of related data are appended. $-V . S$.

9658. Dix, C. H. Efficiency in exploration, I, General [abstract] : Geophysics, vol. 11, no. 3, p. 420, Tulsa, Olila., 1946.

We use the word efficiency in the present context to mean "the value of the found oil divided by the cost of finding" or "the value of what is found per dollar of finding cost." Before the oil is found, we can evaluate each step. At each stage we use the expected efficiency which is "the expected value at the given date per dollar finding cost to date." The "expected value" is "the probability of finding oil times the value of the oil to be found."

Obviously "the value of the oil to be found" can be known only after it is found. However, the expected efficiency is of value insofar as it serves to evaluate alternative exploration process since it does give relative values, making the selection of a most efficient process possible. "Probability of finding" is based on information to date including previous experience of people making the evaluation of this probability. Its value is one for certainty of success and zero for certainty of failure. It is intermediate between zero and one for intermediate situations. The estimate of probability is rough at first but becomes more and more accurate as more and more experience is accounted for by the present process.

9659. McNish, A. G., and Tuckerman, Bryant. The vehicular odograph : Terres. Magn. and Atmos. Electr., vol. 52, no. 1, pp. 39-65, Baltimore, Md., 1947.

A description is given of the vehicular odograph, a device for automatically plotting the course of a vehicle in which the odograph is mounted. The odograph derives information on direction from a magnetic compass, which is read by a photoelectric system, and information on distance from a shaft geared to the speedometer cable. Errors in maps obtained with the device amount to 2 or 3 percent of the total distance traveled under ordinary rough conditions of operation, but with the exercise of certain precautions these errors can be greatly reduced. Detailed discussion on the operation and compensation of a magnetic compass in a vehicle with particular emphasis on problems of subpermanent magnetization is included, together with a theoretical analysis of the integrating proceșs employed which involves averaging of discrete intervals.-Authors' abstract. 
9660. Nettleton; L. L., and Elkins, T. A. Geologic models made from granular materials: Am. Geophys. Union Trans., vol. 28; no. 3, pp. 451-465, Washington, D. C., 1947 .

This paper describes geologic models made with high density powders overlying a lower density fluid. Movement was induced by gravitational forces only and, in most of the models, "deposition" was effected contemporaneously with "deformation." Granular materials were selected because they are particularly adapted to show faulting. Models were made to show salt-dome structures and thrust and tension faults. Some of the thrust structures, in particular, closely resemble known geologic 'structures.-Authors' abstract, condensed by V.S.

9661. Oppenheim, Victor. First generalized geologic map of South America: Pan-Am. Inst. Min. Eng. Geol., U. S. Section; Tech. Paper 2, 15 pp., 1 map, New York, 1945.

This map, drawn on an approximate scale of $1: 11,200,000$ differentiates in color patterns seven divisions of bedrock: Pre-Cambrian sedimentary, metamorphic, and igneous ; Mesozoic and Paleozoic igneous, including some metamorphic; Paleozoic, upper and lower, unseparated; Cenozoic and Mesozoic igneous, unseparated; Lower Mesozoic-Triassic and Jurassic; Upper Mesozoic-Upper and Lower Gretaceous; and Cenozoic-Quaternary and Tertiary.

The dominant units of exposed bedrock are the widespread PreCambrian strata of the Brazilian shield, the great north-south belt of Cenozoic deposits, and the Andean highlands. The value of the map lies chiefly in giving a general picture of a little explored continent.-C. $\boldsymbol{R}$. Longwell, Am. Jour. Sci., vol. 245, no. 8, p. 528, Nèw Haven, Conn., 1947, condensed by $\mathrm{V}$. S.

9662. Petroleum Engineer Publishing Co. Petroleum data book, 1st ed., 1106 pp., Dallas, Tex., 1947.

This volume brings together data on operations of the petroleum industry the world over. The information is presented in 13 sections dealing with exploration and development, drilling, p̀roduction, refining, gas processing, transportation, marketing, finance, taxation, employment, and related subjects. Statistics on geophysical exploration cover work in foreign countries and in the United States, the latter differentiated by States to show the use of geophysical methods for locating exploratory holes and the extent of explosion hazards. A glossary on reservoir behavior and a cross index are appended. Revised editions, brought up to date, will be published annually. $-V$. S.

9663. Reiter, W. A. Contouring fault planes : World Oil, vol. 126, no. 7, pp. 34-35, Houston, Tex., 1947:

Location of fault points in terms of contours which represent the intersection of the fault plane with depth planes parallel to sea level enable the close determination of faulted formations in the course of a projected well. The author outlines the procedure and illustrates the principle with typical fault-plane contours.-Author's abstract. 
9664. Ridenour, L. N., editor. Radar system engineering, 748 pp., New York, McGraw-Hill Co., 1947.

This book, a part of the Massachusetts Institute of Technology Radiation Laboratory Series, is a general treatise and reference book on the design of radar systems. It deals primarily with microwave pulse radar and covers radar equations, properties of radar targets, treatment of radar data, component parts of radar sets, new ancillary techniques, and related subjects. For fuller information on questions of design the reader is referred to the other books of the series. $-\nabla$. S.

9665. Smith, N. C., and Wengerd, S. A. Photogeology aids naval petroleum exploration: Am. Assoc. Petroleum Geologists Bull., vol. 31, no. 5, pp. 824-828, Tulsa, Okla., 1947.

In 1945 a photogeological survey was made of Naval Petroleum Reserve No. 4 in northern Alaska to aid surface petroleum exploration. A previous trimetrogon coverage obtained in 1944 from a height of 20,000 feet

$\because$ for drawing aeronautical charts had given insufficient geologic informa-

$\therefore \quad$ tion, and the subsequent work was conducted from 12,000 feet, providing one vertical and two oblique strips along flight lines spaced at 12 miles. Vertical prints had a contact scale of about $1: 24,000$, which approximated the scale of the field sheets used by the surface geological parties.

Geologic interpretation has dealt mainly with the region of the Umiat

$\therefore$ structure and has aimed at qualitative data. The local topographic

relief was found particularly suited for photogeologic analysis. The total information will be compiled by the U. S. Geological Survey into base sheets on a scale of $1: 48,000 .-V$. $S$.

9666. Thompson, H., D. Fundamentals of earth science, 461 pp., New York, D. Appleton-Century Co., 1947.

This textbook is a brief introduction to geology, geography, meteorology, and related sciences, intended to give to college students a complete elementary picture of the earth. The contents cover the planet's origin, age, composition, structure, and place in the solar system, weather and climate, weathering and erosion, ground waters and surface waters, glaciers, minerals, volcanism, types of rocks, lithosphere, earthquakes, and other subjects. All the fundamental aspects of the earth are treated with equal attention.- $\nabla$. $s$.

9667. Wengerd, S. A. Newer techniques in aerial surveying-The photographic laboratory : world Oil, vol. 127, no. 4, pp. 46-54, Houston, Tex., 1947.

Advances made in aerial photographic surveying during and since the war include improvements in laboratory facilities, in film development and printing, and in ground.control. Three new types of laboratories suitable for various climates have been developed-the photographic trailer, the AAF portable laboratory, and the Quonset air-conditioned laboratory. A portable developing apparatus with electrical motors that wind film negatives through solutions automatically is available; the machine prints aerial negatives in 200 -foot rolls at a rate of 40 feet per minute. The checking of flight coverage is made by printing whole flights on continuous strips and laying them down side by side on long tables for visual inspection. 
In problems of ground control both the standard ground techniques and the new aerial techniques have progressed. Ground surveys are aided by the French $60^{\circ}$ astrolabe, the equiangulator, the zenith camera, the land odograph, and the precise aneroid altimeter. Ground control from the air is improved by the use of the photoalidade and the singleeyepiece plotter. The solar navigator aids controlled flying. Other instruments and techniques are described, and Alàskan experience in . aeiral surveying is outlined.-V. $\boldsymbol{S}$.

9668. Wilson, W. H. Radar proves useful tool in marine surveying: World Petroleum, vol. 18, no. 5, pp. 71-73, New York, 1947.

In marine geophysical exploration, position fixing is increasingly done by radar triangulation. Radar waves are analogous to light waves as to travel speed and reflection. To determine distance, they are transmitted toward the object at regular intervals, and measurement is made of the time required for a wave to be reflected. To determine the angle between two reflecting objects, the radar beam is successively turned upon them and the respective bearings are read. The military radar unit SCR-784 can measure angles with an error of \pm 3.5 minutes and distances with an error of \pm 20 yards. In marine geophysical exploration, radar triangulation is accomplished with the Mariner's Pathfinder apparatus, or the Shoran apparatus. The principles and uses of these radio units and related surveying instruments are described.- $\boldsymbol{V} . \boldsymbol{S}$.

9669. Worzel, J. L. Ocean bottom sampler for ships under way [abstract]: Geophysics, vol. 12, no. 3, p. 501, Tulsa, Okla., 1947.

A simple bottom sampler has been developed which may be used from ships moving at speeds up to 12 knots. The sampler is allowed to fall freely under its own weight and is recovered by reeling in the wire attached to the front. The open tube at the front scoops about $1 / 2$ pint of material from the upper few inches of mud, sand, or cớral bottoms.

Models have been built with trap doors to close the tube after the sample was taken, and to allow a free flow of water through the tube, but these refinements have been discarded as the difference in samples was negligible.

The ability to use the sampler under way makes the location of the position of a sample easier and more accurate, since the ship can maintain its course. Existing models have been used in depths up to 300 fathoms, and one man can take samples from a ship making 8 knots in 3 minutes in 10 fathoms of water, and in 8 minutes in 100 fathoms, with a winch using a $3 / 4$ horsepower motor.

9670. Zunino, J. J. Evaluation of oil exploration methods: World Oil, vol. 12b, no. 6, Internat. Sec., pp. 13-20, Houston, Tex., 1947.

In discussing the geologic characteristics which render an area worthy of exploration for oil, the author points to the need of ascertaining the presence of seven basic factors: Sedimentary rocks, a porous and permeable formation, a thick and impermeable cap, petroliferous source beds, metamorphic processes, structural closure, and hydrostatic conditions suitable for accumulation. Each of these factors is evaluated as a 
diagnostic criterion in exploration and a guide to production possibilities. Special attention is given to problems in relatively unexplored regions.V. S.

\section{PATENTS}

[The figure in parentheses indicates the classification of the entry; see table of contents]

9671. (1) Torsion balance. Roderick Craig. and R. Q. Boyer, Berkeley, Calif., assignors to the Government of the United States, as represented by the Director of the Office of Scientific Research and Development, Office of Emergency Management: U. S. patent 2,417,392, issued March 11, 1947.

A device comprising a pivoted beam whose angular departure from a reference position is to be measured and having a yieldable, horizontally suspended pivot support that is subject to vertical displacement, and also having portions projecting transversely on either side of the pivot support, means for projecting individual images of the respective portions of the beam-into positions dependent upon the relation of the portions to the projecting means, and means for comparing the positions of the individual images relative to each other. Claims allowed, 12.

9672. (1) Werkwijze voor het bepalen van de verandering van de horizontal component van de zwaartekracht met hulp van twee schietlooden en inrichting voor het uitvoering van deze werkdijze [Method of determining the variation of the horizontal component of gravity by means of two plumb lines and an apparatus for applying this method]. Bolidens Gruvaktiebolaget, Stockholm, Sweden: Dutch patent 51,926, issued Feb. 16, 1942.

The angle between the suspension wires of two plumb lines hanging in a frame some distance apart is determined by measuring the capacities of two condensers which are formed by the polished metal surfaces of the two plumb-line weights and the two metal surfaces of a block facing the first-mentioned surfaces and separated therefrom by air spaces. Capacity is measured by a device connected by switches with the frame of the apparatus and with the suspension wires of the plumb lines. Claims allowed, 2.

9673. (1) Anordning vid gravimetrar [Device for gravimeter]. Bolidens Gruvaktiebolaget, Stockholm, Sweden: Swedish patent 105,041 , issued July $22,1942$.

The apparatus measures the force of gravity, or variations thereof, by means of a movable scale mechanism, the weight of which is balanced either by a spring device, or by an electric or magnetic field, or otherwise. The mechanism influences the field by its movements, so that the exact position of the mechanism can be determined by observing the variations of the fida. Between the mechanism and the base of the apparatus are located two or more narrow passages filled with gas or liquid which, by virtue of their inertia, act as a counterforce damping the movements of the mechanism. Claims allowed, 6 .

9674. (2) Gyro magnetic compass system. L. F. Carter, Leonia, N. J., assignor to Sperry Gyroscope Co., Inc., Brooklyn, N. Y., a corporation of New York : U. S. patent 2,414,448, issued Jan. 21, 1947.

A gyro-magnetic compass system having a spaced magnetic compass and directional gyro, a two-part condenser controller at the magnetic 
compass, one part of which is positioned by said magnetic compass, an electrical transmitter positioned by the directional gyroscope, a repeater motor at the magnetic compass controlled by said transmitter and positioning the second part of said condenser, and torque applying means for the gyro controlled by said condenser. Claims allowed. $\boldsymbol{a}$

9675. (2) Flux valve. F. W. Meredith, London, England, assignor to S. Smith \& Sons (England) Limited, a British company: U: S. patent 2,414,654, issued Jan. 21, 1947.

A magnetic flux sensitive device comprising, in combination, a core of magnetic material divided into three substantially parallel legs interconnected at their ends, a pick-up coil wound on the central leg, and the other two legs with their end connections comprising a closed flux loop, a winding on said closed flux loop, and means for supplying both alternating current and direct current to said winding, said alternating and direct currents being of said characteristics as to saturate said loop but once during each cycle. Claims allowed, 3.

9676. (2) Magazine for magnetic recording apparatus. J. H. Heineman, Elkhard, Ind., assignor to C. G. Conn, Ltd., Elkhart, Ind., a corporation of Indiana: U. S. patent 2,415,133, issued Feb. 4, 1947.

A magazine for magnetic recording apparatus and the like comprising a casing having a substantially cylindrical side wall formed with an opening through which wire may pass, a spool in the casing adapted to carry a wire, a closure strip in the casing slidable therein adjacent the side wall, the closure strip being formed with an opening to registerwith the opening in the casing side wall in one position, the closure strip closing the opening in the casing side wall in another position, and cooperating means on the casing and closure strip to move the closure strip into engagement with the spool when the closure strip is moved to said other position. Claims allowed, 6 .

9677. (2) Device for determining compass errors. J. W. Sawyer, United States Navy : U. S. patent 2,424,254, issued July 22, 1947.

Apparatus for determining the error of a compass by comparison of - the compass reading with respect to the true bearing of two diametrically opposed monuments positioned on a known center range line as the compass moves across said line comprising a fixed annular ring provided with a mark to indicate the direction of movement, a vertical spindle positioned at the center of said ring, a frame provided with a base rotatably mounted on said spindle, a compass rose rotatably centered on said spindle below said frame and within said ring, locking means for clamping the frame and compass rose together, a pair of diametrically opposed pointers rigidly attached to the base plate of the frame at right angles to the axis of the spindle and adapted to read on the compass rose, longitudinal center lines inscribed on said pointers lying in the vertical plane passing through the axis of the spindle, a top plate firmly attached to said frame at right angles to the axis of said spindle, a pair of reflecting elements mounted on said top plate with the reflecting surfaces vertically inclined to each other at an interior angle of approximately $93^{\circ}$, symmetrically disposed with reference to a plane which is normal to the inscribed center lines on the pointers and adapted to simultaneously reflect the images of the monuments to a point exterior to and 
above said reflecting elements, transverse center lines and center points inscribed on said reflecting elements at the intersection of the vertical plane through the center lines on the pointers with the reflecting surfaces of the reflecting elements and means mounted on said top plate to indicate when said pointers are level, the apparatus being adapted, when the pointers are level and read the known bearing of the center range line on the compass rose and when the images of the monuments are on the inscribed lines of the mirrors, to indicate the true compass bearing for the direction of movement of the observer as said center range line is approached, crossed and departed from. Claims allowed, 3.

9678. (2) System for detecting magnetic masses. Frank Rieber, New York, N. Y., assignor to Interval Instruments, Inc., a corporation of New York: U. S. patent 2,424,772, issued July 29, 1947.

In an apparatus for indicating differentials of intensity in the magnetic field in a given region, a casing rotatable about a longitudinal axis, and means for rotating the same, a pair of similar coils spaced apart from each other and fixed within said casing and having their axes parallel to each other and transverse to the axis of said casing, and being connected together, a bridge circuit carried by and within said casing, of which said coils form two of the arms, and having two other arms, a. third coil carried within said casing remotely and symmetrically spaced from said first mentioned coils and mounted with its axis at right angles to the axis of said first mentioned coils, and to the axis of said casing, said third coil being bridged across an adjustable portion of one of the arms of said bridge to adjust the phase displacement therein, a nonrotatable stem within said casing, and connections through said stem to diagonally opposite points on said bridge. Claims allowed, 3.

9679. (2) Magnetic field measurements. C. H. Fay, Houston, Tex., assignor to Shell Development Co., San Francisco, Calif., a corporation of Delaware : U. S. patent 2,425,180, issued Aug. 5, 1947.

A system for magnetic field measurements comprising a coil, means pivoting said coil for oscillation in said field, a light source, a photoelectric element, optical means carried by the coil for varying the illumination of the photo-electric element proportionally to the oscillation of said coil, a circuit comprising amplifier means energized by the output of said photo-electric element, said amplifier means having grid control means for varying the amplification gain thereof, rectifier means connected to the output of said amplifier means in said circuit for rectifying a portion of the output of said amplifier means, means for passing the non-rectified portion of said amplifier output through said coil, means for applying the rectified portion of said amplifier output to said grid control means to bias said ampliner means, whereby the gain ratio of said amplifier means is kept at a value necessary for just maintaining said coil in oscillation by the reaction of the current passed therethrough with the magnetic field in which the coil oscillates, and indicator means in said circult for indicating a value proportional to said gain ratio. Claims allowed, 3. 
9680. (2) Magnetic testing apparatus. R. W. Brown, Chicago, Ill., assignor to Western Electric Co., Inc., New York, N. X., a corporation of New York: U. S. patent 2,425,361, issued Aug. 12, 1947.

In an apparatus for testing magnets, a search coil comprising a laminated cylindrical core having a bifurcated upper portion, a coil of semicylindrical shape wound about each part of the core, said coils being interconnected, a block of insulating material for supporting said core, a sleeve of conducting material surrounding said core and coils serving as a shield for said coils mounted on said block and connected to one of said coils, and a ring of conducting material mounted on said block and spaced from said sleeve, said ring being connected to the other of said coils. Claims allowed, 2.

9681. (2) Remote indicating magnetic compass system. A. T. Sinks, deceased, late of Beach Bluff, Mass., by A. C. Sinks, administratrix, Beach Bluff, Mass., assignor to General Electric Co., a corporation of New York: . U. S. patent 2,426,470, issued Aug. 26, 1947.

In a remote indicating compass system of the type having a transmitter and indicator units energized from a source of alternating current and electrical connections between said units for transmitting position-indicating, second-harmonic signal voltages from the transmitter to the indicator, a deviation compensator 'comprising a closed core of magnetically permeable material having windings thereon with single phase and polyphase connections, said single phase connections being connected to said source of alternating current to cause periodic saturation of the core and said polyphase connections being electrically interposed between said transmitter and indicator units, means for producing a unidirectional magnetic flux linking the core of said compensator, said unidirectional flux being caused to pulsate due to the periodic saturation of said core whereby second harmonic voltages are induced in the compensator windings, and means for adjusting the direction and magnitude of said unidirectional magnetic flux in said compensator core to vary the magnitude and polarity of the second harmonic voltages induced in the compensator windings. Claims allowed, 9.

9682. (2) Magnetic field detector. A. G. Laird, Summit, and Thaddeus Slonczewski, Glenwood Landing, N. J., assignors to Bell Telephone Laboratories, Inc., New York, N. Y., a corporation of New York: U. S. patent 2,426,622, issued sept. 2, 1947.

In a magnetic detection system the circuits comprising a source of alternating current of fundamental frequency, a magnetometer having at least one winding thereon, utilization means responsive to a preselected even-order harmonic voltage generated by the magnetometer, and filters coupling the magnetometer winding to the source and to the utilization means, said filters adapted to permit the passage of energizing current of fundamental frequency only from the alternating current source to the magnetometer, the passage of the preselected even-order harmonic current from the magnetometer to utilization means, and the ready circulation through the magnetometer of all other harmonic currents generated therein. Claims allowed, 7. 
9683. (3) Electroácoustic transducer. B. M. Harrison, Newtón Highlands, Mass., assignor, by mesne assignments, to Submarine Signal Co., Boston, Mass., a corporation of Delaware: U. S. patent 2,416,314, issued Feb. 25, 1947.

An electroacoustic submarine transceiver comprising a plate, a hollow polygonal prism mounted on said plate, the walls of said prism being oneeighth of a wave length in thickness at the signaling frequency, means closing the lower end of said prism, means supporting said prism to said casing at said lower end, means closing the upper end of said prism and having a thin edge portion and a central portion having a thickness of one-eighth of a wave length, a plurality of one-quarter wave length Rochelle salt crystals having electrodes with electrical connections attached thereto, the crystals being mounted by their ends upon a plurality of the faces and upon the thick portion of the means closing the upper end of said prism, a cup-shaped diaphragm of molded macerated Bakelite a quarter wave length in thickness secured by its edge to said plate and positioned to enclose with said plate all of said crystals and having its interior surfaces which are opposite the free ends of said crystals only slightly spaced from them, and a compressional wave conducting liquid filling the enclosed space. Claims allowed, 12.

9684. (3) Geophone polarity indicator. L. W. Gardner, Pittsburgh, Pa., assignor to Gulf Research and Development Co., Pittsburgh, Pa., a corporation of Delaware: U. S. patent 2,423,970, issued July 15, 1947.

An electrical circuit comprising a polarized electromechanical transducer having an inaccessible morable element and electrical connections for carrying its output to an accessible point, said movable element being capable of being set into motion by application of electric current to said connections, means for applying direct current of known polarity to said connections whereby said movable element is deflected in a sense dependent on polarity, contact means associated with the movable element to alter the circuit distinctively upon deflection in a predetermined sense, and indicating means at said accessible point responsive to such alteration of the circuit. Claims allowed, 7.

9685. (3) Seismic surveying. J. O. Parr, Jr., San Antonio, Tex., assignor to O. S. Petty, San Antonio, Tex.: U. S. patent 2,424,705, issued July 29,1947 .

In apparatus for lecording seismic waves, the combination with means for receiving and converting seismic waves into electrical wave form signals, of an amplifying and recording system for said signals, said system including means opelable automatically, in part in response to variation in amplitude or the received seismic waves, and in part as a function of time, to vary the extent to which said signals are amplified to provide a visual wave form record of varying amplitude, and device associated with said system for recording, concurrestly with the recording of said wave form record, a visual record of the progressive variation in signal amplification. Claims allowed, $\mathbf{3}$.

9686. (3) Position dampened seismometer. J. F. Tolk, San Antonio, Tex., assignor to 0. S. Petty, San Antonio, Tex.: U. S. patent 2,424,724, issued July 29, 1947.

In apparatus for use in seismic surveying, the combination with a seismometer of the magnetic type having a signal generating winding 
in which electrical currents are induced in response to earth vibrations, of a device carried by said seismometer and automatically operable to short said winding whenever said seismometer is displaced from the normally operative, upright position. Claims allowed, 3.

9687. (3) Apparatus and method for making and analyzing geophysical records. Frank Rieber, Los Angeles, Calif.: U. S. patent 2,427,421, issued Sept. 16, 1947.

In an apparatus for making and analyzing geophysical records, a source of elastic-waves and a plurality of receptors, arranged at predetermined distances along a common line, a record strip driven at a predetermined rate of speed, means for recording on said record strip a plurality of traces laterally spaced in proportion to the spacing between the receptors, means for recording on the record strip the time at which a pulse of elastic waves is generated at said wave source, and analyzing means cooperating with' said plurality of traces, comprising a scanning member. continuously rotated about an axis spaced laterally from said plurality of traces at a distance proportionate to the distance of said wave source from said receptors. Claims allowed, 15.

9688. (3) Seismic wave detector. G. B. Loper; Dallas, Tex., assignor, by mesne assignments, to Socony-Vacuum Oil Co., Inc., New York, N. Y., a corporation of New York: U. S. patent 2,428,168, issued Sept. 30, 1947.

The combination with a detector of seismic waves, of meanș for supporting said detector within a drill hole comprising suspension means for lowering said detector in and lifting it from said hole, means pivoted to said detector and rotatable out of and into engagement with one side of said hole to press said detector against the other side thereof, means connected to said suspension means for operating said pivoted means in one direction by the weight of said detector, and a spring for operating said pivoted means in the opposite direction. Claims allowed, 11.

2689. (4) Amplifier for small voltages. W. E. Sargeant, Ferndale, and H. B. Hoeper, Detroit, Mich., assignors to General Motors Corp., Detroit, Mich., a corporation of Delaware: U. S. patent 2,413,788, issued Jan. 7, 1947.

In means for amplifying small voltages, a source of current, an amplifier having input and output circuits, said input circuit being connected to said source and said output circuit to predetermined apparatus, transformer means connected in the input circuit having a center tapped primary, stationary contacts connected to the outside primary leads, said center tap being connected directly to said source, a pivotal contact reciprocable between the stationary contacts and connected to said source, a double pair of stationary contacts in the output circuit, two pivotally movable contact members cooperating with said stationary contacts, said pivotally movable members being directly connected to said amplifier, said stationary contacts being inversely connected in pairs to the output line and common driving means for all of the pivotal members. Claims allowed, 3. 
9690. (4) Well surveying device. G. L. Kothny, Strafford, Pa., assignor to SperrySun Well Surveying Co., Philadelphia, Pa., a corporation of Delaware: U. S. patent 2,424,358, issued July 22, 1947.

An electrical timing means comprising a plurality of superposed chambers, the upper chamber having a closed upper end, means for controlling flow of electrically conductive liquid from the upper chamber into the lower chamber, electrode means in the upper chamber arranged to be uncovered by the liquid upon flow therefrom, and a passage venting the lower chamber to a fixed level in the upper chamber below the level of liquid therein during a major portion of the timing operation, the passage between said chambers consisting solely of said flow controlling means and said venting passage. Claims allowed, 4 .

9691. (4) Means for and method of locating faults in electrical conductors. D. H. Nelson, Southampton, N. Y., and J. R. Cosby, Towson, Md., assignors to The Western Union Telegraph Co., New 'York, N. Y., a corporation of New York: U. S. patent 2,425,554, issued Aug. 12, 1947.

The method of locating a fault in a communication line which comprises successively and alternately applying alternating voltages of opposite phase with respect to ground to the faulted line and to a companion unfaulted line, and alternating voltages of the same phase with respect to ground to both lines, and measuring along the lines the field around the lines to determine the point at which the character of such field changes. Claims allowed, 6.

9692. (4) Method for electromagnetic-wave investigations of earth formations. W. M. Barret, Shreveport, La., assignor to Engineering Research Corp., Shreveport, La.: U. S. patent 2,426,918, issued Sept. 2, 1947.

In the art of investigating earth formations including a reflector of electromagnetic waves lying beneath the surface of the earth, the step of simultaneously propagating from a sending point electromagnetic waves through the air to a receiving point and through the earth to said reflector and thence to said receiving point, the step of measuring at said receiving point a parameter of electromagnetic field resulting from the combined waves arriving at said receiving point, the step of varying the frequency of said waves through a frequency range sufficient to produce successive maxima or minima in the values of said parameter, and the step of determining the corresponding successive values of said parameter and the frequency at which said parameter is measured, wherein the occurrence of said successive maxima or minima in the values of said parameter is indicative of the presence of said reflector. Claims allowed, 8.

9693. (4) Electrical prospecting apparatus. C. R. Nichols, McAllen, Tex., and S. H. Williston, Aberdeen, Wash., assignors to Sperry-Sun Well Surveying Co., Philadelphia, Pa., a corporation of Delaware: O. S. patent 2,428,034, issued Sept. 30, 1947.

In combination, a drill stem, an electrode mechanically connected to one end of said stem but insulated therefrom, and a source of electrical energy at said end of said drill stem having one terminal electrically connected to said drill stem and the other terminal electrically connected to said electrode. Claims allowed, 1. 
9694. (4) Draagbare inrichting voor het opsporen van eigenschappen van den boden met behulp van hoogfrequentie electrische trillingen [Portable device for ascertaining properties of the earth by means of high frequency oscillations]. Ludwig Machts, Richard Machts, and Bernard Nickel, Marburg, Germany, and August Ruhl, Giessen, Germany : Dutch patent 50,926, issued Sept. 1.5, 1941.

The device consists of a supporting frame, to which are attached a transmitter capable of rotation on a horizontal axis and a receiver. on the two front sides of the frame are placed supporting elements and also the adjustive devices for operating the transmitter and receiver. These devices are connected with parts equipped with insulating rods long enough for manipulating the devices from the front sides of the supporting frame without any interfering influence from the apparatus. The supporting frame can swing with respect to the handles. Claims allowed, 2.

9695: (5) System for detecting sources of radiant energy. M. J. E. Golay and H. A. Zahl, Fort Monmouth, N. J., assignors to the Government of the United States of America, as represented by the Secretary of War: U. S. patent 2,424,976, issued Aug. 5, 1947.

A device for detecting and indicating radiant energy comprising a chamber encompassing a gaseous volume, and including in said volume a radiation absorbing substance characterized by a low specific heat, being formed as a thin blackened membrane and constituting a partition in said chamber; fluid passages to permit fluid flow on opposite sides of said partition; a second partition in said chamber in the form of a thin flexible film responsive to rapid pressure changes produced by the gas expanding or contracting in accordance with the temperature changes of the said heat absorbing substance; means including a restricted passage for slowly relieving the pressure differential produced on the two sides of said flexible film; and optical means including a plane reference surface for observing the movement of said flexible film as these movements cause changes in the interference fringes produced by monochromatic light reflected from said film and said surface. Claims allowed, 25 .

9696. (6) Submarine detecting method and apparatus. Eugene McDermott, Dallas County, Tex. : U. S. patent 2,412,165, issued Dec. 3, 1946.

The method of locating a submarine from aircraft which comprises traversing an area to be patrolled and scanning the surface thereof with fairly directional heat detectors, substantially insensitive to light waves within the visible and higher portions of the spectrum, one of the said detectors being oscillated fore and aft and another of the said detectors being oscillated laterally to scan two strips of said surface, and locating thereby the heat track of a submarine. Claims allowed, 4.

9697. (6) Werkwijze in inrichting vor het onderzoek van bodemlagen in een boorgat [Method and apparatus for studying earth strata in a borehole]. Standard Oil Development Co., Linden, N. J., : Dutch patent 51,653, issued Dec. 15, 1941.

The temperature gradient in the horizontal direction from the middle of a borehole to its walls is measured at successive levels of the borehole. 
For this purpose there is lowered into the borehole filled with liquid a body having in its middle a downwardly projecting part provided with the pole of a thermoelement, and having on its periphery another. downwardly projecting part provided with one or more series-connected poles of thermoelements. The projecting parts are connected with a recording instrument on the ground showing voltages as a function of the temperature difference between the center and the walls of the borehole, the temperature being in turn dependent on the heat conductivity of the walls. Claims allowed, 2.

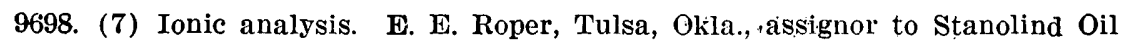
and Gas Co., Tulsa, Okla., a corporation of Delaware: U. S. patent 2,412,359, issued Dec. 10, 1946.

A method for the micro analysis of a gas forming a small constituent of a mixture of gases including the steps of introducing at least a portion of said gases into an evacuąted zone until a known pressure is obtained in said zone, introducing into said zone a substantially pure diluent gas known to have a relatively stable, simple molecule until a second known pressure is obtained in said zone, said diluent gas being characterized in that it is substantially completely composed of molecules of simple and stable structure producing on ionization positive ions mostly of one known ratio of mass number to charge on the ion, said ratio being different than that of the positive ions of any constituent gas in said mixture, ionizing at least a portion of the contents of said zone at a low pressure, and measuring the relative amplitude of the positive ions of said diluent gas and those of said constituent gas. Claims allowed, 3.

9699. (7) Gas analysis. Leo Horvitz, Houston, Tex., assignor to E. E. Rosaire, Houston, Tex. : U. S. patent 2,414,876, issued Jan. 28, 1947.

In the method of gas analysis in which combustible constituents are burned and the products of combustion measured, the steps which comprise admitting the gas to be analyzed into a closed system containing a cold spot of a temperature sufficiently low to effect the condensation of the constituents to be determined and thereafter moving said constituents to different parts of the apparatus by successively moving said cold spot to said different,parts of the apparatus. Claims allowed, 5.

9700. (8) Apparatus for making geophysical surveys under water. J. W. Flude, Houston, Tex. : U. S. patent 2,423,591, issued July 8, 1947.

An apparatus for towing an instrument through the water, comprising a pair of concentric rings, radial fins connected thereto, an instrument casing disposed within the inner ring and contacting the inner edges of said fins, a plurality of flexible members loosely connecting said fins and secured to each along a line diagonally thereof, and a plurality of apertures in one of said fins within the triangle formed by said diagonal lines.' Claims allowed, 5.

9701. (9) Electrical system for use in photorecording. N. A. Hassler, Duncan, Okla., assignor to Halliburton Oil Well Cementing Co., Duncan, Okla.: U. S. patent 2,415,879, issued Feb. 18, 1947.

An electrical control system comprising a thermionic amplifier network, a lamp connected to the output thereof and an arrangement for causing said lamp to emit light in proportion to the speed of a moving 
object, said arrangement including means driven in synchronism with the moving object for generating an alternating current the frequency of which is proportional to the speed of the moving object, means for impressing a regulating bias on said amplifier network proportional to the frequency of the alternating current so generated, and photoelectric means for modifying the regulating bias in accordance with the intensity of the light given off by said lamp. Claims allowed, 6 .

9702. (9) Frequency modulated altimeter or distance indicator. R. C. Sanders, Jr., Hightstown, N. J., assignor to Radio Corporation of America, a corporation of Delaware: U. S. patent 2,422,133, issued June 10, 1947.

The method of distance measuring comprising cyclically frequencymodulating a wave at a periodic rate of $\mathrm{fm}$, transmitting said modulated wave to a reflecting object, heterodyning said wave after reflection from said object with a portion of said wave supplied directly from the point of transmission whereby a cyclically recurring beat-frequency signal is obtained, amplifying said beat-frequency signal, delaying a portion of said amplified signal by an amount substantially equal to $1 / \mathrm{fm}$ times a whole number, and utilizing said delayed signal to regeneratively reinforce said amplification. Claims allowed, 6. (See also U. S. patents 2,422,134 and 2,422,135, of R. C. Sanders, issued June 10, 1947.)

9703. (9) Radio pulse altimeter and object detector. W. D. Hershberger, Haddonfield, N. J., assignor to Radio Corporation of America, a corporation of Delaware: U. S. patent 2,423,024, issued June 24, 1947.

A radio pulse system for measuring altitude and for detecting objects including means for generating a pulse of radio frequency. energy, means for radiating said pulse toward an object to be detected, means for receiving said pulse after reflection, an indicator connected to said receiving means for indicating the presence of the object by indicating the reception of said pulse, means for amplifying a portion of said generated pulse of radio frequency energy, means for radiating said amplified pulse toward the earth to measure altitude, means for receiving said amplified pulse after reflection from the earth, and means including said indicator for indicating distinctively the altitude by indicating the reception of said amplified pulse. Claims allowed, 13.

9704. (9) Distance measuring system. C. W. Earp, London W. C.·2, England, assignor to Standard Telephones and Cables, Limited, London, England, a British company: U. S. patent 2,423,088, issued July 1, 1947.

Obstacle detecting system utilizing electromagnetic waves comprising transmitting means for generating a cyclically frequency modulated wave, means for radiating said frequency modulated wave, means for receiving said frequency modulated wave after reflection by an obstacle, means for combining said received wave with a wave derived directly from said transmitting means to produce a beat-frequency wave whose frequency is proportional to the rate of change of transmitted frequency and whose amplitude of frequency swing depends upon the distance of the obstacle, differentiating means for deriving from said transmitting means a voltage which varies according to the first differential with respect to time of the frequency modulating wave form, an oscillator, an amplitude adjuster, a frequency changer, means for applying said 
derived voltage over said amplitude adjuster to said oscillator to obtain a frequency modulated output therefrom, means for applying said beatfrequency wave and the output of said oscillator to said frequency changer, indicating means, selective means tuned to the mean frequency of said oscillator, and means including said selective means for connecting said indicating means to the output of said frequency changer. Claims allowed, 6.

9705. (9) Superheterodyne radio altimeter or locator. W. L. Carlson, Princeton, N. J., assignor to Radio Corporation of America, a corporation of Delaware: U. S. patent 2,424,796, issued July 29, 1947.

In a radio locator system of the type utilizing reflected waves, transmitting means for transmitting a radio signal to a wave reflecting surface, means for receiving said signal after it has been reflected from said wave reflecting surface, means including a local heterodyne oscillator for heterodyning said reflected signal to an intermediate-frequency signal and for heterodyning a signal transmitted directly from the transmitter to an intermediate-frequency signal, amplifying means for amplifying said intermediate-frequency signals, a second detector to which the amplified intermediate-frequency signals are applied for producing a beat-frequency signal, a frequency discriminator to which at least one of said intermediate-frequency signals is applied, and an automatic-frequency-control means for said heterodyne oscillator to which means the output of said discriminator is applied for reducing the width of the frequency band occupied by said intermediate-frequency signals. Claims allowed, 7.

9706. (9) Pulsed frequency modulated altimeter. R. C. Sanders, Jr., Haddonfield, N. J., assignor to Radio Corporation of America, a corporation of Delaware : U. S. patent 2,424,854, issued July 29, 1947.

In a radio distance determining system, means for producing a carrier wave which is cyclically frequency modulated and for transmitting it to a reflecting surface, a receiver for receiving said wave after reflection from said surface, said receiver comprising a heterodyne detector, means for applying said reflected wave to said detector, means for also applying a portion of said modulated wave directly from the transmitter to said detector whereby a difference or beat frequency is produced, an amplifier including at least one vacuum tube, a frequency indicator connected to said detector through said amplifier to indicate said beat frequency, means for transmitting said carrier wave as a pulse that lasts for the duration of at least one of said cycles of frequency modulation and which is followed by a period lasting for a comparatively large number of succeeding cycles. of frequency modulation before the next pulse occurs, and means for connecting a short-circuiting capacitor across the input circuit of said vacuum tube during said long period following each pulse and for disconnecting said short-circuiting capacitor during the transmission of each pulse. Claims allowea, $z$.

9707. (9) Aerial photographic image motion compensation system. A. A. Koepfer, Dayton, Ohio: U.. S. patent 2,424,989, issued Aug. 5, 1947.

In an aerial camera, a system for compensating for image travel on the focal plan of the camera comprising a film driving means to ad- 
vance the film across the focal plane of the camera, a synchronizing motor, means for varying the transmission speed of the synchronizing motor to advance the film across the focal plane at a predeterminable rate to compensate for the rate of image travel on the focal plane of the camera during the exposure of the film, a recycling motor for advancing the film across the focal plane between exposures to position an unexposed portion of the film in the focal plane for the next exposure, clutch means between the synchronizing motor and the fllm driving means, means for tripping the shutter of the camera.including delayed action operating means between the shutter tripping means and the clutch means for engaging the clutch means to advance the film and subsequently actuate the shutter tripping means, whereby the film driving means may attain synchronized speed prior to the opening of the shutter. Claims allowed, 2. 



\title{
INDEX TO GEOPHYSICAL ABSTRACTS 131
}

\author{
OCTOBER-DECEMBER 1947
}

[The flgure in parentheses indicates the classification of the entry; see table of contents]

\begin{tabular}{|c|c|c|c|}
\hline Class & Abstract | & Class & Abstract \\
\hline Al'pin, L. M & 9597 & Discovery - & 9613 \\
\hline Ambolt, Nils_- & 9537 & Diukov, A. I_____ & 954.1 \\
\hline American Soclety of Civil & & Dix, C. H & 9658 \\
\hline Engineers - & 9652 & Dreyer, R. M-_-_-_- (2) & 9542 \\
\hline Anderegg, Fred_._._. & 9653 & & \\
\hline Andersen, Einar & 9519 & $-\infty-\infty-19)$ & 9704 \\
\hline Andreev, B. A_- (8) & 9629 & Eisler, J. D___-_ & 9601 \\
\hline & & Elkins, T. A & 9660 \\
\hline$--\cdots--n(4)$ & 9692 & Evrard, P__ & 9529 \\
\hline Bartels, J_- & 9538 & Ewing, Maurice & 9564 \\
\hline Bayard-Diclaux, F_...... (3) & 9566 & Eyres, N. R_- & 9621 \\
\hline Bichan, W. J__. & 9654 & & \\
\hline Birch, Francis & 9620 & Fanselau, G_-_. & 9543 \\
\hline Blackburn, M. S & 9598 & Fay, C. H. & 9679 \\
\hline Bolidens Gruvaktiebolaget_- (1) & 9672,9673 & Ferraro, V. C. A & 9544 \\
\hline Boss, R. L & 9630 & Fleming, J. A & 9545 \\
\hline Boyer, R. Q_- & 9671 & Flude, J. W_- & 9700 \\
\hline Bradley, W. S. [H.]_-_- (8) & 9631 & Fock, V_- & 9604 \\
\hline Brown, R. W & 9680 & Foote, F. S & 9657 \\
\hline Bugailo, v. A & 9561 & , Eugene & 9546 \\
\hline Bulashevich, Iu. P & 9610 & Frowe, Eugene._. & 9547 \\
\hline Bull, A. J & 9632 & & \\
\hline Bureau O. F. M. N., A. N., & & 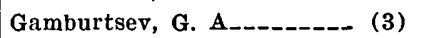 & 9565 \\
\hline S. S. S. R. & 9633 & L. W & 9684 \\
\hline & & ann, Fritz_-_-_- (8) & 9637 \\
\hline California Oil World__-_-_- (5) & 9611 & Goguel, Jean_-_-_-_-_--- (1) & 9521 \\
\hline$\longrightarrow$ & 9634 & M. J. E & 9695 \\
\hline Callaham, Ludmila_....... (9) & 9655 & t, Gaston__- & 9566 \\
\hline Carlson, W. L_ & 9705 & A. W & 9548 \\
\hline Carter, L. F- & 9674 & $o v, A_{-\ldots}$ & 9567 \\
\hline Cechura, F-_. & 9539 & Gunn, Ross___-_- & -9600 \\
\hline Chace, F. M. & 9656 & 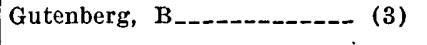 & 9568 \\
\hline Clark, G. L__ & 9520 & 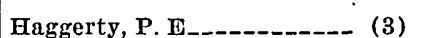 & 9569 \\
\hline Congdon, R. L & 9562 & Sigmund...... (1) & 9522 \\
\hline Conselho Naclonal do $\mathrm{Pe}-$ & & en, R. F & 9570 \\
\hline$--m-\infty-18)$ & 9635 & , Sidon____-_._- (3) & 9571 \\
\hline---12$)$ & 9540 & D, B. M & 9683 \\
\hline Corsaro, G-_. & 9599 & Hartree, D. $R_{-}$ & 9621 \\
\hline Cosby, J, R_- & 9691 & , N. A & 9701 \\
\hline Craig, Roderick & 9671 & an, J, H-_-_- (2) & 9676 \\
\hline Critikos, N. A_t_- (3) & 9563 & berger, W. D_-_-_ (9) & 9703 \\
\hline Cullen, R. J & 9636 & Hills, E. S & 9624 \\
\hline & & eck, W. J____ (8) & 9630 \\
\hline$-\ldots-n-1-=(9)$ & 9657 & r, H. B & 9689 \\
\hline Deegan, C. J & 9623 & E. P & 9590 \\
\hline De Ment, Jack & 9612 & ainen, P. E & 9523 \\
\hline J. $\mathbf{E}_{--1}$ & 9600 & Horvitz, Leo__. & 9699 \\
\hline
\end{tabular}




\begin{tabular}{|c|c|c|c|c|}
\hline & & & Class & abstract \\
\hline $\begin{array}{l}\text { Howatson, C. H- } \\
\text { Iubbert, M. K- K- }\end{array}$ & & $\begin{array}{l}9627 \\
9524\end{array}$ & Parr, J. O., Jr-- & 9685 \\
\hline elin, G. S S & (1) & $\begin{array}{l}9524 \\
9525\end{array}$ & $\begin{array}{l}\text { Pekeris, C. L L-- } \\
\text { Per'kov, N. A- }\end{array}$ & \\
\hline ughes, D. S & (3) & 9572 & $\begin{array}{l}\text { Per'kov, N. A } \\
\text { Petroleum Engine } \\
\text { ing Co }\end{array}$ & 966 \\
\hline kosky, J. J & (8) & 9638 & Pluvinage, $\mathrm{P}$ & 9583 \\
\hline mer & (2) 9 & 9549,9552 & Poisson, Charles. & 9584 \\
\hline-- & (3) & 9573 & & \\
\hline nes, W, N & (2) & 9550 & $\begin{array}{l}\text { Ransone, W. R } \\
\text { Reiter, W. A }\end{array}$ & $\begin{array}{l}9625 \\
9663\end{array}$ \\
\hline Kalinin, Iu. D-- & (2) & 9551 & $\begin{array}{l}\text { Renner, D. S-1- } \\
\text { Richter, C. F- }\end{array}$ & 9585 \\
\hline$B_{---1}$ & (5) & 9614 & $\begin{array}{ll}(3) \\
\cdots\end{array}$ & 9568 \\
\hline A. $\mathbf{I}_{---}$ & (1) & 9526 & $\begin{array}{l}\text { Kidenour, } \\
\text { Rieber, Frank }\end{array}$ & $\begin{array}{l}9664 \\
9678\end{array}$ \\
\hline $\mathbf{M}_{-}$ & (2) & 9552 & 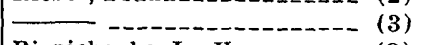 & 9687 \\
\hline $\begin{array}{l}\text { A. A } \\
\text { G. } L_{-}-\ldots \\
\end{array}$ & $\begin{array}{l}(9) \\
(4)\end{array}$ & $\begin{array}{l}9707 \\
9690\end{array}$ & Riznichenko, Iu. V_ & 9586 \\
\hline G. S. A & (6) & 9622 & --- (1) & 9531 \\
\hline L. & (8) & 9639 & Roper, E. E-..-- & 9698 \\
\hline ulict & (4) & 9602 & $\begin{array}{l}\text { Rothe, E E } \\
\text { Rozanov, L. N- }\end{array}$ & 9587 \\
\hline -.. & (2) & 9682 & $\begin{array}{l}\text { Ruhl, August } \\
\text { Rumbaugh, L. H }\end{array}$ & $\begin{array}{l}9694 \\
9552\end{array}$ \\
\hline & (3) & 9574 & & \\
\hline irsen, E. S--.- & (5) & 9614 & Sadovskii, M. A & 9588 \\
\hline ------- & (4) & 9603 & $\mathrm{~L}_{-}$ & 9533 \\
\hline L L & (3) & 9575 & R. C., Jr & 9706 \\
\hline e.... & (1) 9 & 9527,9528 & $\mathbf{E}_{\ldots} \ldots \ldots-\ldots(4)$ & 9689 \\
\hline , M---- & (4) & 9604 & dré- - & 9557 \\
\hline . $\mathbf{B}_{---\cdots}$ & (4) & 9605 & $\ldots$ & 9677 \\
\hline$B_{\ldots} \ldots$ & (3) & 9688 & $\begin{array}{l}\text { E. S } .+\ldots-(5) \\
\text { M. }\end{array}$ & $\begin{array}{l}9616 \\
9606\end{array}$ \\
\hline 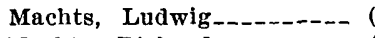 & (4) & 9694 & R. G_- & 9540 \\
\hline & $(4$ & & $-\cdots-(2)$ & 9540 \\
\hline & (6) & & $-(4)$ & \\
\hline & (2) & 553 & $-(4)$ & \\
\hline--( & (9) & 59 & $--(4)$ & 9608 \\
\hline & (3) & 576 & (2) & 9681 \\
\hline & & & $\mathbf{B}_{-\ldots-1}$ & 9644 \\
\hline & (3) & 77 & $\begin{array}{l}\text { zewski, Thaddeus_-_- }(2) \\
\text { N. C }\end{array}$ & \\
\hline$\ldots$ & (5) & 315 & e, & 9665 \\
\hline$-\ldots--($ & (2) & 9675 & $\begin{array}{l}\text { Spence, H. S. } \\
\text { Stagg, J. M. }\end{array}$ & \\
\hline 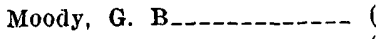 & (8) & 9640 & $\begin{array}{l}\text { Stagg, J. M- } \\
\text { Standard Oil Development }\end{array}$ & 9645 \\
\hline Morelli, & (1) & 9530 & $\begin{array}{l}\text { Standard Oil Development } \\
\text { Co }\end{array}$ & 9697 \\
\hline & & & 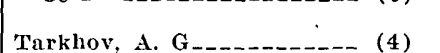 & \\
\hline $\begin{array}{l}\text { National Research Council } \\
\text { of Canada_-_. }\end{array}$ & (8) & 9641 & (2) & \\
\hline & (8) & 9642 & (1) & $\begin{array}{l}9666 \\
9534\end{array}$ \\
\hline L & $\begin{array}{l}(4) \\
(9)\end{array}$ & & $\begin{array}{l}\text { Thyer, K. F-1 } \\
\text { Tois, s. F- (1) }\end{array}$ & \\
\hline $\mathrm{H}_{\ldots} \ldots \ldots$ & (3) & 9574 & $\begin{array}{l}\text { Treskov, A. A-1- } \\
\text { Tripp } \text { R. M }\end{array}$ & \\
\hline 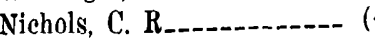 & (4) & 9693 & Tripp, & 9626 \\
\hline$d \ldots \ldots \ldots$ & (4) & 9694 & Tuckerman, Bryant_....... (9) & 9659 \\
\hline & & & & \\
\hline Nish & (3) & 9578 & $\begin{array}{l}\text { Ulrich, F. P } \\
\text { U. S. Coast and Geodetic }\end{array}$ & 9590 \\
\hline$---!$ & (5) & & Survey & 9559 \\
\hline$-(3$ & & & & \\
\hline 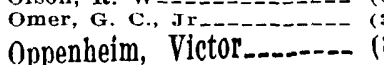 & & & (3) & \\
\hline & (9) & & & \\
\hline n, Dar & & & Vecehia, 0 & 9503 \\
\hline & & & & 8046 \\
\hline
\end{tabular}




\begin{tabular}{|c|c|c|c|}
\hline $\begin{array}{c}\text { Class } \\
-(7)\end{array}$ & $\begin{array}{r}\text { Abstract } \\
9627\end{array}$ & $\begin{array}{c}\text { Class } \\
-(1)\end{array}$ & $\begin{array}{r}\text { Abstract } \\
9536\end{array}$ \\
\hline Weeks, L. G. & 9648 & Worzel, J. L & 9669 \\
\hline Wegener, Kurt & 9535 & & \\
\hline Wengerd, S. A & 9665 & Young, G. J & 9651 \\
\hline$-(9)$ & 9667 & & \\
\hline$--(2)$ & 9560 & Zahl, H. A & 9695 \\
\hline Williston, S. H_- & 9693 & Zetler, B. D_- & 9595 \\
\hline Wilson, C. O_ & 9649 & Zhirov, K. K_ & 9619 \\
\hline n, J. H & 9650 & ZoBell, C. E_. & 9628 \\
\hline V. $\mathrm{H}_{-}-\mathrm{n}_{-}$ & 9668 & Zunino, J. J J & 9670 \\
\hline (3) & 9594 & Zrolinskii, N. V__ & 9596 \\
\hline
\end{tabular}





\title{
INDEX TO GEOPHYSICAL ABSTRACTS 128-131 .
}

\author{
JANUARY-DECEMBER 1947
}

['The figure in parentheses indicates the classification of the entry; see table on contents]

\section{$\mathbf{A}$}

Adkins, J. N., Training the geologist for geophysical work
Aeronautical Chart Service, Reconnaissance mapping with trimetrogon photography

Agamennone, Giovanni, The earthquake of June 1934 in the Carnic Forealps and its hypocentral depth

Macroseismic study of the earthquake of Oct. 18, 1936, at Cansiglio, Friuli__._. 129

No. Class Abst.

(9) 9274

(9) 9461

(3) 9003

(3) $\quad 9181$

Aiken, C. B. Compensatory means for electrical borehole apparatus, U. S. patent $2,411,843 \ldots$

Alexanian, C. L., Magnetic prospecting at the Grande Macholles_._._- 130

Alexanian, C. L., and Rothe, J. P., Gravimetric prospecting at the Grande Mâcholles, near Riom_-_. 130

Allcock, H. J., and Jones, J. R., The nomogram______._. 129

Allison, A. P., and Claypool, C. B., Developments in upper Gulf coast of Texas in 1946

Al'pin, L. M., Sources of the electrical field in the theory of electrical prospecting _._._.

Ambolt, Nils, The Magnetic homogencity of testing grounds for investigation and compensation of airplane compasses_._-_._. 131

American Society of Civil Engineers, Definitions of surveying terms _ 131

Anderegg, Fred, Aerial negatives and prints, their classification. and preservation in the United States_._. 131

Anderson, Einar, Gravity measurements in Sjaelland, Møen, Falster, and Lolland by means of the Askania gravimeter._._._._. 131

Andreev, B. A., The calculation of the spatial distribution of potential fields and its utilization in exploration geophysics__._-_._-_._ 131

Angenheister, G., Determination of a boundary surface by means of the travel times or emergence angles of reflected waves_._._._. 130

Ansel, E. A., Concerning the attraction of spherical masses on the globe viewed from the isostatic standpoint

Antes, L. L., Magnetometer, U. S. patent 2,420,580

Aquilina, C., On the possibility of prospecting the subsoil by using the deviations of the vertical__. 128

- On the interpretation of the results of subsoil exploration by the inductive method with a horizontal net. 130

Archie, G. E., Electrical resistivity an aid in core-analysis interpretation ............ 130

Armstrong, L. D., The use of high permeability materials in magnetometers - 130

Askania-Werke A.-G., Gravimeter determining the vertical displacement of a mass supported by a spring, Dutch patent $49,880_{---\ldots-128}$

Bader, G. E., Geophysical history of the Anahuac oil field, Chambers County, Tex..._. 130

Baird, H. F., Old fallacies and new facts about earthquakes...- 128 
No. Class Abst.

Baker, A. W., Waterproof explosive cartridge, U. S. patent $2,408,189_{---} 129$

Baker, J. S., with Stick, J. C., and Norelius, R. G., New electrical logging techniques in California_._. 130

Ballarin, Silvio, Auxiliary tables for the calculation of the topographic reduction of gravity measurements___- 129

9421

9139

- Graphic determination of the topographic reduction of gravity measurements based on the hypothesis of a spheringl earth

Balsley, J. R., Jr., with Hawkes, H. E., and others, Geophysical investigations, preliminary aeromagnetic maps 1 and 2_- 128

Balsley, J. R., Jr., with Jensen, H., Controlling plane position in aerial magnetic surveying

Bamberg, Carl, Gravimeter determining the vertical displacement of a mass supported by a spring, Dutch patent $49,880 \ldots$

Barauov, Vladimir, Concerning a new master-chart for calculating the effect of thin and plane magnetic layers_._._._._. 128

Bardill, J. D., Magnetic surveys in Clinton County, N. Y

Larret, W. M., Method for electromagnetic-wave investigations of earth formations, $U$. S. patent $2,426,918$

Barschall, H. H., and Bethe, H. A., Energy sensitivity in fast neutron • counters.......... 130

Barstow, O. E., and Bryant, C. M., Deep-well camera 129

Barta, G., On the changes of horizontal intensity and inclination of the earth magnetism in Transylvania, 1943.0__._. 130

Bartels, J., Daily international magnetic character-figures, for the years 1884 to 1889

Bataafsche Petroleum Maatschappij, Method and apparatus for taking gas samples from the earth, Dutch patent 51,017_._. 130

Bateman, H. B., Some integral equations of potential theory

Bayard-Duclaux, F., with Grenet, G., The Modified-Wenner C. G. 1 universal vertical seismograph____ 131

Leach, F. K., Pressure-temperature-gravity relations in wells producing oil and gas _._. 129

Beach, L. F., Magnetic field responsive device, U. S. patent $2,410,039$

Beacham, C. C., with West, T. S., A resistolog survey of the Loma Alto-Seven Sisters area of McMullen and Duval Counties, Tex_._ 128

Beers, R. F., The Committee on Geophysical Sciences of the Joint

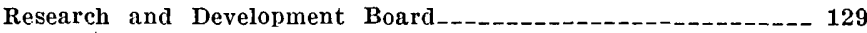

Beers, R. F., and Larsen, H. R., A new station-type magnetometer

Belluigi, Arnaldo, Concerning the graphic-analytical evaluation of the electromagnetic fields of mineral deposits

- On new developments in electrical prospecting- Electro-chemical sounding, Eltran method._. 129

Benfield, A. E., A heat flow value for a well in California_._.

Fennett, H., Concise chemical and technical dictionary_-_._._. 130

Rennett, T. F., Explosive cartridge assembly, U. S. patent 2,403,488__ 129

Berggren, W. P., with Mersman, W. A., and Boelter, L. M. K., The conduction of heat in composite infinite solids

9330

8988

9167

9113

(2) 8981

(2) 9158

9692

9425

9276

9350

9538

9506

9252

9566

9244

9483

9047

9253

9351

9036

(4) 9221

(6) 9434

(9) 9462

(3) 9303

(6) 9247

Berson, I. S., Kinematic possibilities of the existence of Mintrop waves in certain continuously discrete media_._. 128

The interpretation of surface hodographs of reflected waves-- 129 On a solution of the direct problem of the method of refracted waves in continuous media with surfaces of separation

Besuirie, Henri, The new nugnetic network of Madagascar-Magnetic survey of 1938

(3) 9005

(3) 9182

(3) 9376

(2) 9352

Bethe, H. A., with Barschall, H. H., Energy sensitivity in fast neutron counters - 130

9425

(9) 9654 in the Kolar Gold Field. 131

Billings, M. P., and Keevil, N. B., Petrography and radioactivity of four Paleozoic magma series in New Hampshire

9051

Birch, Francis, Crustal structure and surface heat flow near the Colorado Front Range 131 
Hirch, Francis, and Clark, Harry, An estimate of the surface flow of heat in the West Texas Permian Basin

Abst.

Bishopp, D. W., The occurrence of nickel and magnetite in some Irish serpentines in conjunction with a magnetic survey

Black, Robert, Vibration detector, U. S. patent 2,410,805

Blackburn, M. S., Radiographic method of geophysical exploration --_- 131

Blake, Archie, Criteria for the reality of apparent periodicities and other regularities._. 129

Blanchard, Jacques, The hypothesis of pole displacement and Quaternary chronology _. 130

Bodle, R. R., United States earthquakes, 1944_._._._._._._._- 129

Boelter, L. M. K., with Mersman, W. A., and Berggren, W. P., The conduction of heat in composite infinite solids___ 129

Gogdanov, A. I., The role of geophysical methods of exploration in the oil industry of the United States. 130

Bolidens Gruvaktiebolaget, Method of determining variations in the horizontal component of the force of gravity by measurements of relative plumb-line indications, Danish patent 58,229

9061

(2) 9159

(3) 9492

(4) 9598

(3) 9183

(9) 9463

(3) 9184

(6) 9247

(8) 9441 Method of determining the variation of the horizontal com129

9295 ponent of gravity by means of two plumb lines and an apparatus for applying this method, Dutch patent 51,926_.__ 131

Device for gravimeter, Swedish patent 105,041_._._._._._. 131

Bonchkovskii, V. F., The thickness of the earth's crust__.

Boss, R. L., and Hilseweck, W. J., Developments in west Texas and southeastern New. Mexico in 1946

Bostwick, L. G., Acoustic device, U. S. patent 2,404,784__._._._. 129

Bousquet, A., with Kip, A., Evans, R., and Tuttle, W., Design and operation of an improved counting rate meter._._. 128

Bower, T. H., Log map, new type of subsurface map

Boyd, W. B., with Swan, B. G., Geophysical history of the Guthrie Field, Logan County, Okla__._. 130

Boyer, R. Q., with Craig, Roderick, Torsion balance, U. S. patent $2,417,392 \ldots \ldots$

Braddon, IF. D., Magnetic deflection corrected compass, U. S. patent $2,411,866 \ldots$

Bradley, W. S., Program of the United States Geological Survey___._. 131

Bridgman, P. W., Recent work in the field of high pressure

Brown, Andrew, with McCollum, E. V., Use of the gravity meter in establishment of gravity bench marks_._. 130

Brown, C. H., Obstacle detection system, U. S. patent $2,410,424 \ldots \ldots$

Brown, E. L., Prospecting in the Granville Lake mineral area, Manitoba_ 129

Brown, L. E., and Williams, O. W., Well tester, U. S. patent $2,404,825$ - 129

Brown, R. W., Magnetic testing appartus, U. S. patent $2,425,361 \ldots 131$

Bruckshaw, J. McGarva, Geophysical prospecting and petroleum discovery

The magnetic method of geophysical prospecting _._._._._. 131

Brundall, Laurence, Photogeology aids oil exploration _._._._._-_. 129

Bryant, C. M., with Barstow, O. I., Deep-well camera_._. 129

Buckley, O. E., Detection of large magnetic bodies, U. S. patent $2,415,808$

Bugailo, V. A., Determination of average velocity by the methods of summation, difference, and constant difference

Bulanzhe, Iu. D., with Tikhonov, A. N., On the integration of gravitational fields_...

Bulashevich, Iu. P., Concerning the theory of interpretation of radioactive anomalies.............. 129

- Diffusion of emanation in the ground, with a correction for convection _... 131

Bull, A. J., Terrestrial heat and earth movements

Bullen, K. E., An hypothesis on compressibility at pressures of the order of a million atmospheres

Bureau de Recherches Gélogiques et Géophysiques, Gravimetric prospecting of the Bas Dauphine, France._. 130

(1) 9672

(1) $\cdot 9673$

(3) 9006

(8) 9630

(3) 9304

(5) 9055

(4) 9222

(3) 9404

(1) 9671

(2) 9114

(8) 9631

(8) 9068

(1) 9339

(9) 9137

(2) 9160

(7) 9321

(2) 9680

(4) 9415

(2) 9553

(9) 9277

(9) 9276

(2) 9302

(3) 9561

(1) 8978

(5) 9237

(5) 9610

(8) $\quad \mathbf{9 6 3 2}$

(8) 9069

(1) 9331 
Bureau of O. F. M. N., A. N., S. S. S. R., The scientific activity of the No. Class Abst_ Division of Physico-Mathematical Sciences of the Academy of Sciences of the U. S. S. R. and its affiliated institutions in the year 1945

Burns, W. W., Airborne magnetometer surveys of Bahamas soon to start _.

9633.

Burton, G. A., with Thomsen, H. L., Winter operation of geophysical equipment in the Rocky Mountain area_.___._. 129

Buss, K. A. H., Note on Tiberg's method of subterranean magnetic measurements and on the use of a parallelogram of forces_._-_- 128

9353.

9269 .

C

California Oil World, Checking cement behind pipe with radioactivity $\log$

Trends and techniques in petroleum exploration

Callaham, L. I., Russian-English technical and chemical dictionary -- 131

Cameron, E. N., Applications of the concept of zonal structure in pegmatites to prospecting for feldspar._. 130

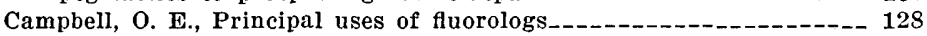

Cantos, J., Hydrological investigations by the method of seismic prospecting in the Province of Castellon - Geophysical methods according to R. M. Noya in their application to problems of subterraneous water

Cantrell, Ralph, with Hagen, C., Development trends in salt dome exploration__._._._._. 128

Carlson, W. L., Superheterodyne radio altimeter or locator, U. S. patent 2,424,796_. 131

Carlson, W. L., and Landon, V. D., Frequency modulated altimeter or distance indicator, U. S. patent $2,422,079$

Carnegie Institution of Washington, Year Book No. 43, July 1, 1943June 30, 1944_..... 128

Year Book No. 44, July 1, 1944-June 30, 1945_-___._-_._- 129

Year Book No. 45, July 1, 1945-June 30, 1946_._._._. 130

Carter, L. F., Gyro magnetic compass system, U. S. patent $2,414,448_{-\ldots} 131$

Čechura, F., Magnetic declination in the region of the middle Moldau_- 129

Magnetic declination on the Rip Mountain and its surroundings_ 131

Chace, F. M., The search for ore deposits-geologic methods and concepts _.

Chalard, J., Application of the Geiger-Müller counter to the stratigraphy of the coal basin in the north of France

Chance, Britton, The interconnection of dead-reckoning and radar data for precision navigation and prediction 129

Charczenko, Pierre, Note on certain geophysical formulas employed in gravimetric prospecting

Chemical Engineering and Mining Review, Bureau of Mineral Resources, Geology, and Geophysics______. 128

Clark, A. R., Geophysical devices as an aid to prospecting

Clark, G. L., The gravitational field of a rotating cohesive system_--_ 129 Note on the velocity of propagation of gravitation

Clark, Harry, with Birch, Francis, An estirnate of the surface flow of heat in the West Texas Permian Basin._. 128

Clark, James, with Williams, F. W., Method and means for testing for imperfections in vibratable objects, U. S. patent $2,412,240 \ldots 130$

9611

(8) 9634

(9) 9655

(9) 9464

(8) 9070

9007

9254

9077

9705

9517

9071

(8) 9255

(8) 9442

(2) 9674

(2) 9161

(2) 9539

9656

9052

9278 .

9685

9072

(1) 9140

(1) 9520

9061

(3) 9495

(2) 9488

Clarke, J. E., Magnetic testing apparatus, U. S. patent 2,423,552_-_- 130

Claypool, C. B., with Allison, A. P., Developments in upper Gulf coast of Texas in 1946

Cody, C., and Cody, M., Seismograph exploration in Venezuela, part 2-- 128

Cody, M., with Cody, C., Seismograph exploration in Venezuela, part 2_- 128

9008

Coffin, R. C., Recent trends in geological-geophysical exploration and methods of improving use of geophysical data_-_. 129

Comite National Français de Géodesie et Géphysique, Transactions for $1939-40,1941-42,1943,1944 \ldots \ldots$ 
Congdon, R. L., The design and testing of a versatile dynamic seismometer -

Conselho Nacional do Petroleo, Brazil, Brazilian National Council of Petroleum, report for 1945

Cooke, S. R. B., with Sloss, L. L., Spectrochemical sample logging of limestones._. 128

Cooper, C., with Vestine, E. H., and Laporte, L., Geomagnetic secular change during past epochs_._._. 128

Cooper, H. J., Scientific instruments___._- 128

Cork, J. M., Radioactivity and nuclear physics

Cork, J. M., Shreffler, R. G., and Shull, F. B, Magnetic field measurement in beta-spectroscopy

'Corsaro, G., Review of the corrosion process

Cosby, J. R., with Nelson, D. H., Means for and method of locating faults in electrical conductors, U. S. patent $2,425,554 \ldots 131$

Courter, L. A., Method of determining permeability of earth formations penetrated by well bores, U. S. patent 2,413,435__._._ 130

Cowles, L. G., with Wolf, Alexander, Well sounding apparatus, U. S. patent 2,411,311_._.

Craig, Roderick, and Boyer, R. Q., Torsion balance, U. S. patent $2,417,392$

Critikos, N. A., Report on the seismicity of Attica

Relationships between seismic phenomena and volcanic manifestations in the Aegean Sea and eastern Greece._-_._._._. 131

Critz, J. S., Oil possibilities of the Gulf coast Continential Shelf-_-- 128

Crompton, Wilfred, with Evans, Percy, Geological factors in gravity interpretation illustrated by evidence from India and Burma_-_-_ 130

Cronshow, H. B., Oil geologists meet in California___. 128

Cuer, Pierre, Prospecting for uranium by the use of its alpha particles 130

Cullen, R. J., Developments in Oklahoma in 1946

Curie, Marie, Radioactivity__-___- 128

Curtiss, L. F., with Krasnow, Shelley, Method and apparatus for direct recording of borehole radioactivity, U. S. patent $2,409,436 \ldots$

Cusset, Francis, English-French and French-English technical dictionary__. . .

\section{D}

Dake, H. C., with De Ment, Jack, Prospecting for uranium minerals_._ 128 Handbook of uranium minerals.

Davis, C. E., Interpretation of electrical well $\operatorname{logs}$ in the midcontinent area_._.

Duvis, R. E., and Foote, F. S., Surveying-Theory and practice, $3 d$ ed_ 131

Deegnn, C. J., Pratt sees great oil potentialities on continental shelf [and] slope._..._. 129

Helicopter aids in oil search The mass spectrometer and what it does..... 131

De Forest, Lee, Method of and apparatus for determining absolute altitude, U. S. patent $2,421,248 \ldots$

De Golyer, E. L., Oil exploration in the Middle East_._. 129

Delaygue, Arthur, A tentative theory of the origin of the geomagnetic field

De Ment, Jack, Fluorescent techniques in petroleum exploration_..-- 129 Uranium and thorium prospecting with the Geiger counter.--- 131

De Ment, Jack, and Dake, H. C., Prospecting for uranium minerals_-- 128

- Handbook of uranium minerais

Dent, G. E.; with Kuehn, H. E., Comparative study of magnetic surveys of Worcester County, Md., made on the ground and from airplane observations._. 130

Depp, M. C., and Fragola, C. F., Flux valve, U. S. patent $2,403,347 \ldots \ldots-129$

De Vries, Louis, German-English science dictionary, 2d ed____.... 128 
Diduy, Marcel, Graphic presentation of the variations of magnetic declination in Switzerland._. 128

Dinger, J. E., and Gunn, Ross, Electrical effects associated with a . change of state of water... 131

Dinsmore, C. B., Magnetic compass compensating field device, U. S. patent $2,417,864$

Discovery, The Geiger-Müller counter_______________________ 131

Disney, R. W., Trimetrogon aerial photography--oil industry's newest surveying tool__._. 128

Diukov, A. I., An experiment in the magnetic orientation of borehole cores from the eastern Donbas

Dix, C. H., The interpretation of well shot data, III _. Efficiency in exploration, I, General

Dix, C. H., Fu, C. Y., and McLemore, E. W., Rayleigh waves and free surface reflections _._._..._. 129

Dobbin, C. E., Geological features of the Rocky Mountain oil region_-_- 129

Dobrin, M. B., and others, Seismic-refraction survey of Bikini Atoll--- 130

Doll, H. G., and Schwede, H. F., Radioactive markers in oil field practice $\mathbf{1 3 0}$

Doll, H. G., Legrand, J .C., and Stratton, E. F., True resistivity determination from the electric $\log$, and its application to $\log$ analysis_-- 130

Donabedov, A. T., and Feofilova, A. P., Geophysical methods in the search and exploration of coal deposits and basins in the U. S. S. R - 130

Doshier, A. W., with Grant, P. A., Developments. in Texas Panhandle_-- 130

Dougherty, E. Y., and Fitzhugh, E. F., Jr., Magnetic reconnaissance in north-central Minnesota in 1945 128

Dougherty, P. F., with Winn, W. E., Method of logging wells, U. S. patent 2,408,964_- 128

Method of logging wells, U. S. patent 2,408,965

Draper, C. S., and Wrigley, Walter, An instrument for measuring low frequency accelerations in flight

Dreyer, R. M., Magnetic survey of the Bala intrusive, Riley County, Kans_._._.

Due Rojo, A., The theory of epicentral migration and the geographic and chronological distribution of seisms in the south and southeast of the Iberian Peninsula_____._. 129

Duffin, R. J., Measurement of magnetic susceptibility with the Hughes induction balance

Duvall, Wilber, with Obert, Leonard, and Windes, S. L., Standardized tests for determining the physical properties of mine rock

Class Abst

8983

9600

(2) 9484

(5) 9613

9097

(2) 9541

(3) 9011

(9) 9658

(3) 9186

(9) 9281

(3) 9377

(5) 9428

9412

(8) 9445

(8) 9446

8984

9131

(7) 9132

9012

9542:

9187

8985

9103

\section{E}

Earp, C. W., Distance measuring system, U. S. patent $2,423,088 \ldots \ldots$

Eisler, J. D., and Sílverman, Daniel, Multichannel pen recorder for electrical logging operations

9704

9601

Eisler, J. D., with Silverman, Daniel, and Evans, J. F., Vehicle borne instrument for continuously indicating road elevations___._. 130

(9) 9475

(9) 9660 granular materials.

Elliott, G. A., and Lee, R. H., The construction of Geiger-Müller tubes of high sensitivity to $\beta$-radiations_-_. 130

Emerson, W. H., and Hering, Donald, Well surveying instrument, U. S. patent 2,412,976_- 128

Emery, K. O., with Shepard, F. P., Submarine photography off the California coast..... 128

Englehardt, G. B., Object locating system, U. S. patent $2,421,747 \ldots \ldots-130$ Ennis, G. H., Method of and apparatus for locating formations in cased wells, U. S. patent 2,414,194__ 128

9429

$913 \%$

(9) 9109

(9) 9515 onteve, $A$. M., On the nvernge aciamic volocity in the conditions of the eastern Apsheron syncline-- 128 
Erickson, D. L., Geophysical history of the Wasco oil field, Kern County, Calif_-_- 129

Esseling, C. J., Drilling with counterflush continuous coring

Evans, J. F., with Silverman, Daniel, and Eisler, J. D., Vehicle borne instrument for continuously indicating road elevations_._._._._. 130

Evans, Percy, and Crompton, W., Geological factors in gravity interpretation illustrated by evidence from India and Burma_._._. 130

Evans, R. D., with Kip, A., Bousquet, A., and I'uttle, W., Design and operation of an improved counting rate meter-_......... 128

Evjen, H. M., and Lewis, W. B., Further experimental proofs of working depths for low-frequency commutated currents____._- 129

Evrard, Pierre, with Magnee, I. de, The value of geological interpretation of magnetic profiles._. 128

The Norgaard gravimeter

Ewing, Maurice, Geophysical investigations of continental borders_-_ 131

Ewing, Maurice, Woollard, G. P., Vine, A., and Worzel, J. L., Recent results in submarine geophysics_._. 129

Eyres, N. R., Hartree, D. R., and others, The calculation of variable heat flow in solids_... 131

(3) $\quad 9188$

(9) 9098

(9) . 9475

(1) 9333

9224

(2) $\$ 993$

(1) 9529

(3) 9564

$\mathbf{F}$

Fanselau, G., The results of Professor Filchner's geomagnetic observations during his second expedition to Tibet in $1935-37$, part 1 _-_ 131

Fay, C. H., Magnetic field measurements, U. S. patent $2,425,180 \ldots-\ldots 131$

Fearon, R. E., Well surveying apparatus, U. S. patent $2,414,862 \ldots-128$

Federal Science Progress, Prospecting by air._._. 129

- The seismograph; Earthquake engineering Geiger counter.

Fedynskil, V. V., The barometric effect in gravimeters_._._._._- 128

Fekete, Etgene, Report on the activities of the Royal Hungarian Baron Roland Eotvös Geophysical Institute during the period 1936-38_- 128

Fene, W. J., and Freas, G. L., Means for collecting gas analysis samples, U. S. patent $2,411,157$. 130

Feofilova, A. P., with Donabedov, A. T., Geophysical methods in the search and exploration of coal deposits and basins in the U.S.S.R.- 130

Ferraro, V. C. A., The radial stability of the geomagnetic ring current .... 131

Fisk, F. K., with Logue, L. L., Exporation and the gravity meter _-_- 129

Fitzhugh, E. F., Jr., with Dougherty, E. Y., Magnetic reconnaissance in north-central Minnesota in 1945. 128

Fleming, J. A., Summary of the year's work, to June 30, 1946, Dept. of Terr. Magn., Carnegie Institution of Washington_._._._. 129

Fleming, J. A., and others, Magnetic results from the Watheroo Observatory, 1919-35, and 1936-44_. 131

Flude, J. W., Apparatus for making geophysical survess under water, U. S. patent $2,423,591$

Fock, V., The field of a plane wave near the surface of a conducting body_..... 130

Fock, V., with Leontovich, M., Solution of the problem of propagation of electromagnetic waves along the earth's surface by the para. bolic equation method

(2) 9543

(2) 9679

(6) 9130

(2) 9162

(3) 9190

(5) 9430

(1) 8966

9074

9505

9445

(2) 9544

(1) 9145

(2) 8984

9700

9413

Foote, F. S., with Davis, R. E., Surveying, theory and practice

Fragola, C. F., with Depp, M. C., Flux valve, U. S. patent $2,403,347--129$

Freas, G. L., with Fene, W. J., Means for collecting gas analysis samples, U. S. patent $2,411,157$

Frey, Eugene, Hartville iron district, Platte County, Wyo.... 131

Friedel, E., and Goguel, J., Geophysical prospecting of the BasDauphine, France

Friedman, Herbert, with Muehlhause, C. O., Measurement of high intensities with the Geiger-Mueller counter.

Fritsch, Volker, The efficacy of radio-prospecting in depth

Frosch, Alex, Well logging, U. S. patent $2,412,575$ 
Frost., A., McIntire, R., Papenfus, E., and Weiss, Oscar, The discovery and prospecting of a potential gold field near Odendaalsrust in the Orange Free State, Union of South Africa

Frowe, Eugene, A total-field magnetometer for mobile operation._._.- 131

Fu, C..Y., Studies on seismic waves, III, Propagation of elastic waves in the neighborhood of a free boundary 129

Fu; C. Y., with Dix, C. H., and McLemore, E. W., Rayleigh waves and free surface reflections

No. Class

Abst.

9191

9186

\section{G}

Gabriel, V. G., Electrical methods of oil exploration________-_ 129

Galanopoulos, A., 'The two violent earthquakes in Larissa, Greece, in 1892 and $1941 \ldots 130$

Gamburtser, G. A., Correlation of refraction shooting - Experimental work on the correlation refraction method in the

Ishimbai region

Contribution to the theory of multiple reflections

On the representation of seismic fields_._. 129

On the theory of the seismic mixer._._.

- Correlation systens of observations in prospecting by methods

of seismic reflection and refraction 131

Garcia-Serrano, with Inglada, Vincente, Lectures on the basic problcms of modern geophysics

Gardiner, E. M., with McDowell, E. B., Photoelectric detecting apparatus, U. S. patent $2,419,459$

Gardner, L. W., Vertical velocities from reflection shooting

Geophone polarity indicator, U. S. patent $2,423,970$

Garrigue, Hubert, Survey of radioactivity in the Vosges Mountains_- 129

Gassmann, Fritz, Concerning the numerical treatment of. potential fields in geophysics_._. 128 Report on experiments with the divining rod... 130

The development of geophysics in Zurich during the last 50 years_____

Gassuiann, Fritz, Weber, E. K., and Niggli, Ernst, Magnetic measurements of the Institute of Geophysics, E. T. H., Tessin

Geyer, R. A., Heiskanen's paper on the structure and figure of the earth, a review

Giannini, G. M., Elimination of vibration errors in magnetic compasses and the like, $U$. S. patent $2,422,960$

Gibbcu. A., Electronic principles used in the discovery of oil

Glebovskii, Iu. S., Concerning the cause of the East-Siberian continental anomaly of the geomagnetic field 129

Gogoladze, V. G., Motion of seismic energy in different media_._... 129

On the propagation of electromagnetic waves in different media in contact along a plane 129

Goguel, J., The equilibrium of pressures in local isostatic compensation of masses

Goguel, J., with Friedel, E., Geophysical prospecting of the BasDauphine, France-_._- 130

Golay, M. J. E., and Zahl, H. A., System for detecting sources of radiant energy, U. S. patent $2,424,976$

9225

(3) $9378^{-}$

(3) 9014

(3) 9015

(3) 9192

(3) 9193

(3) 9379

(3) 9565

(8) 9260

(4) 9499

(3) 9194

(3) 9684

(5) 9238

(8) 9075

(2) 9355

(8) 9637

(2) 8986

(1) 8968

(2) 9487

(4) 9039

(2) 9164

(3) 9195

(4) $\quad 9226$

(1) 9521

(4) 9414

(5). 9695

Goloubinow, R., Existence, exploitability, and exploration of auriferous rocks _._._._. 130

Gowanloch, J. N., and McDougall, J. E., Exploration can be harmless to aquatic life-_- 128

Graaff Hunter, J. de, Report on the deviations of the vertical

Graf, Anton, Gravimeter, General review, parts 1-2 Grant, P. A., and Doshier, A. W., Developments in Texas Panhandle--- 130

Graves, A., Modern Geiger-Müller counters.-_- 129

Gray, J. B., with Roe, R. B., Navigation system, U. S. patent 2,419,970_ 129

Graybeal, J. W., Determining permeability of subsurface formations; U. S. patent $2,409,674$ 
Gregg, E. C., Jr., An alternating current probe for measurement of

magnetic fields_-

No. Class

Abst.

(2) 9165 of rocks of the Massif Central and remarks on methods of determining the intensity of the geomagnetic fleld in the past_-_._-_.-- 128

On the standardization of electromagnetic seismographs_..... 129

On the utilization of the mass of seismographs and the possibility of improving the characteristics of certain apparatus having mechanical amplification.

9380

Grenet, Gaston, and Bayard-Duclaux, F., The Modified-Wenner C. G. 1 universal vertical seismograph

Grinstead, C. E., with Martin, E. J., Inductor compass, U. S. patent $2,403,669$ _._. 129

Grishin, G. L., and Levitskii, P. I., Summary of oil search in 1945 and program for 1946

Groenendyke, G. M., with Shimek, E: I., Gain-controlling system for seismographs, U. S. patent 2,420,571_____ 130

Groves, $A$. W., Results of magnetometric survey at Benallt manganese mine, Rhiw, Caernarvonshire

Gubanov, A., Rayleigh waves at the boundary between a solid body and a liquid_............ 131

Gulmon, G. W., with Smith, N. J., Geophysical history, Lake St. John Field, Concordia and Tensas Parishes, La____._. 130

Gunn, Ross, Quantitative aspects of juxtaposed ocean deeps, mountain chains, and volcanic ranges____. 129

Gunn, Ross, with Dinger, J. E., Electrical effects associated with a change of state of water._... 131

Gutenberg, Beno, Interpretation of records obtained from the New Mexico atomic bomb test, July 16, 1945_____________ 129

_ Microseisms and weather forecasting__._._._._._._._._. 130

Gutenberg, Beno, and Richter, C. F., Seismic waves from atomic bomb tests... 129

_ Larthquake study in southern California, 1946_... 131

Guyod, Hubert, Temperature well-logging - salt intrusions_._..._._. 128

- Temperature well-logging - temperature distribution in the ground-_._-

Well logging methods

- Temperature well-logging-Wells in thermal equilibrium _-_--- 129

-Temperature well-logging-Wells not in thermal equlibrium, rotary holes _._. 129

Temperature well-logging-Wells not in thermal equilibrium, parts 1-2

9566

9298

$(7,8) \quad 9258$

(2) 9548

(3) $9567^{\circ}$

(8) 9455

(9) 9282

(4) 9600

(3) $\quad 9197$

(3) 9381

(3). 9198

(3) 9568

(6) 9062

(6) 9063

(8) 9076

(6) 9245

(6) 9246

(6) 9435

H

Haas, W. J. de, and Westerdijk, J. B., Strong magnetic fields___._- 130

Hagen, C., and Cantrell, R., Development trends in salt dome exploration. 128

Haggerty, P. E., and Olson, R. W., Preliminary results of a study of seismograph sensitivity requirements__. 131

Hamil, A. B., Portable equipment expedites inland marine seismic

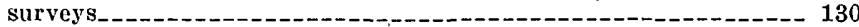

Hammer, Sigmund, Gravimeter ties between gravity base stations in Washington, D. C._. 129 - A new calculation technique for quantitative interpretations in gravity prospecting

Hammond, J. V., and Keenan, D. J., Blasting unit and short-circuiting device, U. S. patent $2,407,605$

Hammond, Laurens, Radiant energy detecting and control apparatus, U. S. patent $2,413,870$

Hansen, R. F., Multiple reflections.

$\triangle$ A new system of seismic reflection profiles 
Happ, S. C., Electrical-resistivity investigations of levee foundations near Kansas City

Abst.

Harris, Sidon, Modern seismic techniques applied to geophysical exploration in west Texas._. 131

Harrison, B. M., Electrical circuits, U. S. patent 2,410,065___-_._- 130 Electroacoustic transducer, U. S. patent 2,416,314__-_-_-_-_ 131

Hartree, D. R., with Eyres, N. R., and others, The calculation of variable heat flow in solids

Hasselmann, K. F., Torsion balance surveys of in undated areas______ 130

Hassler, N. A., Electrical system for use with recording meters, U. S. patent 2,415,880 129

9571

9683

(6) 9621

(1) 9334

9325 879

Hathaway, J. L., Electric altimeter, U. S. patent 2,421,785___..._. 130

Hawkes, H. E., Research on geochemical prospecting by the Geological Survey

Hawkes, H. E., Balsley, J. R., and others, Geophysical investigations, preliminary aeromagnetic maps 1 and 2_._. 128

Hawley, P. F., Geophysical contributions to vibration measurements and micro-chemistry

Hayward, J. T., Apparatus for use in logging wells, U. S. patent $2,404,132 \ldots \ldots$

Hedstrom, Helmer, On geophysical methods in geology

Hee, A., with Rothe, Edmond, Georadiological studies of the rocks of Alsace and the Vosges_._._. 128

Heiland, C. A., Aeromagnetic prospecting

Heiland, C. A., Tripp, R. M., and Wantland, D., Geophysical surveys at

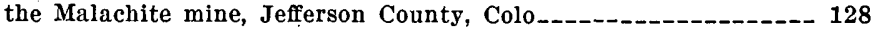

Heineman, J. H., Magazine for magnetic recording apparatus, U. S. patent $2,415,133$

(9) 9516

Heiskanen, W., The gravity anomalies on the Japanese Islands and in the waters east of them

Hemphill, W. B., with Shimek, E. J., Gain-control system for seismic amplifiers, U. S. patent $2,408,001$

Hendricks, T. A., Proposed Continental Shelf program, U. S. Geological Survey_... 120

9307

9259

Hering, Donald, with Emerson, W. H., Well surveying instrument, U. S. patent 2,412,976 128

Hershberger, W. D., Radio pulse altimeter and object detector, U. S. patent $2,423,024$

9135

9703

Hess, V. F., On the ionization produced by the gamma rays from Quincy granite_._. 129

Hills, E. S., The metalliferous geochemical zones of Australia_-_-_- 131

Hilseweck, W. J., with Boss, R. L., Developments in west Texas and southeastern New Mexico in 1946 131

Hoare, S. C., Resonant circuit saturable core measurement apparatus, U. S. patent $2,412,046$

Hodell, C. M., Aerial surveys expedite exploration in Venezuela_._._- 130

Hodgson, J. H., Analysis of travel times from rock bursts at Kirkland Lake, Ontario

Hoeper, H. B., with Sargeant, W. E., Amplifier for small voltages, U. S. patent $2,413,788$

Hollingsworth, w, E., Geophysical history of the East Field, Jim Hogg County, Tex

Hollis, E. P., with Ulrich, F. P., Progress report of seismological work by the United States Coast and Geadetic Survey in the western United States during 1945_._. 131

Holmes, Arthur, A revised estimate of the age of the earth

Holopainen, P. E., On the gravity field and the isostatic structure

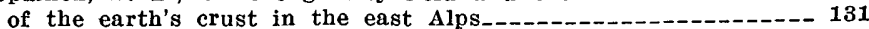

Hoover, Herbert, Jr., Seismometer, U. S. patent 2,417,077

Horton, C. W., On the use of electromagnetic waves in geophysical prospecting. 
Horvitz, Leo, Gas analysis, U. S. patent $2,414,876$

Housner, G. W., Characteristics of strong-motion earthquakes_-___ 129

Howatson, C. H., with Warren, H. V., Biogeochemical prospecting for copper and zinc_._. 131

Hubbert, M. K., Gravitational terrain effects of two-dimensional topographic features_._. 131

Huelin, G. S., The Boliden gravimeter.

- Gravimetry and its present development_-_._-_._-_-_-_ 129

Hughes, D. S., and Pondrom, W. L., Computation of vertical magnetic anomalies from total magnetic field measurements

Response characteristics of seismograph at the University of Texas

9627

Imle, J. F., Accident prevention in geophysical exploration Independent Petroleum Association of America Monthly, Gravimetric service firm provides reports by areas.-130

Inglada, Vincente, and Garcia-Serrano, Lectures on the basic problems of modern geophysics._. 129

Instrument Development Laboratories, Chicago, Radioactivity probe_- 130 Irwin, E. M., Flux measuring system, U. S. patent $2,418,553$ Ising, Gustaf, Method and apparatus for the relative measurement of gravity, Dutch patent 51,580

$\mathbf{J}$

Jakosky, J. J., Whither exploration

Jeffreys, B. S., with Jeffreys, H. H., Methods of mathematical physics 130

Jeffreys, H. H., The genesis of deep foci earthquakes____

Jeffreys, H. H., and .Teffreys, B. S., Methods of mathematical physics_- 130

Jenkins, Howard, System of compass compensation, U. S. patent $2,412,617 \ldots$

Jenny, W. P., Structural correlation of micromagnetic and reflection data_______.

Jensen, Homer, Operational procedure for airborne magnetometer.-_-_ 128

Recent techniques and projects for the airborne magnetometer

Jensen, Homer, and Balsley, J. R., Jr., Controlling plane position in aerial magnetic surveying

Jensen, Homer, with Klaasse. J. M., and Rumbaugh, L. H., Applications of Shoran and photographic techniques to aerial magnetic surveys _.

Jersey, N. J., de, Seismological evidence bearing on crustal thickness in the southwest Pacific

Jillson, W. R., Thrust-shatter theory of oil accumulation

Johnson, E. A., Method and apparatus for logging wells, U. S. patent $2,415,636$

Johnson, G. R., Offshore surveying with radar

Johnson, H. L., Apparatus for undisturbed orerburden sampling, U. S. patent 2,403,002

Jones, J. R., with Alleock, H. J., The nomogram____ 129

Jones, R. H. B., Geologic interpretation of magnetic exploration on the Mesabi range, Minnesota___._. 128

Jones; W. M., Effects of surface relief on anomalies of vertical magnetic intensity - 130 - Some theoretical considerations of anomalies of magnetic declination in New Zealand

Kalaschnikow, A. G., Magnetic field meter-_._. 129

Kalinin, Iu. D., The potential of age-long geomagnetic variations on the territory of the U. S. S. R component of the geomagnetic field for the territory of the U. S. S. $\mathbf{R}$ 
Kalitskil, K. P., Scientific foundations of oil search

Class

Kate, H. ten, with Milatz, J. M. W., The quantitativity of the GeigerMüller counter, the spectrum of $\mathrm{RaE}_{-}$

Kazinskii, V. A., Concerning an appraisal of the accuracy of the variometer method for measuring deviations of plumb lines in the gravitational field of the earth

Keenan, D. J., with Hammond, J. V., Blasting unit and short-circuiting device, $U$. S. patent $2,407,605$

Keevil, N. B., with Billings, M. P., Petrography and radioactivity of four Paleozoic magma series in New Hampshire

Keevil, N. B., with Larsen, E. S., Radioactivity of the rocks of the batholith of southern California___ 131

Keller, Fred, Jr., Response of electronic earthquake recorder-_-_---- 128

Kelly, S. F., What geophysics is and is not

Kelly, S. F., with Patty, E. N., A geological and geophysical study of the Chelan nickel deposit near Winesap, Wash

Keston, A. S., Geiger-Müller counter, U. S. patent 2,409,498_._... 128

Khramoi, A: I., On gravimetric surveying in conditions of complex topography

Kip, A., Bousquet, A., Evans, R., and Tuttle, W., Design and operation of an improved counting rate meter...... 128

Kirilov, F. A., The seismic effect of explosion

- Concerning the dependence of the period of ground oscillation upon the distance to the explosion

Kirnos, D. P., A horizontal seismograph for epicentral zones._._-_.-_ 129

Kissam, P., and others, Radar shows promise in mapping, A symposium _ 128

Klaasse, J. M., Rumbaugh, L. H., and Jensen, Homer, Applications of Shoran and photographic techniques to aerial magnetic surveys -131

Klein, Elias, Acoustical appartus, U. S. patent 2,416,324

Knebel, G. M., Progress report on the A. P. I. Research project 43 , The tranformation of organic material into petroleum

Knoerr, A. W., The airborne magnetometer, a new aid to geophysics_-- 129

Koch, W. R., Record reproduction circuit, U. S. patent $2,410,982 \ldots \ldots$

Koepfer, A. A., Aerial photographic image motion compensating system, U. S. patent $2,424,989$

Koliubakin, V. V., A màgnetometer-_._-_._- 129

Koning, L. P. G., On the determination of the faultplanes in the hypocenter of the deepfocus earthquake of June 29, 1934, in the Netherlands East Indies.

Kosygin, Iu. A., The mechanism of salt-dome formation

Kothny, G. L., Well surveying device, U. S. patent 2,424,358

Kraskovsky, S. A., On the variation of temperatures at great depth over long periods of time 131

Krasnow, Shelley, Method and apparatus for taking physical measurements in boreholes, U. S. patent 2,421,423 130

U. Apparatus and method for recording borehole radioactivity,

U. S. patent $2,416,702$

Krasnow, Shelley, and Curtiss, L. F., Method and apparatus for direct recording of borehole radioactivity, U. S. patent $2,409,436$

Krinitzsky, E. L., Geophysies and its applications to speleology

Krumbach, Gerhard, Principles and construction of a local-vibration seismometer with mechanical registration 130

Kuehn, F. E., and Dent, G. E., Comparative study of magnetic surveys of Worcester County, Md., made on the ground and from airplane observations._._. 130

Kulichenko, N. I., The electrical probe_______ 131

Kunetz, Gera, with Schlumberger, Marcel, Rapid simultaneous variations of the telluric field in France and Madagascar....... 130

9337.

9306:

9051

(5) 9614

(3) 9017

(8) 9447

(4) $904 \overline{5}$

(5) 9129

9526

(5) 9055

(3) 9018

(3) 9387

(3) 9201

(9) 9100

(2) 9552

(3) 9311

(9) 9101

(2) 9169

(3) 9493

(9) 9707

(2) 9170

(3) 9019

(9) 9285

(4) 9690

(6) 9622

(4) 9501

9503:

(5) 9128

(8) 9630

9388

(2) 9360

(4) 9602

(4) 9420

$\mathbf{L}$

Lahee, F. H., Exploratory drilling in 1945 128

(9) 9102

Exploratory drilling in 1946_._._._. 130

(8) 9448

Laird, A. G., and Slonczewski, Thaddeus, Magnetic field detector, U. S. patent 2,426,622 131 
Lambert, W. D., Deflections of the vertical from gravity anomalies___- 129

Landon, V. D., with Carlson, W. L., Frequency modulated altimeter or distance indicator, U. S. patent $2,422,079$

(1) 9144

Landsberg, H., Note on the frequency distribution of geothermal

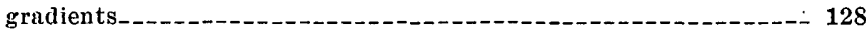

Landsberg, H., and Neuberger, H., On difference of P-wave velocities_-- 131

Laporte, L., with Vestine, E. H., and Cooper, C., Geomagnetic secular change during past epochs__-_._-_._- 128

Larsen, E. S., and Keevil, N. B., Radionctivity of the rocks of the batholith of southern California_._.

Larsen, H. R., with Beers, R. F., A new station-type magnetometer_-_-- 130

Isauterjung, K. H., and Neviert, H., After-effect with counter tubes_-_-- 128

Laycock, G. F., Mineral exploration and the outlook for mineral supplies_-__._. 128

Iazan, B. J., Oscillator, U. S. putent 2,410,170_.

Le Conte, Joseph, Geophysical history of the North Coles Levee oil field, Kern County, Calif

Lee, B. D., Potentiometric model studies__-___._- 131

Lee, R. H., with Elliott, G. A., The construction of Geiger-Muiller tubes of high sensitivity to $B$-radiations

Lees, G. M., Oil in the Middle East_._. 130

Leet, L. D., The velocity of $P$ in the granitic layer._.

Microseisms in New England-Case history of a storm_-_-_-_ 131

Legrand, J. C., with Doll, H. G., and Stratton, E. F., True resistivity determination from the electric log, and its application to $\log$

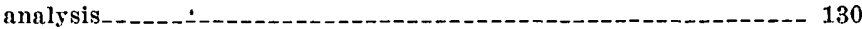

Legraye, Michel, Origin and formation of gold deposits__._._._. 129

Lejay, Pierre, Measurements of gravity in the south of France in 1940_- 130 Measurements of gravity in the southeast of France in 1941_-_- 131

Measurements of gravity in the Massif Central, September 1941_ 131

Leontovich, M., and Fock, V., Solution of the problem of propagation of electromagnetic waves along the earth's surface by the parabolic equation method

9517

(6) 9064

(3) 9574

(2) 9001

(5) 9614

(2) 9351

(5) 9056

(8) 9079

(3) 9491

(3) $\quad 9389$

(4) 9603

(5) 9429

(9) 9469

(3) 9020

(3) 9575

(4) 9412

(9) 9286

(1) 9338

(1) 9527

(1) 9528

Levitskii, P. I., with Grishin, G. L., Summary of oil search in 1945 and program for 1946

Lewis, W. B., Practical consideration for electrical prospecting---_---- 13.

Lewis, W. B., with Evjen, H. M., Further experimental proofs of working depths for low-frequency commutated currents_-_-__-__-_-_ 129

Lindsey, H. A. D., Submarine detector, U. S. patent $2,404,806 \ldots 129$

Liustikh, E. N., The treatment of gravity data in preparation for geological interpretation

Logachev, A. A., Aeromagnetic survey in the Karelian-Finnish S. S. R $\mathbf{R}_{--} \mathbf{1 3 0}$

Logan, $K$. H., Recent progress in the mitigation of underground corrosion -

Logue, L. L., and Fisk, F. K., Exploration and the gravity meter-_-_ 129

Lokman, Kemal, Kurzot oil___- 129

Loper, G. B., Seismic wave detector, U. S. patent $2,428,168 \ldots \ldots$

Ludeke, C. A., An experimental investigation of forced vibrations in a mechanical system having a nonlinear restoring force_-_._- 129

Lundberg, H. T. F., Airborne magnetometer._. 128

- Mining geophysics: Annual review 1946_..._._._._._._. 128

Luoma, N., Gravity formulas derived by the aid of latitude and longitude zones_-_._. 128

Lyons, P. L., The low velocity layer in seismic exploration, parts $1-2_{--} 128$

\section{(4) 9604}

$(7,8) \quad 9258$

(4) 9605

(4) 9224

(2) 9299

(1) 8971

(2) 9361

(4) 9042

(1) 9145

(9) 9287

(3) 9688

(3) 9202

(2) 8992

(8) 9080

(1) 8972

(3) 9021

\section{M}

McCarver, H. C., and West, I. G., The geology and geophysics of the Odem oil field, San Patricio County, Tex._._. 129

McCollum, E. V., The interpretation of gravity anomalies_._.

McCollum, E. V., and Brown, Andrew, Use of the gravity meter in establishment of gravity bench marks_... 130

McDermott, Eugene, Submarine detecting method and apparatus, U. S. patent $2,412,165$ 
McDougall, J. E., with Gowanloch, J. N., Exploration can be harmless

to aquatic life
McDowell, E. B., and Gardiner, E. M., Photoelectric detecting apparatus, U. S. patent $2,419,459$

Macelwane, J. B., Origin of microseisms____ 129

Study of large-scale vibrations at a pumping station__._._._- 130

McGaka, S. W., with Walker, J. M., Some practical considerations of radioactivity well logging 130

McGarva-Bruckshaw, J., Geophysical prospecting and petroleum discorery _._._._. 130

- The magnetic method of geophysical prospecting

Maclits, Ludwig, Machts, Richard, Nickel, Bernard, and Ruhl, August, Pcrtable device for ascertaining properties of the earth by means of high frequency electric oscillations, Dutch patent 50,926 - 131

Machts, Richard, with Machts, Ludwig, Nickel, Bernard, and Ruhl, August, Portable device for ascertaining properties of the earth by means of high frequency electric oscillations, Dutch patent 50,926 .

McIntire, R., with Frost, A., Papenfus, E., and Weiss, Oscar, The discovery and prospecting of a potential gold field near Odendaalsrust in the Orange Free State, Union of South Africa._._. 128

McLenore, E. W., with Dix, C. H., and Fu, C. Y., Rayleigh waves and free surface reflections_._. 129

McMillan, W. D., Exploration of the Bourbon magnetic anomaly, Crawford County, Mo 129

MacNeil, D. J., Searching for petroleum in the Maritimes

McNish, A. G., and Tuckerman, Bryant, The vehicular odograph____ 131

Magnani, Mario, Tectonics and seismicity of the Albanian region_._.- 131

Magnee, I. de, and Evrard, P., The value of geological interpretation of magnetic profiles. 128

The Nørgaard gravimeter

Maillet, Raymond, Geophysical prospecting, U. S. patent $2,420,672$

Mansfield, R. H., Universal slide rule for linear velocity vs. depth calculations_-_._._.

Mantle, Edward, Amateur seismology in the making 130

Marble, J. P.; and others, Report of the Committee on the Measurement of Geologic Time, 1943-46.

Marshall, D. L., and Oliver, L. R., Some uses and limitations of model studies in cycling.-. 129

Martin, E. J., and Grinstead, C. E., Inductor compass, U. S. patent $2,403,669$

Martin, Hans, Technical problems of vibration in the interior of the earth

Masarskii, S. I., On the question of selecting hodographs of adequate length._... 129

Medsger, H. O., Seismograph prospecting for oil

Mercanton, P. L., The new vertical seismograph Kreis-Wanner of the Federal Seismological Observatory at Zurich

- Seismometric sounding by the Helvetian Glaciological Commission at Unteraar, Switzerland__. 130

Mercanton, P. L., and Wanner, E., The magnetic anomaly of the Jorat, Vaud-The vertical component__. 129

Meredith, F. W., Flux valve, U. S. patent 2,414,654 131

Mersman, W. A., Berggren, 'W. P., and Boelter, L. M. K., The conduction of heat in composite infinite solids

Migaux, Leon, A new method of applied geophysics-Prospecting by telluric currents - 129

Milatz, J. M. W., and Kate, H. ten, The quantitativity of the GeigerMiller counter, the spectrum of RaE_._. 128

Miller, A. H., Gravimetric surveys of 1944 in New Brunswick

Miller, M. C., Galvanic couples and cathodic protection

Miller, R. D., with Muzzey, D. S., Electronic commutator, U. S. patent $2,417,609$ :

Mining and Metallurgy, Magnetometer surveys made from helicopters_-_ 128

$(3,9) \quad 9099$

(4) 9499

(3) 9204

(3) 9390

(5) 9433

(4) 9415

(2) 9553 .

(4) 9694

(4) 9694

$(1,2) \quad 896 \tau$

9186

(2) 9171

(8) 9261

(9) 9659

(3) 9576

(2) 8993

(1) 9529

(3) 9498

(3) 9577

(3) 9391

(5) 9615

(4) $922 \mathrm{~s}$

(2) 9298

(3) 9205

(3) 9206

(3) 9022

(3) 9207

(3) 9392

(2) 9172

(2) 9675

(6) $\quad 9247$

(4) 9229

(5) $905 \%$

(1) 9147

(4) 9416

(4) 931:

(2) 8994 
Mining Congress Journal, The airborne magnetometer-

Mitchell, D. H., Translating circuit and apparatus for portable electrical devices, U. S. patent 2,420,609__- 130

Montana Oll and Mining Journal, Geological Survey trying out geochemical methods_.

Moody, G. B., Developments in California in 1946_._. 131

Morelli, Carlo, The normal field of the vertical component of the geomagnetic field in Italy Concerning the fundamental constant of the pllipsoidal international formula for normal gravity - The normal magnetic field of declination in Italy according to the determinations of the Military Geographical Institute._._._- 129 On an international reference system of gravity measurements 130 Normal distribution of the horizontal component of the geomagnetic field in Ituly New foundations of seismic safety

Concerning vertical electric currents in Italy__._- 130 Compensation of the international net of reference stations for the measurement of relative gravity - Italy's magnetic anomalies and declinations at high altitude, with special reference to aerial navigation by instrument__._._.- 131 Muehlhause, C. O., and Friedman, Herbert, Measurement of high intensities with the Geiger-Müller counter-_._- 129

Muffly, Gary, Disturbing influence detecting element, U. S. patent $2,412,742 \ldots$

Munk, W. H., Increase in the period of waves traveling over large distances, with application to tsunamis, swell, and seismic surface waves_._.

Murphy, L. M., Microseisms, the unknown__-_-_-_- 128 Geological effects on microseisms in the Caribbean..._... 130

Murray, H. W., Submarine relief of the Aleutian 'Trench_______-_ 128

Muzzey, D. S., and Miller, R. D., Electronic commutator, U. S. patent $2,417,609$

Myers, G. N., Battle for Arctic oil_. 128 9508

(7) 9066

(8) 9640

(2) 8996

(2) 9173

(1) 9340

(2) 9362

(3) 9393

(4) $\quad 9417$

(1) 9530

(1) 9554

(5) 9241

(3) 9208

(3) 9023

(3) 9394

(3) 9024

(4) 9315

(8) .9081

\section{$\mathbf{N}$}

National Oil Scouts and Landmen's Association, Oil and gas field development in United States, 1945_. 128

National Research Council of Canada, Associate Committee on Geodesy

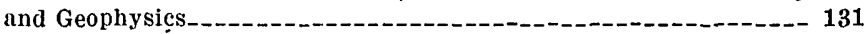

Nature, Geophysical prospecting and English oilfields__._._._._. 128 Canadian research in geodesy and geophysics________._._._. 131

Nelson, D. H., and Cosby, J. R., Means for and method of locating faults in electrical conductors, U. S. patent $2,425,554$

Nettleton, L. L., Geophysical history of typical Mississippi piercement salt domes..._._. 129 - Early geophysical papers of the Society of Exploration Geophysicists (edited by L. L. Nettleton)

Nettleton, L. L., and Elkins, T. A., Geologic models made from granular materials_._._. 131

Neuberger, $\mathbf{H}$., with Landsberg, H., On difference of $P$-wave velocities_-_ 131

Neuert, H., with Lauterjung, K. H., After effect with counter tubes_-_-_ 128

Neufeld, Jacob, Navigational method and apparatus, U. S. patent $2,412,003$

Neumann, Frank, The accuracy of seismogram analysis as revealed by shaking-table tests_._-_-_-_-_- 130

Nichols, C. R., and Williston, S. H., Electrical prospecting apparatus, $U$. S. patent $2,428,034$

Nickel, Bernard, with Machts, Ludwig, Machts, Richard, and. Ruhl, August, Portable device for ascertaining properties of the earth by means of high frequency electric oscillations, Dutch patent 50,926_- 131

Niggli, Ernst, Magnetic measurements at the manganese-iron ore deposit of Fianell, Val Ferrera____ 131 
Niggli, Ernst, with .Grassmann, Fritz, and Weber, E. K., Magnetic measurements of the Institute of Geophysics, E. T. H., Tessin___-_ 128

Nikolsky, A. P., Dual laws of the course of magnetic disturbances and the nature of mean regular variations._._.

Nishkian, L. H., Vertical vibrątion recorders for the Golden Gate Bridge_ 131

Niskanen, Erkki, Gravity formulas derived by the aid of the level land stations_._._.

- On the deformation of the earth's crust under the weight of a glacial ice-Ioad and related phenomena_._. 129

Nordström, Allan, Comparison between the results of some electrical surveys and the subsequent mining work

Norelius, R. G., Electrical logging in oil-base drilling fluid__._._._- 128

Norelius, R. G., with Stick, J. C., and Baker, J. S., New electrical logging techniques in California._._. 130

Northern Miner, Local CIM hears talk on geophysics from the air.---_- 129

Nugent, L. E., Jr., Aerial photographs in structural mapping of sedimentary formations

Abst.

8986

(2) 9363

(3) 9578

8973

9043

(4) 9044

(4) 9421

(2) 9174

9288

Obert, Leonard, Windes, S. L., and Duval, Wilber, Standardized tests for determining the physical properties of mine rock

O'Boyle, C. C., with Tripp, R. M., Beta activity of some carbonaceous materials_... 131

O'Connell, D. J. K., The calculation of the ground movement for the initial impulses of Galitzin seismographs__._-_._-_._- 130 Deep focus earthquakes, 1909-12 131

Offman, P. E., On the geological interpretation of geophysical maps of the Ishimbai pre-Urals_________._. 130

Ogg, A., Periodicity of geomagnetic activity

Oil, Gulf pioneered in exploration and drilling in south Louisiana_-_-_- 128

Oil and Gas Journal, Miniature models aid mapping of salt-dome areas_ 128 Radar, new exploration tool.

Oil News, Flying eye survey may revolutionize geological labors_..._._- 130

Oil Weekly, Geophysical and core drilling activity during 1946_._-_- 129

- 1947 World Oil Atlas______ 130

Oliver, L. R. with Marshall, D. L., Some uses and limitations of model studies in cycling 129

Olsen, Johannes, Persistent solar rotation period of 26,875 days and solar-diurnal variation in terrestrial magnetism

Olson, R. W., with Haggerty, P. E., Preliminary results of a study of seismograph sensitivity requirements__. 131

Olson, R. W., with. Shook, E. M., System for geophysical exploration, U. S. patent $2,413,116$

Omer, G. C., Jr., Differential-motion seismographs_. 131 Oppenheim, V. E., First generalized geological map of South America_-- 131 Oonitskaia, L. K., On petroleum genesis

Oulianoff, Nicolas, The earthquake of Jan. 25, 1946, and the deep structure of the Alps

Owen, David, The lines of force through neutral points in a magnetic field.--.-- 131

9103

9618

(3) 9396

(3) 9579

$(1,4) \quad 9341$

(2) 9175

(8) 9084

(9) 9104

(8) 9450

(2) 9364

(8) 9262

(9) 9470

9228

9365

9569

9122

(3) 9580

(9) 9661

(9) 9105

9581

9556

$\mathbf{P}$

Papenfus, E., with Frost, A., McIntire, R., and Weiss, Oscar, The discovery and prospecting of a potential gold field near Odendaalsrust in the Orunge free state, Union of South Africa___._._._. 128

Parejas, Edouard, Transverse, tectonics and petroleum deposits

Pariisky, N. N., Acceleration of gravity at the principal gravimetric point of Transcaucasia in Tbilissi

Parker, B. H., with Van Tuyl, F. M., Oil-its origin and accumulation. 130

Parker, F. S., California petroleum exploration and discoveries in 1945_ 128 Parr, J. O., Jr., Separation of blasting circuit leads, U. S. patent $2,407,442$ 
Patty, E. N., and Kelly, S. F., A geological and geophysical study of the Cheland nickel deposit near Winesap, Wash__________._._- 128

No. Class Abst.

Patzke, Werner, Detailed gravity measurements with the static gravimeter_._._._._._. 129

9045

9152

Pauwen, L. J., On a static instrument for measuring the value of gravity _-_._- 128

Pekeris, C. L., New methods for interpretation of seismic records from underwater explosions__________ 131

Per'kov, N. A., Methods of oil-well logging in the United States_...-- 131

Petraglia, F. A., The electronic engineering master index._-__-_-_ 129

Petroleum Engineer Publishing Co., Petroleum data book, 1947_-_-_-- 131

Petroleum Times, Bahamas oil search by Standard Oil (N. J.) _..-_-_ 128

Petropavlovskii, S. A., Practical techniques of detailed geophysical exploration of pyrite deposits in the Urals

Petrucci, G., Concerning the possibility of increasing the sensitivity of the Ising gravimeter._.

Petty, O. S., Seismic surveying, U. S. patent $2,410,303$

- Measuring instrument, $U$. $S$. patent 2,413,651_._._. 130

Pinar, Nuriye, Seismic geology and meteorology of the basin of the Sea of Marmara___. 130

Pinfold, E. E., Prospecting in the Punjab and Northwest Frontier Provinces -_._-

Pirson, S. J., Laboratory of Applied Geophysics and Geochemistry-.- 129

An evaluation of present-day geophysical exploration for oil-- 129

Pluvinage, Philippe, Application of symbolic calculus to certain problems of regulation of electromagnetic seismographs__._._._. 131

Poisson, Charles, The seismicity of Mudagascar.

Pondrom, W. L., with Hughes, D. S., Computation of vertical magnetic anomalies from total magnetic field measurements_______ 130

Foole, J. H. J., with Seeds, W. E., The magnetic properties of the serpentine deposits in the Slishwood Gap, County Sligo, Ireland_. 129

Pospelov, P. A., The five-year plan of geophysical work for the oil industry and its equipment problems_... 130

Poulter, T. C., Seismic measurements on the Ross shelf ice

Prange, F. A., The agents, basic causes, control, and prevention of corrosion _-

Pratt, W. E., Petroleum on the continental shelves

Petroleum on continental shelves_._. 130

Price, P. H., Evolution of geologic thought in prospecting for oil and natural gas._. 130

Prishletsov, V. I., Geophysics

Puranen, Mauna, The calculation of the strength of the anomaly of a magnetic ore at a given distance above the surface of the earth_- 128

8974

(3), 9582

(8) 9643

(9) 9289

(9) 9662

(1) . 8975

(4) 9418

(1) 9153

(3) 9119

(8) 9507

(3) 9397

(9) 9290

(7) 9249

(8) 9263

(3) 9583

(3) 9584

(2) 9537

(2) 9178

(8) 9451

(3) 9398

(4) 9230

(9) 9291

(9) 9471

(9) 9472

(8) 9086

(2) 8997

\section{$\mathbf{R}$}

Raadshooven, B. van, with Rutten, L., On earthquake epicenters and earthquake shocks between 1913 and 1938 in the region between $0^{\circ}$ and $30^{\circ} \mathrm{N}$. and $56^{\circ}$ and $120^{\circ} \mathrm{W}$

Ramachandra Rao, M. B., Geophysical survey report on the Sowanahalli copper ore block, Nanjangud Taluk, Mysore District____- 130

Rankama, Kalervo, What is geochemistry?

Rankine, A. O., Developments of geophysical prospecting in Germany during the war. 128

Ransone, W. R., Geochemical history of the Hardy oil field, Jones County, Tex_. 131.

Ravignani, G. L., Regarding the resolution of reflections in seismic exploration _..... 128

Observations on the note of $G$. Petrucci concerning the possibility of increasing the sensitivity of the Ising gravimeter._.-130

Rayner, J. M., Recent developments in geophysical prospecting--- 129 Ra\%vedika, Nedr, Problems of the Ministry of Geology of the U. S. S. R_ 130

Reed, Paul, Guarico's 1946 exploration program is most extensive in Venezuela_-

9401

(4) 9419

(7) 9250

(9) 9473 
Reiter, W. A., Contouring fault planes.__- 131

Renner, D. S., Seismometer engineering _._. 131

Kichter, C. F., Recording with Beniof instruments at Pasadena [Calif.] 130

Richter, C. F., with Gutenberg, Beno, Seismic waves from atomic bomb

tests._._.

Earthquake study in southern California, 1946_..._._._._. 131

Ridenour, L. N., editor, Radar system engineering_______._. 131

Rieber, Frank, Uses of the vibration in geophysics__._. 129

- System for detecting magnetic masses, U. S. patent 2,424,772_ 131

Apparatus and method for making and analyzing geophysical

records, U. S. patent $2,427,421$

Rinehart Oil News Co., Rinehart's Yearbook 1947_.________. 130

Ritzmann, O. F., Patents [a classification]__._._. 130

Riznichenko, Iu. V., Development of the theory of the interpretation

of seismic hodographs_._. 128

- On the determination of average velocities in conditions of poor correlation between seismic reflections_____._._._. 128 - Method for transforming media in geometrical seismics _..._. 129

- Problem of the spatial interpretation of hodographs of re-

flected waves_._.

Master chart of theoretical hodographs of reflected waves...- 131

Rioberts, E. B., Magnetic work of the United States Coast and Geodetic Survey from Apr. 1, 1945, to June 30, 1946_. 130

Roberts, W. O., with Shapley, A. H., The correlation of magnetic disturbances with intense emission regions of the solar corona__._- 128

Robertson, E. I., Gravitational methods of prospecting for oil___._. 131

Robson, W. T., Rock burst incidence, research, and control measures at Lake Shore mines___._. 128

Kodanet, C. H. H., Apparatus for testing altimetric devices, U. S. patent 2,422,702_. 130

Roe, R. B., and Gray, J. B., Navigation systęm, U. S. patent $2,419,970_{-}-129$

Rolfes, If. J., Means for safeguarding electric igniters of blasting detonators against accidental hing, U. S. patent $2,408,124 \ldots 129$

- Means for safeguarding electric igniters of blasting detonators against accidental firing, U. S. patent $2,408,125 \ldots$

Roman, Irwin, The resolving power of magnetic observations_-_._- 128

Roper, E. E., Ionic analysis, U. S. patent $2,412,359$

Rosa, I. A. de, Distance indicating detection system, U., S. patent $2,419,541$.

Rosuzzo Ferraris, M., Italy and its hydrocarbon deposits-petroleum_- 128

Rose, R. B., Radioactive exploration_____ 129

Rothé, Edmond, On the utilization of the network of heavy pendulums - 129

Earthqúakes and radioactivity

Rothe, Edmond, and Hée, A., Georadiological studies of the rocks of Alsace and the Vosges._. 128

Rothe, J. P., The seismic method of prospecting and scientific research, possibilities of application in France

Rothe, J. P., with Alexanian, C. L., Gravimetric prospecting at the grande Macholles, near Riom 130

Rove, $O$. N., Some physical characteristics of certain favorable and unfavorable ore horizons__._. 130

Rozanov, L. N., On the relationship between rock density and tectonics in the Buguruslan region--

Ruhl, August, with Machts, Ludwig, Machts, Richard, and Nickel, Ber-
nard, Portable device for ascertaining properties of the earth by means of high frequency electric oscillations, Dutch patent 50,926 - 131 Kumbaugh, L. H., with Klaasse, J. M., and Jensen, Homer, Applications of Shoran and photographic techniques to aerial magnetic surveys 131 reust, w. M., Jx., well lossing. U. S. patent $2,414,899-1 .-$
Rutten, L., and Raadshooven, B. van, On the earthquake epicenters and earthquake shocks between 1913 and 1938 in the region between $0^{\circ}$ and $30^{\circ} \mathrm{N}$. and $56^{\circ}$ and $120^{\circ} \mathrm{W}$

Class Abst.

(9) 9663

(3) 9585

(3) 9399

(3) 9198

(3) 9568

(9) 9664

(8) 9265

(2) 9678

(3) 9687

(8) 9452

(8) 9453

(3) 9026

(3) 9027

(3) 9209

(3) 9400

(3) 9586

(2) 9366

(2) 8999

(1) 9531

(3) 9028

(9) 9518

(9) 9328

(3) 9308

(3) $\quad 9309$

(2) 8998

(7) 9698

(9) 9327

(9) 9108

(5) 9242

(3) 9210

(3) 9587

(5) 9058

(2)

(4) 0312
9029

9329

9474

9532

9694

9552 
Sadovskil, M. A., Experimental investigations of the mechanical effect of an impact wave from explosion

The seismic effect of explosions in the case of weak ground and monolithic structure-_._- 131

Sagui, C. L., Variations of the geomagnetic field__- 130

- Earthquakes and gravitation._. 131

Sanders, R. C., Jr., Frequency modulated altimeter or distance indićator, U. S. patent 2,420,199_- 130

_ Frequency modulated altimeter or distance indicator, U. S. patents $2,422,133,2,422,134$, and $2.422,135 \ldots$

Pulsed frequency modulated altimeter, U. S. patent $2,424,854 \ldots 131$

Sanford, R. L., Magnetic testing

Sargeant, W. W., and Hoeper, H. B., Amplifler for small voltages, U. S. patent $2,413,788$

Savarenskii, E. F., Concerning the principles of interpretation of seismic observations

Savornin, André, Magnetic prospecting at Ambohidranomoro, in western Madagascar___________._. 131

Sawyer, J. W., Device for determining compass errors, U. S. patent $2,424,254 \ldots \ldots$

Sayers, R. R., Bureau of Mines' geophysical explorations______. 129

Schelleng, J. C., Position locating system, U. S. patent 2,416,351...._ 129

Scherbatskoy, S. A., Seismometer, U. S. patent $2,411,117 \ldots \ldots \ldots \ldots$

Sclulumberger, Marcel, Cartridge, U. S. patent 2,419,371__._. 129

Schlumberger, Marcel, and Kunetz, Géra, Rapid simultaneous variations of the telluric field in France and Madagascar_-__-_._- 130

Scholte, J. G., On the relations between sea waves and microseisms_-_- 129

Schwede, H. F., with Doll, H. G., Radioactive markers in oil field practice._._. 130

Scott, W. E., American magnetic character-figure, $C_{A}$, three-hour-range indices, $K$, and mean $K$-indices, $K_{A}$, for July to September and October to December 1946, 'with summary for 1946

Mean $K$-indices from 30 magnetic observatories and preliminary international character-figures, $C$, for 1945

Seeds, W. E., and Poole, J. H. J., The magnetic properties of the serpentine deposits in the Slishwood Gap, County Sligo, Ireland.....-- 129

Sergeev, E. A., Analysis of waters as a method of prospecting for polymetal deposits_._. 129

Shapley, A. H., and Roberts, W. O., The correlation of magnetic disturbances with intense emission regions of the solar corona_-__-_ 128

Shchepot'eva, $E$. S., The methods of radioactivity measurements-A vacuum method for measuring the Rn content of waters and gases_- 131

Sheinman, S. M., On transient electromagnetic fields in the earth_-_._. 131

Shepard, F. P., and Emery, K. O., Submarine photography off the California coast._...

Sheppard, C. W., and Whitehead, W. L., Formation of hydrocarbons from fatty acids by alpha-particle bombardment____._.

Shimek, E. J., and Groenendyke, G. M., Gain-controlling system for seismographs, U. S. patent $2,420,571$

Shimek, E. J., and Hemphill, W. B., Gain-control system for seismic amplifiers, U. S. patent 2,408,001 129

Shook, E. M., and Olson, R. W., System for geophysical exploration, U. S. patent $2,413,116$

Short, E. H., Jr., Improved marine equipment facilitates distant offshore exploration

Shoupp, W. E., Measuring apparatus, U. S. patent $2,408,230$

Shreffler, R. G., with Cork, J. M., and Shull, F. B., Magnetic field measurement in beta-spectroscopy

Shull, F. B., with Cork, J. M., and Shreffler, R. G., Magnetic fleld measurement in beta-spectroscopy

(3) $\quad 9402$

(3) $\quad 9588$

(2) 9367

$(1,3) \quad 9533$

9513

(9) 9702

(9) 9706

(2) 9176

(4) 9689

(3) 9211

(2) 9557

(2) 9677

(8) 9266

(4) 9314

(3) 9120

(9) 9326

(4) 9420

(3) 9212

(5) 9428

(2) $\quad 9177$

(2) 9368

(2) 9178

(7) 9251

(8) 9454

(2) 8999

(5) 9616

(4) 9606

(9) 9109

(9) 9292

(3) 9497

(3) 9307

(3) 9122

(3) 9213

(5) 9317

(2) 95040

(2) 9540 
Sieberg, August, Investigation of structures with a view to protection against earthquake damage, conducted at the Reichsanstalt für

Erdbebenforschung, Series C_-_._- 130

Silverman, Daniel, Well logging, U. S. patent $2,412,363$

Silverman, Daniel, with Eisler, J. D., Multichannel pen recorder for. electric logging operations___._-_._- 131

Silverman, Daniel, Eisler, J. D., and Evans, J. F., Vehicle borne instrument for continuously indicating road elevations___._._._. 130

Simpson, W. H., An experience with the "megger"'-_._. 131

Siñeriz, J. G., Hydrological investigation in Castellon de la Plana by the direct current electrical method._._._. 131

Sinks, A. T., Compass transmitter, U. S. patent 2,414,128 - Remote indicating magnetic compass system, U. S. patent $2,426,470$

Sinnett, C. M., Transducer system, U. S. patent 2,411,008_.___._-_ 130

Sitter, L. U. de, Geological and geophysical studies during the war on behalf of the Associated Collieries of the Netherlands_._-_-_-_-_ 128

Skeels, D. C., Ambiguity in gravity interpretation

Skeels, D. C., and Vajk, Raoul, Geophysical exploration and discovery of the Budafapuszta (Lispe) oil field in Hungary

Skillings' Mining Review, Magnetometer survey to use airplane_-_._._- 128

- Helicopter prospecting to get under way this year.....- 130

Slichter, L. B., Geophysical prospecting for ores___. 129

- C Current status and potentialities of geophysical prospecting for ores

Sloat, John, Geophysical history of Raisin City field, Calif_._._._-_ 129

Slonczewski, Thaddeus, with Laird, A. G., Magnetic field detector, U. S. patent $2,426,622$

Sloss, L. L., and Cooke, S. R. B., Spectrochemical sample logging of of limestones_..... 128

Smith, G. A., Well surveying instrument, U. S. patent $2,413,005$ Well surveying device, U. S. patent 2,414,702

Smith, N. C., and Wengerd, S. A., Photogeology aids naval petroleum. exploration _._.

Smith, N. J., and Gulmon, G. W., Geophysical history, Lake St. John Field, Concordia and Tensas Parishes, La___-__- 130

Smith, P. S., Alaska's potential oil resources

Sneddon, Richard, Submarine prospecting

Société de Prospection Electrique, Method of studying earth strata traversed by a borehole, Dutch patent 50,712 - Method of studying earth strata in a borehole by means of their caloric properties, Dutch patent 5.1,271_. 129

- Method of studying the earth strata traversed by a borehole by means of periodic electromagnetic fields, Dutch patent 50,919 -- 130

Solaini, L., Concerning topographic reduction of gravity measurements__._._._._. 130

- Variometric determinations of the horizontal and vertical components of the geomagnetic field made in Abruzzi in 1943_._. 130 Institute of Applied Geophysics at the Polytechnicum of Milan

Solovov, A. Current problems of the Geophysical Division of Geological Committee attached to the Council of Ministers, U.S.S.R

South African Mining and Engineering Journal, Fluorescent lamps, effects of impurities. 128

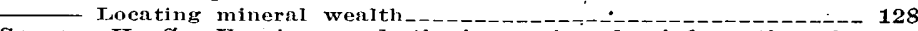

Spence, H. S., Uranium and thorium minerals二information for the use of prospectors._._. 131

Spicor, H. C.; Gamma-ray studies of notassium salts and associated geologic formations__._- 128

Stagg, J. M., Summary report on the extraordinary general assembly of the International Union of Geodesy and Geophysics (IUGG), Cambridge, England, July 29 to Aug. 2, 1946

(3) 9403

(4) 9125

(4) $\quad 9601$

(9) 9475

(4) 9607

(4) 9608

(2) 9300

(2) 9681

(3) 9494

(1) 8976

(1) 9154

$(1,3) \quad 9343$

(2) 9000

(2) 9369

(4) 9231

(8) 9644

(3) 9214

(2) 9682

(7) 9067

(2) 9117

(2) 9301

(9) 9665

(8) 9455

(9) 7476

(1) 8977

(4) 9316

9319

9502

9344

9370

9456

9267

(5) 9059

(8) 9088

(5) 9617

(5) 9060 
Standard Oil Co. of California, Device for the determination of the magnetic polarity of a cylindrical, weakly magnetized borehole sample, Dutch patent $48,7.92$

No. Class Abst. andard Oil Development Co., N. J., Method of indicating the presence of oil or earth gases in the ground by the analysis of samples, Dutch patent 48,410__-_._._- 128

Steenland, N. C., with Woollard, G. P., Gravity and magnetic survey of Cortlandt complex

Stefanescu, S. S., Theory of the conducting plane and transient electromagnetic stathod and apparatus for studying earth strata in a borehole, Dutch patent 51,653

Sterne, W. P., Traveling towns solve seismo crew's housing problems_-- 129

Stick, J. C., Baker, J. S., and Norelius, R. G., New electrical logging techniques in California... 130

Storm, L. W., Limit of accuracy of seismic work in Alberta_____._- 128

Stoyke, Nicolas, The attraction exerted by the moon and the sun, and the international formula of gravity 130

Stratton, E. F., with Doll, H. G., and Legrand, J. C., True resistivity determination from the electric $\log$ and its application to $\log$ analysis._._._._. 130

Svenska Instrument Aktiebolaget, Acoustic detecting apparatus, Swedisb patent 104,908 128

Swan, B. G., Index of wells shot for velocity Geophysical history of East Lance Creek and Little Buck Creek flelds, Niobrara County, Wyo___._. 129

Swan, B. G., and Boyd, W. B., Geophysical history of the Guthrie field, Logan County, Okla___._. 130

Swennes, B. A. Amphibian vehicle, U. S. patent $2,413,850$

9412

(3) 9123

(3) 9031

T

Tabasaranskii, z. M., Geochemical surveys of deposits in the Fergana Valley -...-_. 130

Tarklıov, A. G., Regarding the geo-electrical field of filtration._. 129 induction.

Technical News Bulletin, High-speed electronic digital computers - 130

Téchnifax Service, How to build electric treasure finder._._.-.-- 129

Terada, K., Electric current as a probable cause of daily magnetic variation....... 131

(4) 9234

Texas Oil Journal, New era of oil exploration seen in use of "Flying Eye" to map oceans and jungle

Thom. E. M., Bibliography of North American geology, 1944 and 1945_- 130

Thomas, H. F., Oil in Alaska_____ 128

Thomas, J. E., Argentina's oil industry during the war years_______- 129

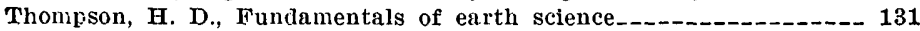

Thomsen, H. L., and Burton, G. A., Winter operation of geophysical ecuipment in the Rocky Mountain area_____- 129

Thyer, R. F., Gravity survey to determine extent of coal measures_-_- 131

Tikhonov, A. N., On the transient due to an electric pulse in a homogenecus conductive half-sphere

- Concerning electrical sounding over an inclined layer.....- 130

Tikhonov, A. N., and Bulanzhe, Iu. D., On the integration of gravitational fields._. 128

Tiratsoo, E. N., D'Arcy crews continue Great Britain's oil search_-_- 129

Tiurkisher, R. I., Electrical coring in an anisotropic medium _._._._- 128

-Calculations of the fleld of a point-source placed over an inclined layer.-. 130

Todd, J. D., What is wrong with the eastern Gulf coast?

Tolk, J. F., Position dampened seismometer, U. S. patent $2,424,724 \ldots-\ldots 131$

T'olson, W. A., Heat responsive device, U. S. patent 2,410,317___._- 130

T'reskcv, A. A., Concerning reflected seismic wares_________-_ 131. 
Tripp, R. M., Geophysical principles for determining subsurface con-

Tripp, R. M., and O'Boyle, C. C., Beta activity of some carbonaceous

Tripp, R. M., with Heiland, C. A., and Wantland, D., Geophysical sur-

veys at the Malachite mine, Jefferson County, Colo
Tromp, S. W., First report on experiments concerning the influence of variations in the strength of magnetic fields, in particular the magnetic field of the earth, on muscular contraction... 130

Tuckerman, Bryant, with McNish, A. G., The vehicular odograph_-_ 131

Turner, E. E., Jr., Apparatus for echo distance measurement, U. S. patent 2,408,458_._. 130

Tuttle, W., with Kip, A., Bousquet, A., ánd Evans, R., Design and operation of an improved counting rate meter-_._. 128

Tvaltvadze, G., Some data on the structure of the earth's crust in the region of Abastumani-Tsnisi-Moktsevi, eastern Georgia_._...- 129

No. Class Abst.

$128(2,4) \quad 9040$

(2) $937 \mathrm{I}$

(9) 9659

\section{U}

Ulrich, F. P., and Hollis, E. P., Progress report of seismological work by the United States Coast and Geodetic Survey in the western United States during 1945

U. S. Coast and Geodetic Survey, Magnetic observations in the American Republics, 1941-44. 129

- Isogonic chart for 1945, United States_._._._.

U. S. Office of Scientific Research and Development, Radar - A report on science at wax

\section{$\mathbf{\nabla}$}

Vajk, Raoul, with Skeels, D. C., Geophysical exploration and discovery of the Budafapuszta (Lispe) oil field in Hungary

Valle, P. E., New method for determining the hypocentral coordinates of a distant earthquake._._._. 128 - On the relation between the coefficient of absorption and the. period of seismic waves _..._. 129

Absorption and damping of some types of seismic waves______ 130 Concerning the energy associated with seismic waves $S K S$ and $S K K S$

Van Beveren, O. F., Seismic exploration in Sumatra

Vanderwilt, J. W., A view of fluorescence as applied to minerals with special reference to scheelite

Van Tuyl, F. M., and Parker, B. H., Oil-its origin and accumulation -- 130

Van Weelden, I. A., Modern developments in geophysical prospecting-- 131

Veber, V. V., The presence of oil in the Miocene of the southeastern Callcasus

Vecchia, O., Determination of velocity in seismic prospecting

- Geochemical prospecting for petroleum_-_._- 130 Certain cases of geologic structure with layers characterized by

a low seismic refraction velocity

131 The future of geophysics in oil exploration in the United states 131

Veitsman, P. S., An experiment in two types of areal survey by the correlation-refraction method

Veldkamp, J., Seismic records at De Bilt, no. 30

Vening Meinesz, F. A., Gravity in the East Indies and its interpretation.

- Tensions in the earth's crust as a consequence of pole-shift-

ing ........... 128

suear patterns of the earth's crust_... 129

Deep-focus and intermediate earthquakes in the East Indies_- 130

vercelli, Francesco. Periodicity, analyses of diagrams_... 130 
Ver Steeg, Karl, Temperatures in some deep wells in Pennsylvania and West Virginia___._. 128

Vestine, E. H., Description of the earth's main magnetic field and its secular change, 1905-1945_-_._- 130

Vestine, E. H., Laporte, L., and Cooper, C., Geomagnetic secular change during past epochs__-_-_-_._- 128

Vine, A., with Ewing, Maurice, Woollard, G. P., and Worzel, J. L., Recent results in submarine geophysics

Visser, S. W., Tensions in the earth's crust resulting from pole shift and the terrestrial magnetic field

- Seismology _._-

Vitalis,. I. von, Measurements with the Eotvös torsion balance and the exploration for coal._... 130

Voronca, A., Prospecting during the war and its future outlook___-_- 130

Vsekhsviatskii, S. K., Concerning the question of the nature of geomagnetic disturbances

No. Class Abst.

(6) 9065

(2) 9372

(2) 9002

(3) 9034

(1) 9346

(8) 9457

(2) 9373

W

Wade, E. J., Locating equipment, U. S. patent $2,411,071$

9509

Walker, J. M., and McGaha, S. W., Some practical considerations of radioactivity well logging

Wanner, E., with Mercanton, P. L., The magnetic anomaly of the Jorat, Vaud-The vertical component_._. 129

Wantland, Dart, with Heiland, C. A., and Tripp, R. M., Geophysical surveys at the Malachite mine, Jefferson County, Colo___-_._- 128

Warren, H. V., and Howatson, C. H., Biogeochemical prospecting for copper and zinc_.

Warren, P. R., Geophysical history of the Ville Platte oil field, Evangeline Parish, La__._. 129

Warshaw, H. D., Magnetic vane type ratiometer, U. S. patent $2,419,612$ - 130

Waterman, J. C., Geophysical history of the Ten Section oil field, Kern County, Calif._-_._._. 130

Weaver, Paul, Petroleum geophysics, 1946_._. 128

Weber, E. K., with Gassmann, Fritz, and Niggli, Ernst, Magnetic measurements of the Institute of Geophysics, E.T.H., Tessin_-_- 128

Weeks, L. G., Highlights on developments in foreign petroleum flelds_. 131

Wegener, Kurt, The change of gravity values over the sea_-___-_-_ 131

Weiss, Oscnr, Geophysical prospecting for water in the dolomite_._- 130

Weiss, Oscar, with Frost, A., McIntire, R., and Papenfus, E., The discovery and prospecting of a potential gold field near Odendaulsrust in the Orange Free State, Union of South Africa_____- 128

Wengerd, S. A., Newer techniques in aerial surveying-The photographic laboratory

Wengerd, S. A., with Smith, N. C., Photogeology aids naval petroleum exploration _..._._.

Werner, Sture, Determinations of the magnetic susceptibility of ores and rocks from Swedish iron ore deposits

West, L. G., with McCarver, H. C., Geology and geophysics of the Odem oil field, San Patricio, Tex

West, T. S., and Beacham, C. C., A resistolog survey of the Loma Alto-Seven Sisters area of McMullen and Duval Counties, Tex..- 128

Westby, G. H., Geophysics in the mid-continent, past results and future application

Westerdijk, J. B., with Haas, W. J. de, Strong magnetic fields____-_-_ 130

Westinghouse Electric \& Manufacturing Co.; Corrosion ratings of metals_._._.

White, C. C., Electrical well logging, a study of the self-potential curve _..._.

White, W. S., A cotangent ruler for simplifying the graphic solution of problems in structural geology

$(1,3) \quad 9220$

(4). 9500

(3) 9409

(8) 9091

(2) $\quad 8986$

(8) 9648

(1) 9535

$(4,2) \quad 9424$

$(1,2) \quad 8967$

(9) $\quad 9667$

(9) 9665

(2) 9560

(3) 9203

(4) 9047

(8) 9092

(2) 9356

(4) 9048

(4) 9236

(9) 9112 
Whitehead, W. L., with Sheppard, C. W., Formation of hydrocarbons from fatty acids by alpha-particle bombardment_........ 129

No. Class Abst.

Wickman, F. E., A graph for the calculation of the age of minerals according to the lead method._._. 129

Williams, F. J., Notes on shot point procedure

Williams, F. W., and Clark, James, Method and means for testing for imperfections in vibratable objects, U. S. patent $2,412,240_{--} 130$

Williams, J. R., Developments in Arkansas and north Louisiana in 1946

Williams, O. W., with Brown, L. E., Well tester, U. S. patent 2,404,825- 129

Williams, P. S., Well logring, IJ. S, patent $2,40 S, 012$

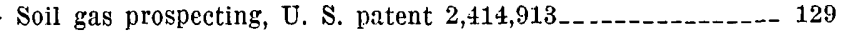

Williston, S. H., with Nichols, C. R., Electrical prospecting apparatus,

U. S. patent $2,428,034$

Wilson, C. O., Seeking Arctic oil

Wilson, J. H., Case history of the Fort Collins extension, Larimer County, Colo

Wilson, W. H., Radar proves useful tool in marine surveying--_--- 131

Windes, S. L., with Obert, Leonard, and Duval, Wilber, Standardized tests for determining the physical properties of mine rock

Winn, W. I., and Dougherty, P. F., Method of logging wells, U. S. patent 2,408,964_... 128

Method of logging wells, U. S. patent $2,408,965$

Wolf, Alexander, with Cowles, L. G., Well sounding apparatus, U. S. patent $2,411,311 \ldots 128$

Wolf, Alfred, Electric field of an oscillating dipole on the surface of a two layer earth

Wong, Wen-Hao, Geophysical work of the National Geological Survey of China and of the Institute of Physics of the National Academy of Peiping of China

Wood, H. O., Earthquakes in southern California with geologic relations, parts 1-2__- 131

Woodard, S. W., Unique tripod speeds water gravimetric survey

Woollard, G. P., Regional gravity survey of northeastern United States and eastern Canada__-__._. 131

Woollard, G. P., and Steenland, N. C., Gravity and magnetic survey of Cortlandt complex._. 129

Woollard, G. P., with Ewing, Maurice, Vine, A., and Worzel, J., Recent results in submarine geophysics

9292

(5) 9243

(3) 9035

(3) 9495

(8) 9458

(7) 9321

(8) 9134

(7). 9322

(4) 9693

(8) $\quad 9649$

(S) 9650

(9) 9668

(9) 9103

(7) 9131

(7) 9132

(3) $\quad 9121$

(4) 9049

(8) $\quad 9272$

(3) 9594

(1) 9347

(1) $\quad 9536$

$(1,2) .9155$

(3) 9189

(1) 9156

World Petroleum, Seven groups to search Bahamas for petroleum_._ 129 - Marine exploration develops new techniques_._-_._-_._. 130 Bacteria help to produce oil

Worzel, J. L., Ocean bottom sampler for ships under way-_._._. 131

Worzel, J. L., with Ewing, Maurice, Woollard, G. P., and Vine, A., Recent results in submarine geophysics._... 129

Wrather, W. E., Oil and mineral possibilities on the continental shelves of the United States and Alaska____ 130 Wrigley, Walter with Draper, C. S., An instrument for measuring low frequency accelerations in flight 128

\section{$\mathrm{Y}$}

Tacimientos Petroliferos Fiscales, Annual report of the Argentine Administration of Government Oil Fields for 1945_...... 129

Young, G. J., Elements of mining, 4th. ed._. 131

Zabelli, Arnaldo, Geophysical surveys in quest of ferriferous sands, made particularly on the ocean floor

Zahl, H. A., with Golay, M. J. E., System for detecting sources of radiant energy, $U$. S. patent $2,424,976$ 
No. Class Abst.

Zahradnicek, Josef, Undampened oscillations of a system of coupled torsion pendulums.-_... 128

Zetler, B. D., Travel times of seismic sea waves to Honolulu_...... 131

Zhirov, K. K., Some questions of radioactivity in geology._._... 131

Zhongolovich, I. D., Concerning reductions of the force of gravity --- 129

ZoBell, C. E., Marine microbiology

Action of microorganisms on hydrocarbons

Bacteriological process for treatment of fluid-bearing earth for

mations, U. S. patent $2,413,278$

Bacterial release of oil from oil-bearing materials______. 131

Zunino, J. J., Evaluation of oil exploration methods_._._._. 131

Zuschlag, 'Theodore, Demagnetizing apparatus, U. S. patent $2,403,424 \ldots 129$

Zvolinskii, N. V., Rayleigh waves in a heterogeneous elastic hemisphere of a particular type

(1) 8980

(3) 9595

(5) 9619

(1) 9157

(9) 9294

(7) 9439

(9) 9511

(7) 9628

(9) 9670

(2) 9297

(3) 9596 